\title{
ZEITRÄUME UND FORMENKREISE - ZUR CHRONOLOGIE DER KUPFERZEITLICHEN NEKROPOLEN IM ÖSTLICHEN KARPATENBECKEN
}

\author{
ISTVÁN ZALAI-GAÁL
}

\author{
Forschungszentrum für Humanwissenschaften \\ der Ungarischen Akademie der Wissenschaften \\ Archäologisches Institut \\ Úri u. 49, H-1014 Budapest, Ungarn \\ gaal.istvan@btk.mta.hu
}

\begin{abstract}
The author searches answers for chronological questions of the Complex of Polgár (Bodrogkeresztúr and Hunyadihalom cultures) that existed in the second half of the $5^{\text {th }}$ millennium BC in the eastern parts of the Carpathian basin. The work is based on 47 cemeteries that supplied sufficient material for the analysis. Methodology was provided by metrical analysis and seriation of 818 dish types and 577 graves. Artificial periods ("künstliche Perioden") and the phases of cemetery usage ("Belegungsphasen") were identified both in the particular cemeteries and in the five analyzed regions. As a result of the analyses, we may identify three phases of development of the Polgár complex cemeteries (Formenkreis $1=$ Tiszapolgár, Formenkreis $2=$ TiszapolgárBodrogkeresztúr, Formenkreis 3 = Bodrogkeresztúr, with the features of the ceramics from Hunyadihalom). Thus, the two groups that had been differentiated so by their ceramics (Tiszapolgár and Bodrogkeresztúr), in fact existed in the same time period and in geographical proximity.
\end{abstract}

Keywords: Copper Age cemetery analysis, Bodrogkeresztúr and Hunyadihalom cultures, metrical analysis, seriation

\section{EINLEITUNG}

\subsection{Arbeitsraum und Fundgeschichte}

Den Arbeitsraum der vorliegenden Arbeit bildet das Verbreitungsgebiet der kupferzeitlichen Gemeinschaften (Tiszapolgár- und Bodrogkeresztúr-Kulturen) des ostkarpatischen Raumes aus dem 5. vorchristlichen Jahrtausend. Als terminus technicus verwenden wir dabei den Ausdruck „Polgár-Komplex“, dessen Keramik von der der anderen früheren und späteren Gemeinschaften stilistisch gut absonderbar ist. In der vorliegenden Arbeit handelt es sich ausschließlich um die Grabkeramik: Sie besitzt nämlich einen von der Siedlungskeramik abweichenden Charakter. Fraglich bleibt, ob alle in den Gräbern deponierten Gefäße direkt für die Bestattungszeremonie hergestellt wurden oder auch Haushaltskeramik für diesen Zweck benutzt wurde. Auch die Absichten der Hinterbliebenen mit diesen keramischen Deponierungen in den Gräbern bleiben für uns unbekannt. Gemäß den Tierknochenfunden und der allgemeinen Meinung der Autoren enthielten die Grabgefäße Speise und Getränk für die „überirdische Existenz", aber bei diesen Deponierungen dürften wahrscheinlich auch Prestige-Absichten eine Rolle gespielt haben.

Wir gingen bei der Bearbeitung des grabkeramischen Bestandes des Polgár-Komplexes davon aus, dass eine detaillierte Interpretation regionaler archäologischer Phänomene eine Grundbedingung ist, um Funde, Befunde und Gemeinschaften auf einer überregionalen Skalenebene miteinander vergleichen zu können. „Aus den archäologischen Quellen lassen sich überregionale Prozesse bereits erkennen, die als großräumige Konstellationen bezeichnet werden können. Das Wechselspiel zwischen solchen allgemeinen Tendenzen und den regionalen 
Entwicklungen stellt eine wichtige methodische Herausforderung dar. “1 Auch die Formänderungen der frühkupferzeitlichen Grabkeramik sind sowohl mit dem Wandel der ökonomischen als auch mit den politischen und ideologischen Aspekten verbunden.

In seinem Beitrag versuchte R. Gleser ein Chronologiemodell der spätneolithisch-frühkupferzeitlichen Entwicklung für Zentraleuropa zu entwerfen. Dabei wurde die Regionalität mit unterschiedlicher Geschwindigkeit der Stilentwicklungen immer deutlich erkennbar. „Trotz mehrerer, in Konkurrenz zueinander stehender Entwürfe, die zu unterschiedlichen und wiederholt abgeänderten Terminologien führten, kann die relative Chronologie der Lengyel-Kultur überregional als abgesichert gelten. Dabei wird von einer sequenziellen Abfolge der Kulturelemente, insbesondere der charakteristischen Tonware, ausgegangen. “2 Ähnliches kann auch für die früh- und mittelkupferzeitliche Belegungszeit des östlichen Karpatenbeckens festgestellt werden.

In den Katalog der Grabkeramik nahmen wir die Daten von insgesamt 1969 Grabgefäßen aus nicht weniger als 575 Bestattungen auf, die aus 47 kupferzeitlichen Nekropolen des östlichen Karpatenbeckens stammen (Codenamen der Fundorte in eckigen Klammern). Es gibt zugleich zwölf Fundorte, auf denen nur je eine Bestattung in die Analyse aufgenommen werden konnte und auch die Anzahl der Fundorte mit je zwei Gräbern sieben beträgt.

Die geographische Lage der untersuchten kupferzeitlichen Gräberfelder im östlichen Teil des Karpatenbeckens zeigt Verbreitungskarte 1.

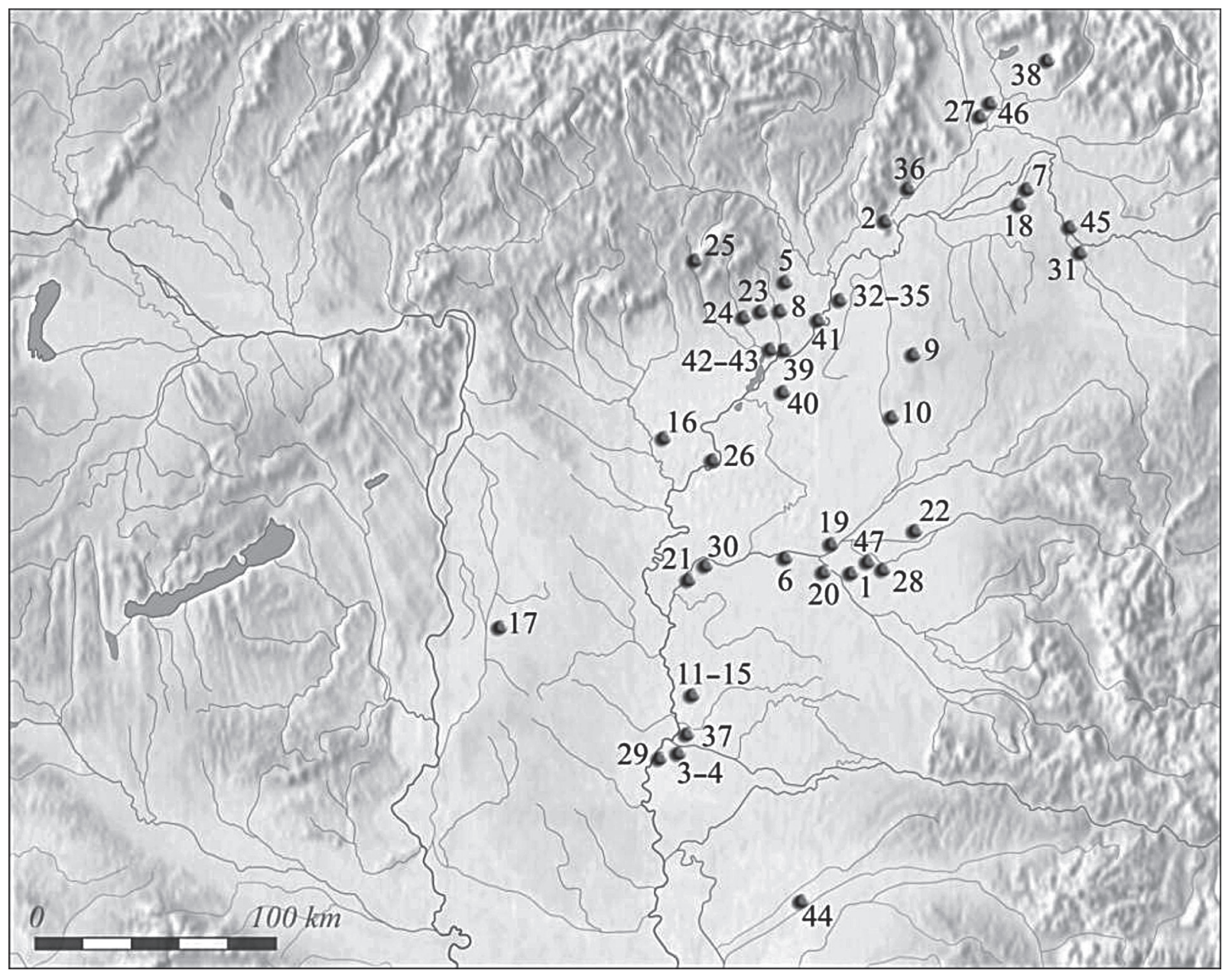

Verbreitungskarte 1. Untersuchte Gräberfelder des Polgár-Komplexes

${ }^{1}$ HANSEN-MÜLLER 2011, 3.

${ }^{2}$ GLESER 2012, 35-36. 
Die geographische Lage gemäß den Verbreitungsregionen, die Anzahl der in die Analyse aufgenommenen Keramiken und die Anzahl der Gräber mit diesen Gefäßen auf den einzelnen Fundorten stellt Tabelle 1 dar.

Tabelle 1. Anzahl der in die keramische Analyse aufgenommenen Keramiken und Gräber

\begin{tabular}{|c|c|c|c|}
\hline Fundort & Region & Gefäßanzahl & Gräberanzahl \\
\hline 1. Bélmegyer ${ }^{3}$ & 2 & 2 & 1 \\
\hline 2. Bodrogkeresztúr ${ }^{4}$ & 4 & 9 & 4 \\
\hline 3. Deszk A ${ }^{5}$ & 1 & 47 & 8 \\
\hline 4. Deszk B ${ }^{6}$ & 1 & 71 & 16 \\
\hline 5. Emöd ${ }^{7}$ & 3 & 5 & 1 \\
\hline 6. Endrőd-Hegedüs-tanya ${ }^{8}$ & 2 & 9 & 5 \\
\hline 7. Fényeslitke ${ }^{9}$ & 4 & 121 & 55 \\
\hline 8. Gelej-Füzeshát ${ }^{10}$ & 3 & 3 & 2 \\
\hline 9. Hajdúböszörmény-Ficsori-tó-dűlö ${ }^{11}$ & 3 & 16 & 2 \\
\hline 10. Hajdúszoboszló ${ }^{12}$ & 3 & 23 & 8 \\
\hline 11. Hódmezővásárhely-Bodzáspart ${ }^{13}$ & 1 & 4 & 3 \\
\hline 12. Hódmezővásárhely-Kotacpart ${ }^{14}$ & 1 & 14 & 8 \\
\hline 13. Hódmezővásárhely-Népkert ${ }^{15}$ & 1 & 22 & 5 \\
\hline 14. Hódmezővásárhely-Szakálhát ${ }^{16}$ & 1 & 7 & 1 \\
\hline 15. Hódmezővásárhely-Laktanya ${ }^{17}$ & 1 & 3 & 1 \\
\hline 16. Jászladány ${ }^{18}$ & 3 & 30 & 20 \\
\hline 17. Kiskőrös-Seregélyes ${ }^{19}$ & & 18 & 9 \\
\hline 18. Kisvárda ${ }^{20}$ & 4 & 13 & 1 \\
\hline 19. Körösladány-Bikeri ${ }^{21}$ & 2 & 5 & 3 \\
\hline 20. Köröstarcsa-Kossuth tér ${ }^{22}$ & 2 & 4 & 1 \\
\hline 21. Kunszentmárton-Pusztaistvánháza ${ }^{23}$ & 2 & 63 & 14 \\
\hline 22. Magyarhomorog-Kónyadomb ${ }^{24}$ & 2 & 150 & 51 \\
\hline 23. Mezökeresztes-Csincse-tanya ${ }^{25}$ & 3 & 8 & 3 \\
\hline 24. Mezőkövesd-Patakra járó-dülö ${ }^{26}$ & 3 & 16 & 6 \\
\hline 25. Mónosbél ${ }^{27}$ & 3 & 4 & 1 \\
\hline 26. Nagykörü-Hidashát ${ }^{28}$ & 3 & 5 & 2 \\
\hline 27. Oborín/Abara ${ }^{29}$ & 5 & 5 & 2 \\
\hline 28. Okány-Baromfitelep ${ }^{30}$ & 2 & 9 & 2 \\
\hline 29. Ószentiván VIII ${ }^{31}$ & 1 & 7 & 3 \\
\hline 30. Öcsöd-Kendereshalom ${ }^{32}$ & 2 & 8 & 1 \\
\hline 31. Panyola-Vásármező-domb ${ }^{33}$ & 4 & 24 & 7 \\
\hline 32. Polgár-Basatanya ${ }^{34}$ & 3 & 525 & 139 \\
\hline
\end{tabular}

${ }^{3}$ GYUCHA 2009, 246.

${ }^{4}$ Bella 1923; PATAY 1961, 6-17.

${ }^{5}$ Foltiny 1941; BognÁR-KutZiÁn 1972, 22-27.

${ }^{6}$ BÁlint 1941, 36; Foltiny 1941, 69-88; BognáRKUTZIÁN 1972, 27-34.

${ }^{7}$ Patay 1961, 19-20; Hellebrandt-Patay 1977, 49.

${ }^{8}$ GYUCHA 2009, 247.

${ }^{9}$ Patay 1950; Patay 1961, 22-23; Patay 1969, 15.

${ }^{10}$ Hellebrandt-Patay 1977, 47-49.

${ }^{11}$ KovÁCS-VÁcZi 2007, 397-397.

${ }^{12}$ Patay 1961, 25-30; Bognár-Kutzián 1972, 173.

${ }^{13}$ BANNER 1935; BANNER 1936; BognÁR-KutZián 1963; BOGNÁR-KuTZIÁN 1972, 37-40.

${ }^{14}$ PÁrducz 1932; Banner 1933-1934; BognáR-KutziÁN 1972, 41-44.

${ }^{15}$ GaZdapusztai 1964, 251; BognÁr-KutZián 1972, 44-47.

${ }^{16}$ Banner-BÁlint 1935; Banner 1937; PATAY 1961, 32 ; BoGNÁR-KUTZIÁN 1972, 48.
${ }^{17}$ R. PATAY 2008.

${ }^{18}$ PATAY 1944-1945.

${ }^{19}$ Csalogovits 1931; Patay 1961, 34-35.

${ }^{20}$ RÓMER 1870; JósA 1899; BANNER 1927; PATAY 1961 , 37-39; BOGNÁR-KUTZIÁN 1972, 554-556.

${ }^{21}$ Gyucha 2009, 286, 306.

${ }^{22}$ Ebenda, 250.

${ }^{23}$ Hillebrand 1929; Patay 1961, 40-54.

${ }^{24}$ PATAY 1976.

${ }^{25}$ Patay 1961, 56-57; Hellebrandt-Patay 1977, 49.

${ }^{26}$ R. PATAY 2004.

${ }^{27}$ PATAY 1961, 58-59.

${ }^{28}$ Ebenda, 59-61.

${ }^{29}$ VízDAL 1970, 219-234.

${ }^{30}$ GyUCHA 2009, 252-254.

${ }^{31}$ Ebenda, 252-254.

${ }^{32}$ RACZKY 2011.

${ }^{33}$ R. PATAY 2003, 11.

Acta Archaeologica Academiae Scientiarum Hungaricae 67, 2016 
Tabelle 1. (Fortsetzung) Anzahl der in die keramische Analyse aufgenommenen Keramiken und Gräber

\begin{tabular}{|c|c|c|c|}
\hline Fundort & Region & Gefäßanzahl & Gräberanzahl \\
\hline 33. Polgár-Hajdúnánási út ${ }^{35}$ & 3 & 6 & 3 \\
\hline 34. Polgár-Nagy-Kasziba ${ }^{36}$ & 3 & 11 & 1 \\
\hline 35. Polgár-Bacsókert ${ }^{37}$ & 3 & 17 & 9 \\
\hline 36. Sárazsadány ${ }^{38}$ & 4 & 4 & 1 \\
\hline 37. Tápé-Lebő $\mathrm{A}^{39}$ & 1 & 17 & 14 \\
\hline 38. Tibava/Tiba ${ }^{40}$ & 5 & 215 & 29 \\
\hline 39. Tiszabábolna-Szilpuszta ${ }^{41}$ & 3 & 27 & 7 \\
\hline 40. Tiszaigar-Csikóstanya ${ }^{42}$ & 3 & 2 & 1 \\
\hline 41. Tiszakeszi-Fáy-kert ${ }^{43}$ & 3 & 27 & 16 \\
\hline 42. Tiszavalk-Kenderföldek ${ }^{44}$ & 3 & 138 & 48 \\
\hline 43. Tiszavalk-Tetes ${ }^{45}$ & 3 & 113 & 24 \\
\hline 44. Uivar/Újvár ${ }^{46}$ & & 5 & 1 \\
\hline 45. Vásárosnamény ${ }^{47}$ & 4 & 3 & 2 \\
\hline 46. Vel'ké Raškovce/Nagyráska ${ }^{48}$ & 5 & 101 & 32 \\
\hline 47. Vésztő-Bikeri ${ }^{49}$ & 2 & 4 & 2 \\
\hline
\end{tabular}

Einige Gräberfelder, wie z. B. Szabolcs-Kisfalud, ${ }^{50}$ Tiszadorogma, ${ }^{51}$ Szentes-Kisktőke, ${ }^{52}$ Lucska/Lúčky ${ }^{53}$ bzw. weitere einzelne Bestattungen, wie z. B. Valkó-Tópart, ${ }^{54}$ konnten wir in die Analyse nicht aufnehmen.

\subsection{Zur Forschungsgeschichte}

Die Forschungsgeschichte der frühkupferzeitlichen Tiszapolgár- und der mittelkupferzeitlichen Bodrogkeresztúr-Kultur wurde jüngst mehrmals ausführlich und eingehend betrachtet. ${ }^{55}$ Wir berühren hier deshalb nur die Streitfragen und zu beantwortenden Probleme der gegenwärtigen Forschungslage.

Man kann mit Sicherheit feststellen, dass die Tiszapolgár-Kultur bei der Entstehung der frühkupferzeitlichen Zivilisation im Karpatenbecken eine entscheidende Rolle gespielt hatte. Die Tiszapolgár- und die Bodrogkeresztúr-Kulturen nehmen die Karpato-Ukraine, die Ostslowakei, Ostungarn, Westrumänien und die Woiwodine ein: „Innerhalb dieses Komplexes, der sich auf der Basis der spätneolithischen Theiß-Kultur entwickelt hat, sind drei Perioden zu unterscheiden: die Periode der Tiszapolgár-Kultur, die klassische Bodrogkeresztúr-Kultur und die späte Bodrogkeresztúr-Kultur mit Hunyadihalom und der Lažňany-Gruppe. “"56 Im Ostteil Siebenbürgens und in der Moldau lebten die Gemeinschaften der anfänglichen Periode B der Cucuteni-Kultur bzw. im westlichen Karpatenbecken die Völker der Furchenstichkeramik mit denen der Hunyadihalom-Kultur gleichzeitig. Nördlich der Karpaten lebte u. a. die Lažňany-Gruppe - stellt P. Patay fest. ${ }^{57}$

${ }^{34}$ BognÁr-KuTZián 1946; BognÁR-KutZián 1955; BoGNÁR-KuTZIÁN 1963; BoGNÁR-KuTZIÁN 1972, 96.

${ }^{35}$ Bender 1909; BANNER 1927; BognáR-KutZián 1963; BOGNÁR-KUTZIÁN 1972, 97-98.

${ }^{36}$ RACZKY et al. 1998, 47-50.

${ }^{37}$ PATAY 1958.

${ }^{38}$ PATAY 1961, 70-73.

${ }^{39}$ ReIZNER 1899; REIZNER 1904; KoREK 1958, 132; PATAY 1938, 103; BogNÁR-KuTZián 1972, 86-89.

40 ŠIŠKA 1964, 294-356; ŠIŠKA 1968, 63-164; ŠIŠKA 1969, 415-428; ŠIŠKA 1972, 13-21.

${ }^{41}$ HellebrandT-Patay 1977, 43-47.

${ }^{42}$ SzABÓ 1956; BognÁr-KutZián 1972, 93-94.

${ }^{43}$ PATAY 1957, 31-36.

${ }^{44}$ Patay 1966-1967; Patay 1971; Patay 1978b, 7.

${ }^{45}$ PATAY 1978a.

${ }^{46}$ SCHIER 2008, 61-62; SCHIER 2013.

${ }^{47}$ KoreK 1964, 252; BoGNÁR-KuTZIÁN 1972, 110-111.

${ }^{48}$ VÍZDAL 1977.
${ }^{49}$ GYUCHA 2009, 277-278, 286.

${ }^{50}$ ECSEDY 1977, 11-38.

${ }^{51}$ Hellebrandt-Patay 1977, 49-50.

${ }^{52}$ ZaLOTAY 1933-1934; PATAY 1961, 75-76.

${ }^{53}$ ŠIŠKA 1964

${ }^{54}$ R. PATAY 2006-2007, 102.

${ }^{55}$ Meisenheimer 1989; SzILÁGYi 2008. A. Gyucha gibt einen forschungsgeschichtlichen Überblick der Tiszapolgár-Kultur in der Großen Ungarischen Tiefebene und den benachbarten Regionen (GyUCHA 2009). M. Szilágyi betrachtet die Forschungsgeschichte nicht nur der Tiszapolgár-Kultur, sondern auch die der Bodrogkeresztúr-Kultur und der Hunyadihalom-Gruppe. Er stellt die Frühkupferzeit (Tiszapolgár- und Bodrogkeresztúr-Kultur) in den Zeitraum von 4500-4000 cal BC, die Frühkupferzeit und die Hunyadihalom-Gruppe in die Mittelkupferzeit (4000-3600 BC) (SZILÁGYI 2015, 7). Auch ein neues keramiktypologisches System ist mit seinem Namen verbunden: Er analysierte sowohl die Gefäßtypen und -formen als auch die keramischen Verzierungen eingehend (ebenda, 12-24, 83-99, Abb. 5.13).

${ }^{56}$ LiCHARDUS 1991a, 767. 
Chronologie, Typologie und Totenritual der behandelten Gemeinschaften wurden erstmals von I. BognárKutzián bei der Veröffentlichung des Fundmaterials aus dem Gräberfeld von Tiszapolgár-Basatanya ausführlich betrachtet. ${ }^{58}$ Die Wichtigkeit dieses Gräberfeldes liegt auch darin, dass es bislang das einzige ist, in dem sowohl die Tiszapolgár- als auch die Bodrogkeresztúr-Kultur vertreten ist. ${ }^{59}$

Die neueste kritische Überprüfung der von Bognár-Kutzián durchgeführten typochronologischen Bearbeitung des Gräberfeldes von Polgár-Basatanya stammt von M. Meisenheimer. ${ }^{60}$ Bognár-Kutzián widmet sich „in erster Linie der - formenkundlich und chronologisch orientierten - Entwicklung der Funde und Befunde sowie deren Vergleich mit weiteren Gräberfeldern in und außerhalb Ungarns. Da sie jedoch teilweise mit Grundannahmen operiert, deren Gültigkeit in Frage gestellt werden muß, wurde eine Neubearbeitung der relativen Chronologie des Gräberfeldes und als Voraussetzung dafür der typologischen Gliederung der Keramik notwendig“ - bestätigt Meisenheimer. ${ }^{61}$ Als Beispiel dafür erwähnt sie, dass die Bestimmung der relativchronologischen Abfolge der Gräber in Basatanya ,,ausschließlich an den Grabreihen orientiert ist“. ${ }^{62}$

S. Šiška setzte voraus, dass die Funde von Tibava „Elemente enthalten, die der Lengyel-Keramik eigen sind, ... doch die bisherigen Funde ergeben, dass bereits während der Entwicklung der älteren Stufe der TiszapolgárKultur, wahrscheinlich aus der Westslowakei, ihre unmittelbare Einwirkung stattfand... Einflüsse der LengyelKeramik findet man am Fundmaterial aus der jüngeren Phase des Gräberfeldes von Tibava und umgekehrt.“63

P. Raczky studierte die chronologischen Fragen der Kupferzeit des Karpatenbeckens und die weiten Beziehungen zwischen dem Karpatenbecken und dem südosteuropäischen Raum in mehreren Arbeiten ausführlich und eingehend. ${ }^{64}$

Bis vor Kurzem dominierten unterschiedliche Meinungen über die Entstehung der Tiszapolgár-Kultur. Diese Theorien wurden kürzlich von M. Szilágyi ausgewertet und zusammengefasst. ${ }^{65}$

I. Bognár-Kutzián spricht über eine kontinuierliche Entwicklung vom Spätneolithikum in die Frühkupferzeit. Sie nimmt genetische Beziehungen zwischen den beiden Epochen an ${ }^{66}$ Sie behauptet, dass der Übergang zwischen dem Spätneolithikum und der Frühkupferzeit nicht als eine ethnische Änderung zu betrachten ist: Sie nimmt kulturelle Kontinuität und genetische Beziehungen zwischen dem Spätneolithikum und der TiszapolgárKultur an.$^{67}$ „Die frühkupferzeitliche Zivilisation Mitteleuropas kann nicht mit Hilfe einer autochthonen Entwicklung erklärt werden. Aber auch rein diffusionistische Vorstellungen sind nicht annehmbar" - schreibt J. Lichardus. ${ }^{68}$

Die Probleme der Prototiszapolgár-Phase betrachtete jüngst F. Horváth. Er bestimmt die keramischen Typen, die diese Übergangsperiode nach seiner Meinung vertreten dürfen. ${ }^{69}$

Zwei Theorien müssen hier noch ebenfalls hervorgehoben werden: I. Ecsedy beschreibt den Übergang als ein Ergebnis von äußeren Wirkungen, die genetische Kontinuität nicht bezweifelnd. Auffallend ist die Tatsache nämlich, dass die Tiszapolgár-Kultur in erster Linie nicht die örtlichen Theiß-Traditionen spiegelt, sondern jene der transdanubischen Lengyel-Kultur. ${ }^{70}$ Darauf folgend bestätigte F. Horváth, dass die Elemente der Lengyel-Kultur in die Tiefebene eingedrungen waren und die Gruppen der Lengyel-Kultur während der Prototiszapolgár-Zeitperiode schon die ganze Tiefebene beherrscht hatten. ${ }^{71}$ Die Prototiszapolgár-Phase stellt den Übergang zwischen der jungäneolithischen und altäneolithischen Besiedlung in der Ostslowakei dar und im Bereich der Lengyel-Kultur ist diese „,theoretische“ Phase durch den Horizont Topolcsány-Szob gekennzeichnet. „Funde ähnlichen Gepräges befinden sich auch im Theißgebiet und ... auch in den westlichen Gebieten Europas. " ${ }^{72}$ Auch die gemeinsamen Keramikformen der Nyitra-BrodzányGruppe (Spätlengyel) und der Tiszapolgár-Kultur deuten auf die engen Beziehungen zwischen beiden Kulturen hin. ${ }^{73}$

Eine ausführliche Forschungsgeschichte der Bodrogkeresztúr-Kultur stammt von P. Patay. ${ }^{74}$ Die Gemeinschaften waren im Donau-Theiß-Zwischenraum beheimatet, mit Auswirkungen auch nach Syrmien. Ihre Fundorte

${ }^{57}$ PATAY 2005, 131.

${ }^{58}$ Bognár-KutZí́n 1963.

${ }^{59}$ Meisenheimer 1989, 5.

${ }^{60}$ Ebenda.

${ }^{61}$ Ebenda, 2

${ }^{62}$ Ebenda.

${ }^{63}$ ŠIŠKKA $1964,355$.

${ }^{64}$ RACZKY 1988; RACZKY 1991; RACZKY 1995; RACZKY

2011.

\footnotetext{
${ }^{65}$ SZILÁGYI 2008, 369-389.

${ }^{66}$ BognáR-KutZián 1972, 170-171, 183-186.
}

${ }^{67}$ Ebenda, 170-171, 183-186.

${ }^{68}$ LichaRdus 1991b, 222.

${ }^{69}$ HoRváth 2014, fig. 9. „The use of the terminus technicus PTP can hardly be understood as an ethno-archaeological unit because of the different pace of the transition in the different regions as can be seen from contradictions between absolute chronology and typological aspects of traditional archaeology as well“" (ebenda, 316).

${ }^{70}$ ECSEDY 1981, 80-81.

${ }^{71}$ HORVÁth 1988, 30-31.

72 VLADÁR-LICHARDUS 1968, 342.

${ }^{73}$ Ebenda.

Acta Archaeologica Academiae Scientiarum Hungaricae 67, 2016 
karbondaten von hier datieren die Belegungszeit des Gräberfeldes in eine Zeitspanne von 4334 bis 4047 v. Chr. ${ }^{93}$ Die Daten können darauf hinweisen, dass diese archäologischen Kulturen miteinander in Raum und Zeit in Kontakt waren bzw. sie sich zueinander parallel entwickelten. ${ }^{94}$ Die eigenartigen Befunde von anderen Nekropolen der Bodrogkeresztúr-Kultur (z. B. Tiszavalk-Tetes, Magyarhomorog-Kónyadomb usw.) unterstützen nicht die zeitliche Abfolge der beiden Kulturen, sondern ihre in Raum und Zeit parallele Entwicklung. ${ }^{95}$

Die Probleme des Übergangs vom Spätneolithikum zur Frühkupferzeit in den östlichen Regionen Rumäniens (Cucuteni-Kultur) betrachtete jüngst C.-M. Lazarovici. ${ }^{96}$ Die Fragen der relativen und absoluten Chronologie des Spätneolithikums und des frühen Äneolithikums im gesamten östlichen Karpatenbecken erörterte jüngst F. Draşovean mit Anwendung der Bayesischen Methode. ${ }^{97}$ Y. Boyadzhiev studierte diese Themen auf Grund von bulgarischen Funden und Befunden und synchronisierte auf Radiokarbondaten basiert auch die neolithischen und kupferzeitlichen Kulturen des südosteuropäischen Raumes und des Karpatenbeckens miteinander. ${ }^{98}$

R. Gleser stellte bezüglich seines Versuchs Folgendes fest: „Insgesamt betrachtet ist es nicht möglich, ein schlüssiges Gesamtmodell für das 5. Jahrtausend zwischen Mosel und Morava sowohl auf einer ordinalen als auch einer metrischen Skala zu entwickeln, weil die Widersprüche der ... vergleichend dargestellten Chronologiemodelle nicht ohne Weiteres überregional auflösbar sind. Gründe dafür müssen jeweils regionale Stilentwicklungen sein, die in unterschiedlicher Geschwindigkeit abgelaufen sind. Die vorhandenen Kontaktfunde bestätigen zwar prinzipiell die meisten der in der Literatur schon lange herausgestellten chronologischen Verbindungen, doch da im Einzelfall nicht geklärt ist, aus welchen Regionen oder gar Siedlungen das jeweils importierte Material stammt und wo es auf der Zeitachse daher zu verorten ist, scheitert die Konstruktion überregionaler Horizonte. Da insgesamt noch viel zu selten Radiokarbondaten gemessen wurden, sind die Geschwindigkeiten des Stilwandels in den einzelnen Regionen noch nicht zu entschlüsseln. ... Dies steht vermutlich damit im Zusammenhang, dass die Kulturphänomene tatsächlich primär als aufeinander folgend zu rekonstruieren sind. Zudem ist die Anzahl der von der Forschung bislang herausgestellten , archäologischen Kulturen“ in Proportion zum Faktor Zeit, der durch zahlreiche neu gemessene AMS-Daten immer besser fassbar wird, deutlich kleiner.“99

\section{ZIELSETZUNG}

Im Fall der vorliegenden Arbeit handelt es sich um die erste Auswertung aller, in die Datenbasis aufgenommenen Keramiken des Polgár-Komplexes. Bei diesen Gräbern geht es um geschlossene Befunde, in denen absichtlich und gleichzeitig deponierte Funde vorhanden sind. Die von uns behandelten Funde stammen aus Nekropolen und es wird dabei nur ein einziger Aspekt, die Grabkeramik getestet, die aber nur eine Art der bis heute erhaltenen Funde in diesen Ensemblen darstellt. In Bezug auf die analytischen Methoden urzeitlicher Nekropolen gab es viele Probleme in der jüngsten Vergangenheit. Die Fragen der deutschen Gräberarchäologie diskutierte jüngst K. P. Hofmann ausführlich: „Der Umgang mit dem Tod und den Toten ist zeit- und kulturspezifisch. Dies trifft auch auf die archäologische Erschließung, Auswertung und Präsentation von Bestattungen zu, die durch unterschiedliche Forschungstraditionen, aktuelle Interessenlagen etc. geprägt sind.“100 So steht fest, „dass es in der Gräberarchäologie viele verschiedene Prämissen gibt, die die jeweiligen Interpretationen von Grabbefunden determinieren. Insbesondere die Konzepte zu Grabbeigaben wurden bisher jedoch zu wenig hinterfragt. “101

Das Ziel der vorliegenden Arbeit können wir folgenderweise zusammenfassen. 1. Die Klassifikation des grabkeramischen Bestandes der untersuchten Nekropolen, um die typologischen Einheiten innerhalb unseres typo-

${ }^{92}$ CSÁNYI et al. 2009; CSÁNYI et al. 2010, 261.

${ }^{93}$ CsÁNYI et al. 2010, Abb. 17.

${ }^{94}$ Ebenda, 263.

${ }^{95}$ Ebenda.

${ }^{96}$ LAZAROVICI 2014

${ }^{97}$ Draşovean 2014.

${ }^{98}$ BoyADZHIEV 2014, 50, fig. 2.

${ }^{99}$ GLESER 2012, 82-83.

${ }^{100}$ Hofmann 2013. Als wichtigste Elemente des Themas spricht sie Folgende an: die archäologische Quelle Grab; Gräber Spiegel der Gesellschaft?; vertikale Sozialstruktur; Gräberfeld- und
Regionalanalysen; horizontale Sozialstruktur; zum Umgang mit dem Tod; Tod und post mortem; Symbole, Rituale und Indizien; Gräber als Orte des Umgangs mit der Vergangenheit

${ }^{101}$ Hofmann 2014; Hofmann 2013, 286-287. Sie stellt die folgenden wichtigen Fragen: „Wie können von uns heute geborgene Funde und Befunde als Handlungsträger/-innen in wissenschaftliche Erzählungen eingebettet werden? Können wir in der prähistorischen Archäologie wirklich Biographien mit archäologischen Funden und Befunden als Protagonist/-innen schreiben? Welche Implikationen hat dieser häufig geäußerte Wunsch? Und - last but not least - welche Alternativen gibt es, Ding- bzw. Objektgeschichten zu verfassen?““ (HofMANN 2015, 88). 
logischen Systems (Klassen, Gattungen, Serien, metrische Gruppen, Typen und Varianten) bestimmen zu können. 2. Zur Klassifikation der Grabkeramiken des Polgár-Komplexes wurden die archäologische vergleichende Methode, die hierarchisch aufgebaute metrische Analyse (mAnalyse), die Korrelation und Seriation (WINBASP 5.2) verwendet. 3. Bestimmung der Tendenzen der Belegungsgeschichte der Gräberfelder nach künstlichen Perioden und Belegungsphasen. 4. All diese Untersuchungen wurden mit der Absicht durchgeführt, ein besseres Bild - im Verhältnis von Radiokarbondaten - zu den nachfolgenden sozialarchäologischen Forschungen in Raum und Zeit zu erhalten.

Die Gefäßformen sind auf den Fotoabbildungen gut erkennbar, aber Einzelheiten, wie z. B. Randbildung, sind nicht zu erkennen und so können nicht in die Typologie eingehen - stellt auch M. Meisenheimer fest. ${ }^{102}$

Die Klassifizierung der behandelten Funde nahmen wir mit Hilfe eines hierarchisch aufgebauten merkmalanalytischen Systems vor, die wir schon früher, bei der Bearbeitung der lengyelzeitlichen Grabkeramik und der sozialarchäologischen Verhältnisse von neolithischen Gräberfeldern, anwendeten. ${ }^{103}$ Somit erhalten wir eine Reihenfolge von Funden und Befunden, die sich nach einem statistischen oder typologischen Bild ordnen. Es muss aber entschieden bzw. nachgewiesen werden, ob dieses Bild auch die relativchronologische Reihenfolge der untersuchten Objekte spiegelt oder nicht. ${ }^{104}$ Wir berücksichtigten nur die Merkmale, die für unsere Fragestellung als relevant gelten.

Zur kontextuellen Merkmalanalyse stellen P. Biehl und R. Gleser Folgendes fest: „Dabei wird das Artefakt, hier das keramische Gefäß, als eine kontextuelle Einheit verstanden, in der alle erfassbaren Merkmale eines Artefakts in einem inhaltlichen und zeitlichen Kontext zueinander stehen und in ihrer Gesamtbetrachtung zum einen die Bedeutung und Funktion des Artefakts, zum anderen die Gestaltungsregeln erkennen lassen, denen sein individueller Hersteller unterworfen war." ${ }^{\text {"105 }}$

B. Dammers charakterisiert ihre analytische Methode folgenderweise: „Ziel ist es, auf metrischer Basis solche Ähnlichkeiten herauszuarbeiten, die auch optisch erkennbar sind. Damit kommt der metrischen Analyse eher die Funktion einer Illustration als die eines Beweises zu. “106

Unser hierarchisch aufgebautes typologisches System besteht aus Klassen, Gattungen, Serien, metrischen Gruppen, Typen und Formvarianten. Die Definition der Klassen stützt sich auf die Längen-Breiten-Verhältnisse der Grabgefäße. Keramiken, deren Höhe länger ist als die größte Breite, wurden in der Klasse 1 (Hochgefäße) gruppiert. Gefäße, deren Breite größer ist als die größte Länge, bilden die Klasse 2 (Breitgefäße). Die Sonderformen der Keramiken wurden der Klasse 3 zugeordnet. Die Definition der Gattungen basiert auf unserer früheren Klassifikation der lengyelzeitlichen Grabkeramik. Auf diesem Grund können die Einheiten von Fußgefäßen (Gattung 1a), Becherformen (Gattung 1b), Näpfen (Gattung 1c), Schultergefäßen (Gattung 1d), Butmir-Gefäßen (Gattung 2a), Schüsselformen (Gattung 2b) und Schalen (Gattung 2c) der kupferzeitlichen Funde eingeordnet werden. Dadurch wird dann die Gesamtanalyse der chronologischen Verhältnisse der beiden großen prähistorischen Komplexe möglich. Die keramischen Serien stellten wir anhand der Unterschiede der A-Indexwerte (Längen-Breiten-Indices) fest. Die weitere Gruppierung der untersuchten Keramiken wurde auf Grund des Verhältnisses der verschiedenen Gefäßteile zueinander und anhand der Gefäßformen vorgenommen - somit konnten wir die metrischen Gruppen (mGruppen) feststellen. Innerhalb der metrischen Gruppen wurden die Typen schon allein auf Grund der Gefäßformen bestimmt. Als letzter Schritt der Klassifikation wurden die Formvarianten auf der Basis der Unterschiede der Keramiken auf den einzelnen Typen definiert.

Die hier dargestellte Methode ermöglichte die in zunehmendem Maße möglichst schmalere Gruppierung der untersuchten kupferzeitlichen Grabkeramik. Mit der Anwendung dieser Methode können wir zu den eigentlichen keramischen Typen und Formvarianten immer näher kommen.

Wie gesehen, wurde es zufolge der neuesten Forschungsergebnisse festgestellt, dass alle Gemeinschaften des Polgár-Komplexes weitgehend zur gleichen Zeit gelebt hatten. Die Grabkeramiken dieser Gemeinschaften unterscheiden sich sowohl in Form als auch in Dekoration deutlich voneinander. Im Verlauf einer keramischen Analyse müssen auch die Gefäßdekoration, die Verzierungssysteme usw. berücksichtigt werden. Die Verzierungen der Grabkeramik von Polgár-Basatanya wurden von M. Meisenheimer schon ausführlich typologisiert. ${ }^{107}$ Die Gefäßverzierungen wie die Gefäßformen der Siedlungskeramik der diskutierten kupferzeitlichen Gemeinschaften analysierte jüngst M. Szilágyi. ${ }^{108}$ Die Forschungskonzepte und Möglichkeiten der Analyse der prähistorischen

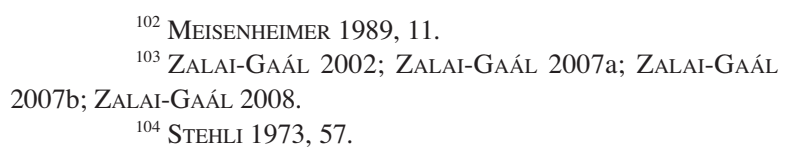

${ }^{105}$ BieHL-Gleser 2003, 168.
${ }^{106}$ DAMMERs 2005, 26.
${ }^{107}$ MeISENHEIMER 1989. 
Gefäßverzierungen wurden u. a. von P. Biehl und R. Gleser ausführlich erörtert. ${ }^{109}$ Dem Thema „Keramik als chronologisches Indiz und ,ethnischer" Indikator" widmete auch A. Zeeb-Lanz mehrere Studien. ${ }^{110}$ Die kontextuelle Merkmalanalyse der prähistorischen Keramiken setzt selbstverständlich die Untersuchung aller erfassbaren Merkmale der Artefakte voraus. Die Untersuchung der Verzierungen aller in die Analyse aufgenommenen Keramiken auf Grund der Fotoabbildungen war für uns nicht möglich. Die zeitlichen und räumlichen Änderungen der Grabkeramik dieser Gemeinschaften behandelten wir nur anhand der Profilierung der Funde.

Die Feststellung von M. Szilágyi ist beachtenswert: „Aufgrund der früheren Forschungen in den kupferzeitlichen Nekropolen wurde darauf hingedeutet, dass zwei Identiätsgruppen in der Tiefebene in gleicher Zeit gelebt hatten, die sich in dem Totenritual voneinander unterschieden. Anhand der Siedlungskeramik kann man dagegen keine solche zwei, eindeutig abgrenzbaren Gruppen bestimmen, die als ,Tiszapolgár‘ oder ,Bodrogkeresztúr' genannt würden. “111 Daher verwenden wir - als terminus technicus - nachstehend die Ausdrücke „Formenkreis 1“, „Formenkreis 2“ und „Formenkreis 3“ statt der bisherigen Benennungen Tiszapolgár, Bodrogkeresztúr und Hunyadihalom.

Die Fragen und Probleme der materiellen Kultur, Territorialität und Bedeutungsinhalte der oben erwähnten Identitäten in prähistorischen Zeiten erörterte jüngst J. Müller. Man kann ihm zustimmen, dass keine ethnischen Identitäten mit archäologischen Mitteln nachgewiesen werden können. „Mit archäologischen Mitteln lassen sich dagegen Raumstrukturen darstellen und z. B. auch Territorialität im Sinne ökonomischer oder politischer ,Grenzziehungen" rekonstruieren." ${ }^{112}$

\section{KLASSIFIKATION DER GRABKERAMIK}

Im Laufe der formalen Gliederung der Keramik muss man berücksichtigen, dass es nicht einmal zwei genau übereinstimmende Gefäße gibt, die in allen Merkmalen gleich sind. Im besten Fall finden wir nur solche, „die durch Übereinstimmung in sehr vielen Merkmalen ähnlich sind. Um die Vielzahl der Variationen überschaubar zu machen, müssen sie in Typen untergliedert werden. “" ${ }^{113}$ Der Vorgang des Typenbildens besteht darin, ähnliche Formen zu gleichen Typen zusammenzufassen, indem man offensichtlich irrelevante Unterschiede beiseite lässt: Im Begriff des Typs ist es bereits ausgedrückt, dass es sich nicht um eine Identität bis ins kleinste Detail, sondern nur um eine Übereinstimmung in charakteristischen Merkmalen handelt. ${ }^{114}$

Auch die von B. Dammers vorgenommene Formengliederung der Rössener Keramik in Rheinhessen wurde mit vertikalen und horizontalen Streckenmaßen zwischen charakteristischen Punkten sowie mit Rand- und Wandneigungswinkeln vorgenommen. „Dabei werden die Indices als genauer erachtet und nach Möglichkeit bevorzugt, weil gerade bei der oft nur zeichnerisch rekonstruierbaren Siedlungsware die Orientierung und damit der Winkel nicht gesichert ist. “115 Diese Klassifikation ist aber nur eine typologische. „Die Prüfung auf chronologische Relevanz bleibt ein weiterer Arbeitsschritt nach der Erarbeitung einer Chronologie" - schreibt Dammers. ${ }^{116}$

Die untersuchte Keramik des Polgár-Komplexes wurde gemäß 3 Klassen, 11 Gattungen, 26 Serien, 86 metrischen Gruppen und 817 Typen klassifiziert. Die Anzahl der Formvarianten beträgt 1132. Die Verteilung dieser Grabkeramik nach Typen und Varianten zeigt Diagramm 1.

Die Fußgefäßtypen erscheinen in 17,65 \% $(\mathrm{n}=144)$ und die Fußgefäßvarianten in $11,67 \%(\mathrm{n}=132)$. Bechertypen werden durch 32,72 \% $(\mathrm{n}=267)$ repräsentiert und Bechervarianten durch 38,02\% $(\mathrm{n}=430)$ vertreten. Die Napftypen können nur in 2,94 \% $(\mathrm{n}=24)$ und die Napfvarianten in 3,45 \% $(\mathrm{n}=39)$ belegt werden. Der Anteil der Schultergefäßtypen beträgt 8,33 \% $(\mathrm{n}=68)$ und der der Schultergefäßvarianten 9,81\% $(\mathrm{n}=111)$. Butmir-Gefäße kommen nur in 0,37 \% $(\mathrm{n}=3)$ vor, Schüsseltypen sind dagegen in 11,89\% $(\mathrm{n}=97)$ und Schüsselvarianten in $10,61 \%(\mathrm{n}=120)$ nachgewiesen. Die Schalentypen sind zugleich schon in 23,53\% $(\mathrm{n}=192)$ und die

${ }^{108}$ SzILÁGYi 2015.

${ }^{109}$ BIEHL-GLESER 2003

${ }^{110}$ ZEEB-LANZ 2003. „Die Zusammenstellung keramischer Varianten zu Haupt- und Untergruppen erfuhr häufig eine Interpretation als jeweils verschiedenen Kulturen zugehörig, denen eine historische Dimension im Sinne real existierender ethnischer Gruppierungen zugebilligt wurde, wie sie so sicherlich nicht der prähistorischen Realität entsprochen hat“" (ZEEB-LANZ 2006, 5).
${ }^{111}$ SZILÁGYi 2015, 326

${ }^{112}$ MÜLLER 2009. 105.

113 MeISENHEIMER 1989, 9.

114 ,Jedes Gefäß kann als ,geschlossener Fund“ verstanden werden, an dem die Ausgestaltungen der verschiedenen Elemente miteinander verbunden sind“" (MEISENHEIMER 1989, 9).

${ }^{115}$ DAMMERS 2005, 26.

${ }^{116}$ DAMMERS 2005, 27.

Acta Archaeologica Academiae Scientiarum Hungaricae 67, 2016 


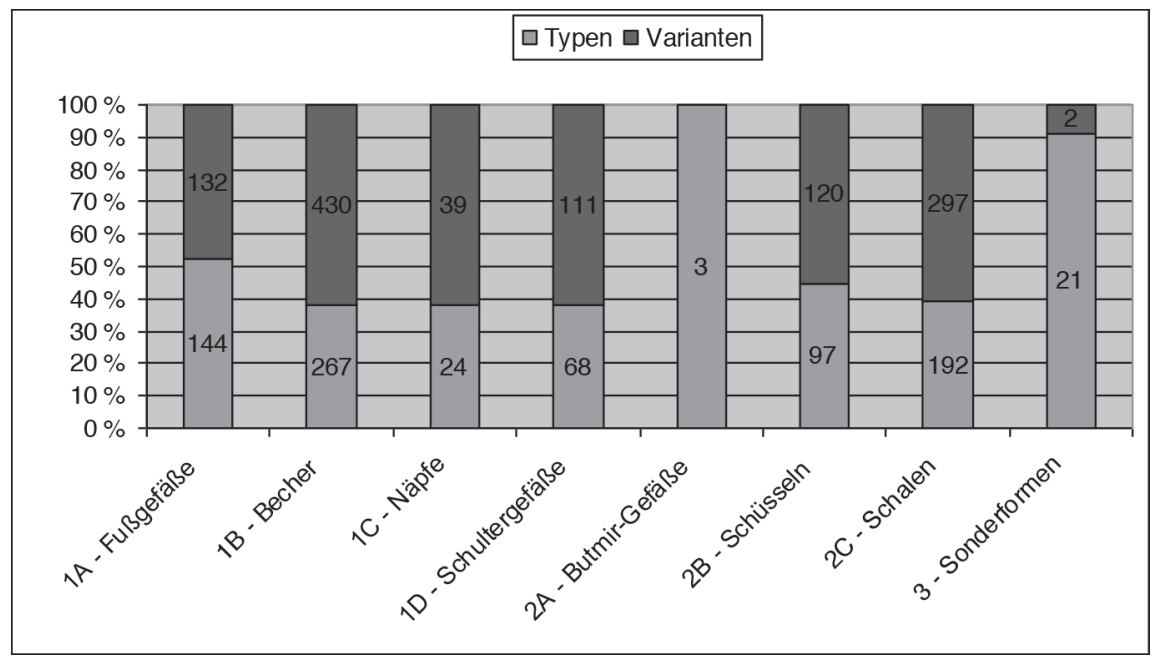

Diagramm 1. Verteilung der klassifizierten Grabgefäße nach Typen und Formvarianten

Schalenvarianten in 26,26 \% $(\mathrm{n}=297)$ vorhanden. Die als Sonderformen behandelten Typen erscheinen nur in $2,57 \%(\mathrm{n}=21)$ und ihre Varianten nur in $0,18 \%(\mathrm{n}=2)$ der Fälle.

\subsection{Klasse 1 - Hochgefäße}

Die Klasse 1 der untersuchten kupferzeitlichen Grabkeramik vertreten Exemplare, deren Höhe größer ist als die größte Breite. 1116 Artefakte von den Hochgefäßen konnten nach 4 Gattungen (1A - Fußgefäße, $1 \mathrm{~B}-\mathrm{Be}$ cherformen, 1C - Näpfe und 1D - Schultergefäße), 13 Serien, 48 metrischen Gruppen und 503 Varianten gruppiert werden.

\subsubsection{Gattung la-Fußgefäße}

Die Gefäße dieser Gattung können in zwei formale Teile gegliedert werden: eine Schüssel oder Schale und einen Hohlfuß. In die Analyse konnten wir 254 Exemplare aus 176 Bestattungen von 32 Nekropolen einbeziehen.

Die Maßbezeichnungen der Fußgefäße zeigt Abbildung 1.

Der wichtigste typologische Charakter der prähistorischen Fußgefäße besteht darin, dass sie aus zwei selbstständigen strukturellen Teilen, aus einem Oberteil und aus einem Hohlfuß, zusammengesetzt sind. Bei der Analyse sollen deswegen beide dieser Gefäßteile einzeln untersucht und gruppiert werden. Der obere Teil der Fußgefäße wird allgemein als „Schüssel“ bezeichnet, sie haben aber oft keine Schüsselform, sondern eine Schalen- oder Becherform, bzw. die Gestalt eines Butmir-Gefäßes (pedestalled bowl, jar, goblet, vessel usw. nach der typologischen Bestimmung von I. Bognár-Kutzián). ${ }^{117}$

Die Klassifizierung der Fußgefäße wurde auf Grund folgender Indices durchgeführt: Die Serien stellten wir mit Hilfe des Indexwertes al (Höhe des Hohlfußes/Höhe der Schüssel) fest. Zur Bestimmung der mGruppen verwendeten wir folgende Indices: Die Hohlfüße können grundlegend durch den Vergleich der Indexwerte (Hohlfußhöhe/größte Breite des Fußes) und $\boldsymbol{f} \boldsymbol{b}$ (Halsbreite/größte Breite des Fußes) gruppiert werden, während die Schüsselteile durch den Vergleich der Indexwerte $\boldsymbol{S} \boldsymbol{a}$ (Schüsselhöhe/größte Schüsselbreite) und $\boldsymbol{S} \boldsymbol{b}$ (Mündungsbreite/ Halsbreite) klassifiziert wurden. Zur Bestimmung der Varianten innerhalb der einzelnen mGruppen haben wir in erster Linie den Index $\boldsymbol{S} \boldsymbol{c}$ (Höhe des Unterteiles der Schüssel/Höhe des Unterteiles der Schüssel) und die Profilform berücksichtigt.

\footnotetext{
${ }^{117}$ BognÁR-KuTZIÁN 1963.
} 


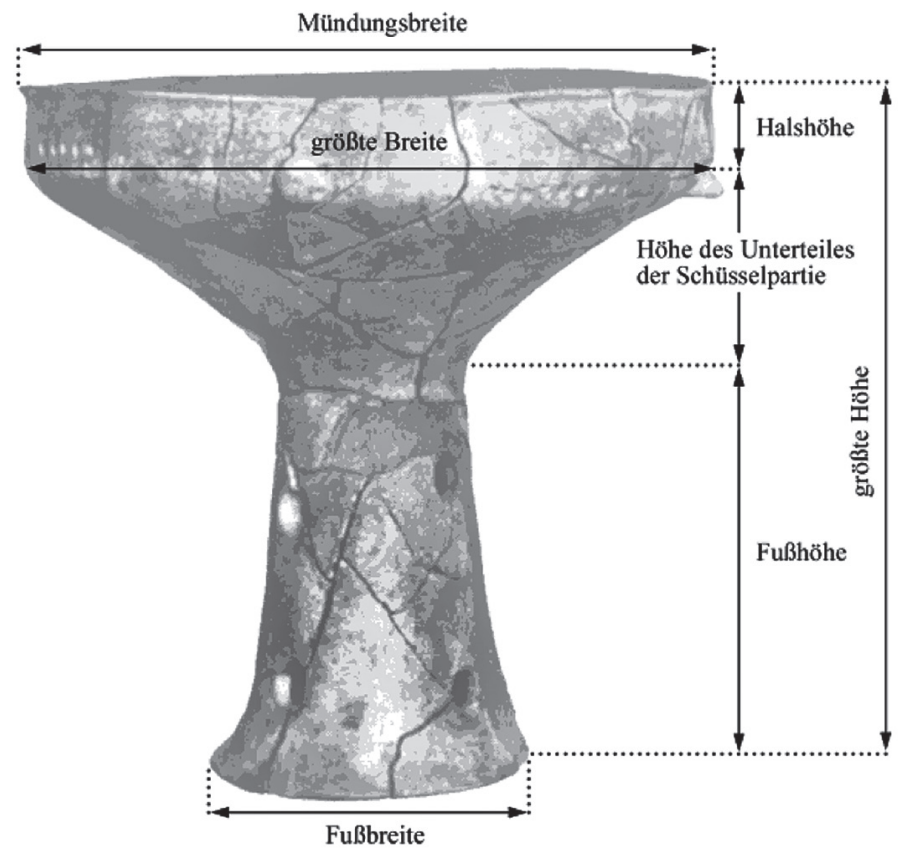

Abb. 1. Maßbezeichnungen eines Fußgefäßes auf den verschiedenen Ebenen

Anhand dieser Zusammenhänge konnten wir 5 Serien, 21 metrische Gruppen sowie 144 Typen mit 132 Formvarianten definieren (Diagramm 2).

Die Serie 1a1 der Fußgefäße vertreten Keramiken mit Index A1. Diese Serie wird durch 12,16\% $(\mathrm{n}=31)$ der untersuchten Funde innerhalb der Gattung 1a vertreten. Die Serie umfasst vier metrische Gruppen und 21 Typen. Der Serie 1a2 der Fußgefäße wurden Exemplare mit Index A2 zugeordnet. Sie treten mit 35,0 \% ( $\mathrm{n}=87)$ der Fußgefäße innerhalb der Gruppe Gattung 1a auf. Die Serie besteht aus 5 metrischen Gruppen und 49 Typen. Bei der Serie 1 a3 handelt es sich um Fußgefäße mit Index A3. Sie sind in 29,41\% $(n=75)$ innerhalb der Gattung 1a nachgewiesen. Die Keramiken konnten in 5 metrische Gruppen sowie 40 Typen eingereiht werden. Der Serie 1a4 wurden Artefakte mit Index A4 zugeordnet, die in 19,22 \% $(n=49)$ der Gattung 1a erscheinen. Sie wurden nach fünf metrischen Gruppen und 25 Typen klassifiziert. Bei der Serie 1a5 von Fußgefäßen mit Index A5 handelt es sich um nicht mehr als 5,10 \% $(n=13)$ der Fußgefäße, die 2 metrischen Gruppen und 9 Typen zugeordnet werden können.

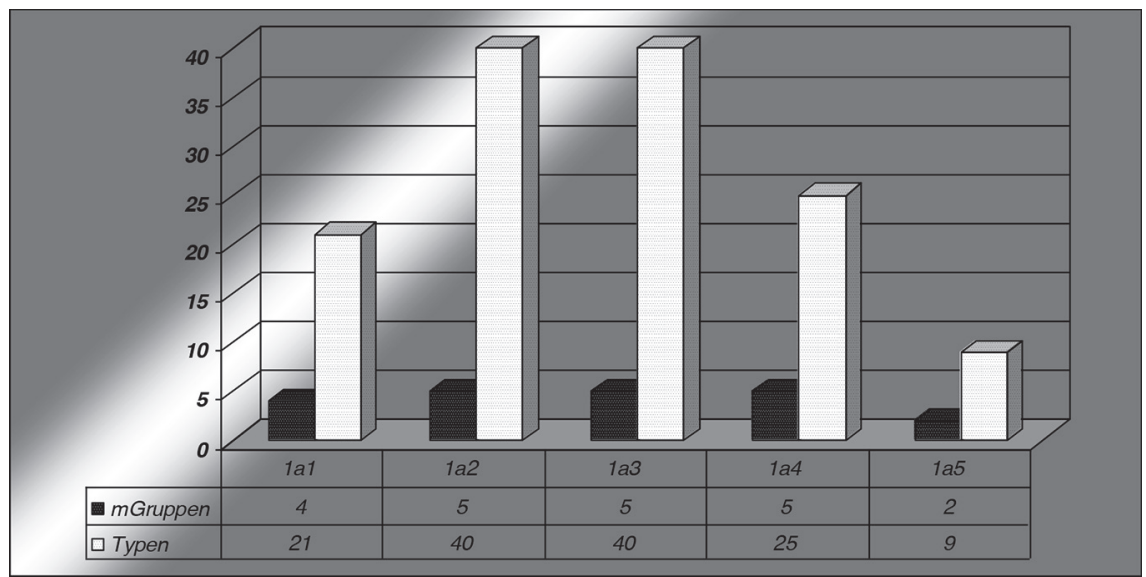

Diagramm 2. Verteilung der Serien, metrischen Gruppen und Typen der Gattung 1a der Fußgefäße 


\subsubsection{Gattung $1 b-$ Becherformen}

Die keramische Gattung der Becher kann verschiedenartig definiert werden. R. Gleser rechnet Keramikgefäße, die einen Randdurchmesser mit einer Größe von 70 \% bis 130 \% der Höhe aufweisen, zu dieser Gattung. ${ }^{118}$ Ein weiteres Kriterium können auch die mehr oder weniger betonte Halspartie und ein Höhen-Breiten-Index von ca. $100 \%$ darstellen. ${ }^{119}$

Die Gattung der Becher wird durch ein-, zwei- und dreigliedrige Keramikgefäße vertreten (Abb. 2-3).

Mit Hilfe der Merkmalanalyse konnten insgesamt 57,41 \% (n=640) der Keramiken aus 384 Bestattungen von 42 Nekropolen eingeordnet werden. Die Gattung 1b umfasst 3 Serien, 14 metrische Gruppen, 267 Typen und nicht weniger als 430 Varianten. Vorkommen und Verteilung der Becher gemäß Gattung, mGruppe und Typen zeigt Diagramm 3.

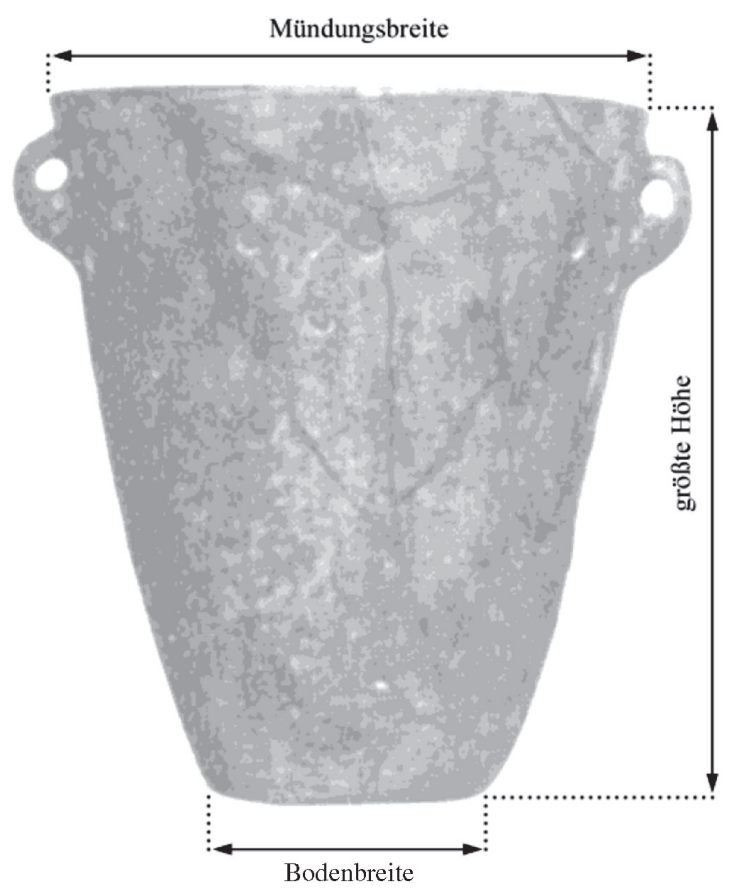

Abb. 2. Maßbezeichnungen eines Bechers auf den verschiedenen Ebenen

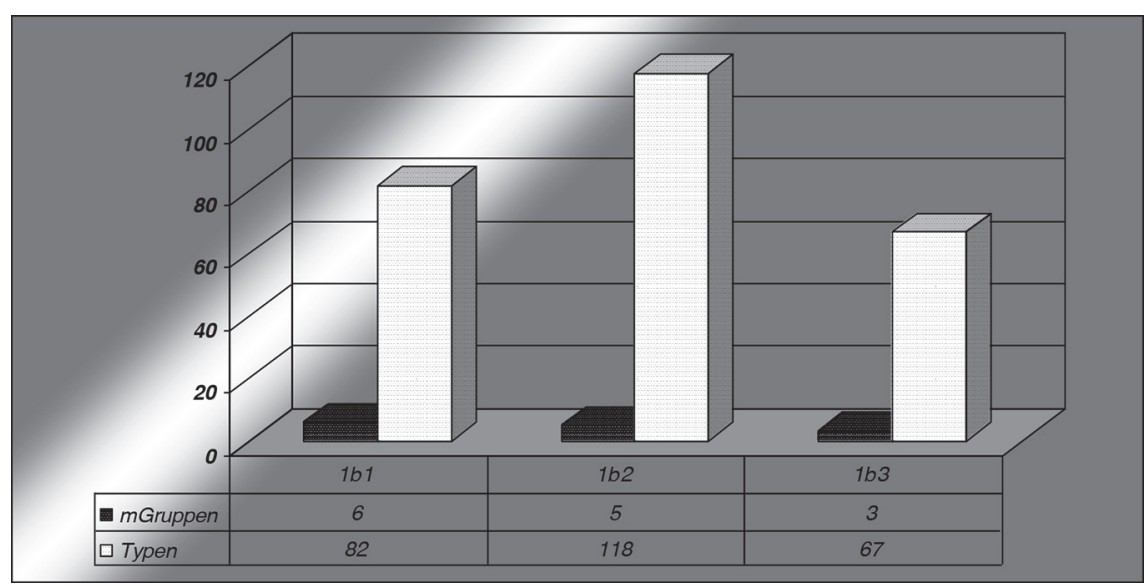

Diagramm 3. Vorkommen der Keramiken der Gattung 1b nach Serien, metrischen Gruppen und Typen

${ }^{118}$ GLESER 1995, 38.

${ }^{119}$ STROBel 1996, 25. 


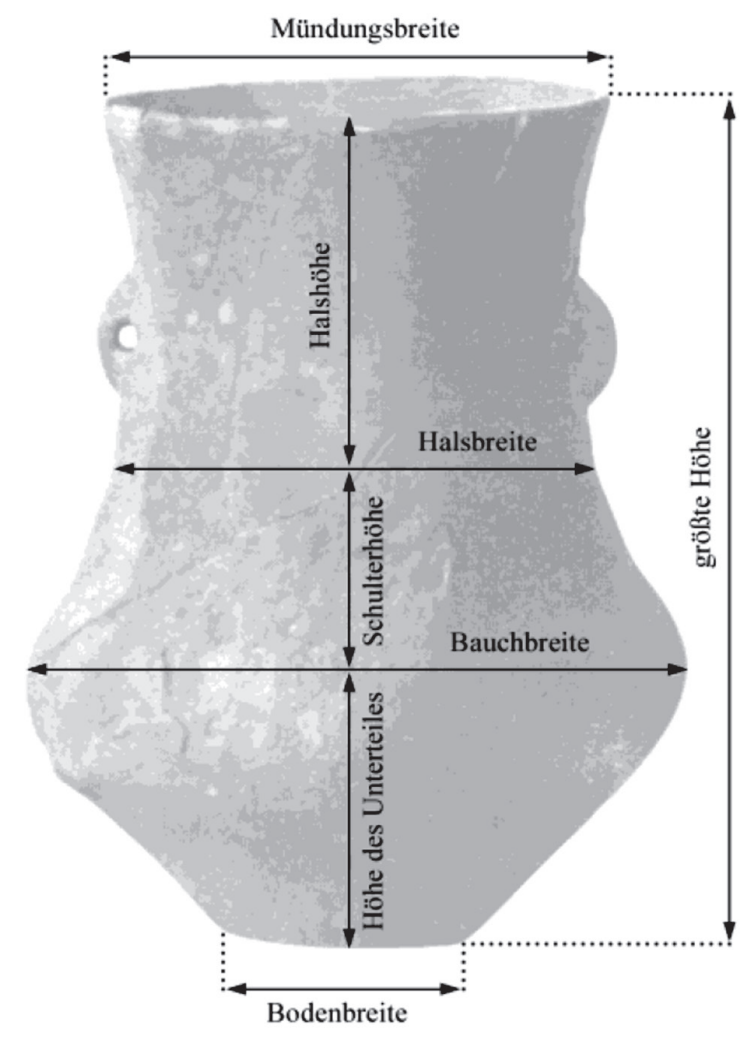

Abb. 3. Maßbezeichnungen der Becher auf den verschiedenen Ebenen

Die Serie 1b1 der Becher repräsentieren Keramiken mit Index A3. Hierher gehört 42,86 \% ( $n=209)$ der Becher. Sie konnten nach 6 metrischen Gruppen und 82 Typen klassifiziert werden. Zu der Serie 1b2 gehören Becherformen, deren größte Länge die größte Breite der Gefäße viermal übersteigt. 40,09 \% ( $n=257)$ der Becher vertritt diese Serie mit fünf metrischen Gruppen und 118 Typen. Die Becher der Serie $1 \mathrm{~b} 3$ können durch A5 Indexwerte charakterisiert werden. 27,30 \% $(n=175)$ dieser Gefäße können 3 metrischen Gruppen und 67 Typen zugeordnet werden.

\subsubsection{Gattung 1c-Näpfe (Serie 1c1)}

$6,27 \%(\mathrm{n}=70)$ der Keramiken aus 60 Bestattungen und bloß 8 Nekropolen wurden einer einzigen Serie, 5 metrischen Gruppen, 24 Typen und 39 Varianten zugeordnet.

\subsubsection{Gattung 1d-Schultergefäße}

Die Gattung der Schultergefäße vertritt 13,44 \% $(\mathrm{n}=150)$ der Keramiken, die in 4 Serien, 8 metrische Gruppen, 68 Typen und 111 Varianten gruppiert wurden. Diese Gefäße stammen aus 106 Gräbern, die auf 19 Fundplätzen geborgen wurden. Vorkommen und Verteilung der Schultergefäße gemäß Serien, mGruppen und Typen sind in Diagramm 4 dargestellt.

Die Serie 1d1 der Schultergefäße vertritt nur 2,0\% $(n=3)$ der Schultergefäße mit Index A3, die in einer metrischen Gruppe und 2 Typen erscheinen. Der Serie $1 \mathrm{~d} 2$ der Schultergefäße wurde 6,0\% $(n=9)$ der Keramiken mit Index A3-4 innerhalb der Gattung 1d zugeteilt. Das gemeinsame Charakteristikum dieser Keramiken liegt darin, 
dass sie mit vier kurzen Füßen versehen sind. Sie können in eine metrische Gruppe und 3 Typen gruppiert werden. Der Serie 1d3 der Schultergefäße mit Index A4 kann 71,33\% $(n=107)$ der Keramiken innerhalb der Gattung 1d zugeordnet werden. Sie stellen 3 metrische Gruppen und 44 Typen dar. Der Serie 1d4 der Schultergefäße gehört 20,67\% ( $n=311)$ der Gefäße mit A5 Index an. Sie konnten in 3 metrische Gruppen und 19 Typen klassifiziert werd

\subsection{Klasse 2 - Breitgefäße}

Der Klasse 2 der untersuchten kupferzeitlichen Grabkeramik wurden insgesamt 751 Exemplare zugeordnet, deren Breite größer ist als die absolute Länge. Sie wurden nach drei Gattungen (2A - Butmir-Gefäße, 2B - Schüsseln und 2C - Schalen), 5 Serien, 24 metrischen Gruppen und insgesamt 292 Typen klassifiziert (Diagramm 5).

\subsubsection{Gattung 2a-Butmir-Gefäße}

Diese Gattung repräsentieren bloß 0,40 \% $(n=3)$ der Keramiken innerhalb der Klasse der Breitgefäße, die nach einer Serie, 2 metrischen Gruppen und 3 Typen klassifiziert werden können.

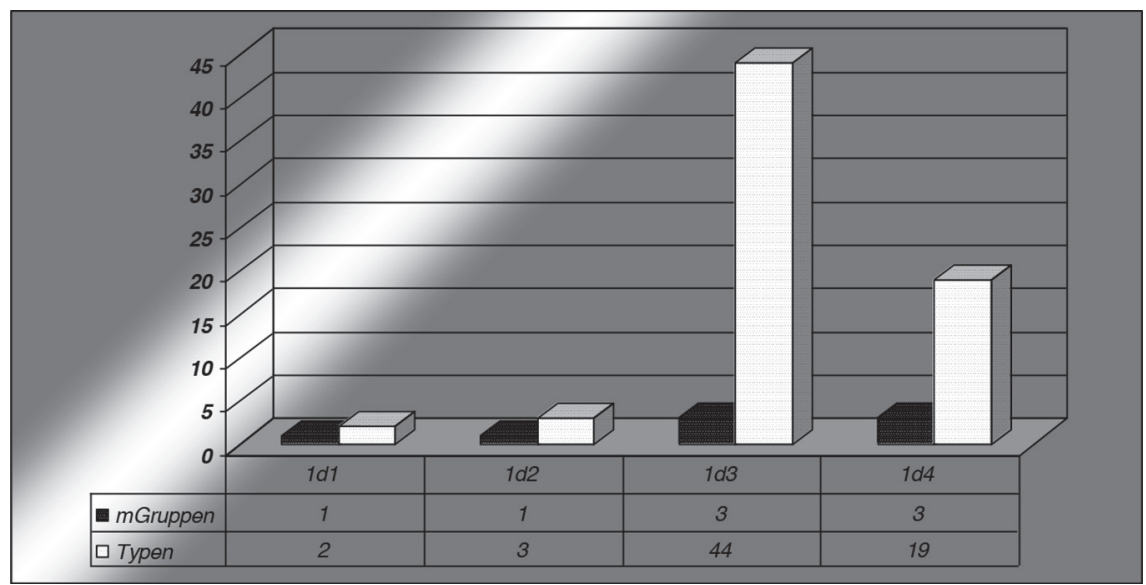

Diagramm 4. Verteilung der metrischen Gruppen und Typen der Gattung 1d der Schultergefäße

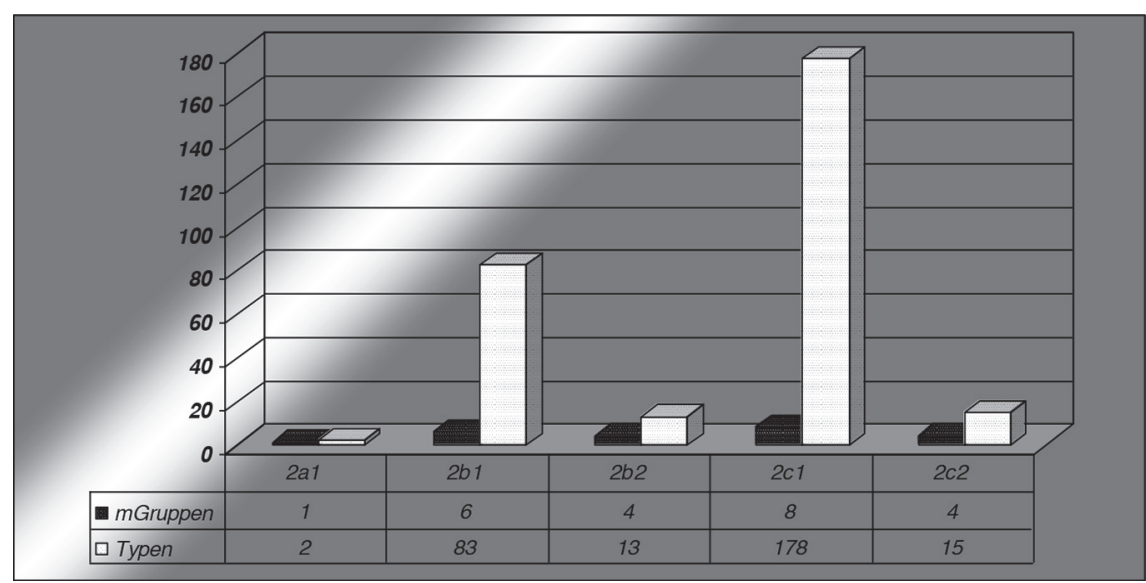

Diagramm 5. Verteilung der untersuchten Breitgefäße nach keramischen Gattungen, Serien, metrischen Gruppen und Typen 


\subsubsection{Gattung $2 b-$ Schüsseln}

Die Schüsseln können dadurch gekennzeichnet werden, dass ihre größte Breite etwa der doppelten Höhe entspricht. ${ }^{120}$ Die Schwierigkeiten bezüglich der Klassifikation der Keramiken, die auf den Umstand, dass es keine Uniformität bei den neolithischen und kupferzeitlichen Gefäßen gibt, zurückzuführen sind, zeigten sich bei der Klassifizierung der Schüsseln und Schalen am markantesten. ${ }^{121}$ Die Maßbezeichnungen der Schüsseln illustriert Abbildung 4.

35,55 \% ( $\mathrm{n}=269)$ der Keramikgefäße innerhalb der Klasse der Breitgefäße wurde 2 Serien, 10 metrischen Gruppen, 97 Typen und 120 Varianten zugeordnet (Diagramm 6).

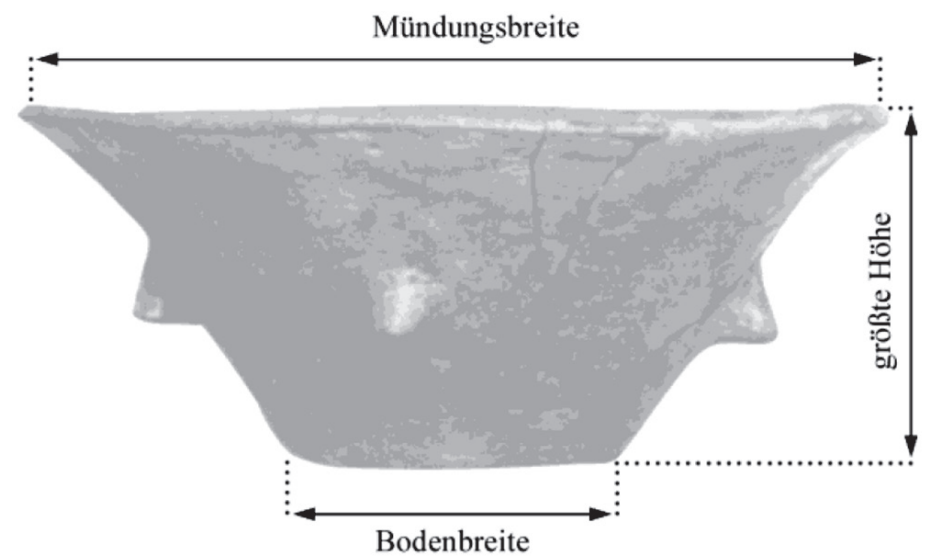

Abb. 4. Maßbezeichnungen einer Schüssel auf den verschiedenen Ebenen

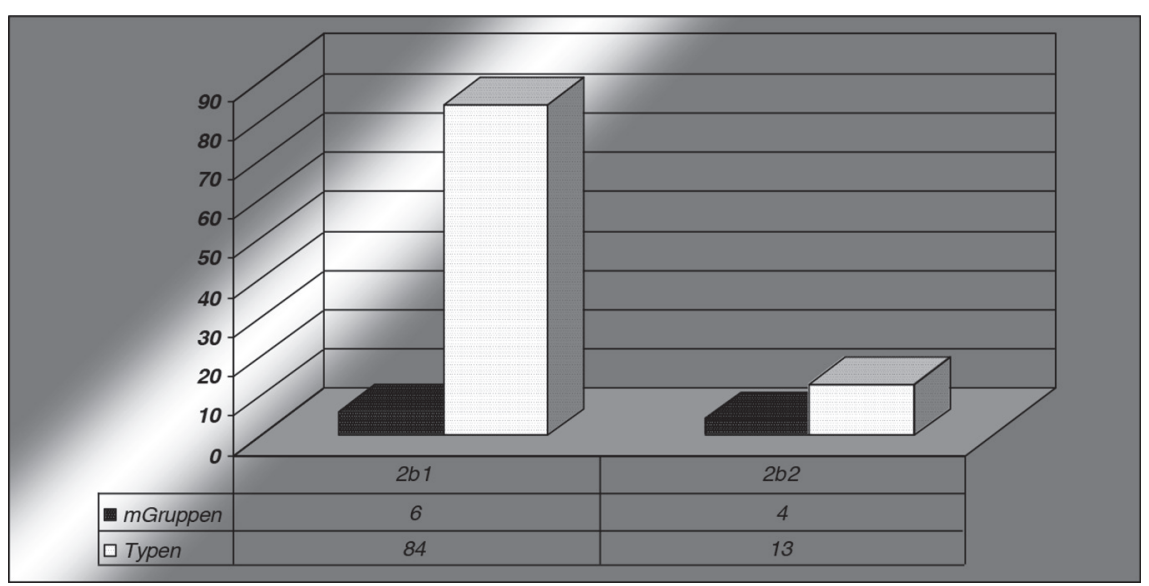

Diagramm 6. Verteilung der Keramiken der Gattung 2b der Schüsseln nach Serien, metrischen Gruppen und Varianten

Die Serie 2b1 repräsentiert die überwiegende Mehrheit, 91,39 \% $(n=244)$ der Schüsseltypen mit A1 Indexwerten. Sie treten in 6 metrischen Gruppen und 84 Typen auf. In die Serie 2 b2 wurden Schüsseln mit Index A2 gruppiert. Sie sind nur mit 8,61 \% $(n=23)$ innerhalb der Klasse der Breitgefäße vorhanden. Sie treten in 4 metrischen Gruppen und 13 Typen auf. 


\subsubsection{Gattung $2 c-$ Schalen}

Die Schalen wurden durch die den Schüsseln ähnlichen Indices klassifiziert. Die Maßbezeichnungen der Schalen zeigt Abbildung 5.

Die Gattung der Schalen vertritt beinahe die Hälfte, d. h. 46,05 \% ( $n=481)$, der untersuchten Funde. Sie wurden in 2 Serien, 12 metrische Gruppen, 192 Typen und 297 Varianten gruppiert (Diagramm 7).

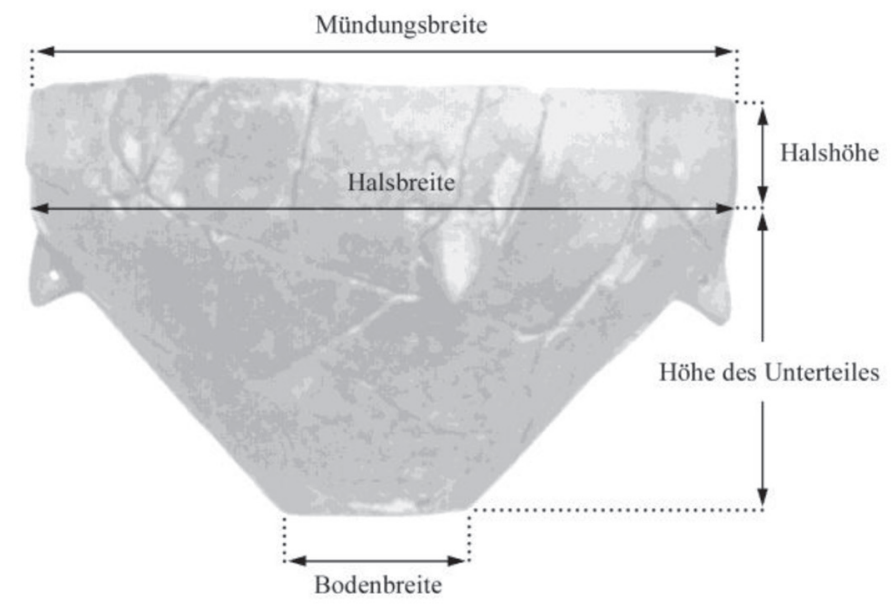

Abb. 5. Die Maßbezeichnungen der Schalen auf den verschiedenen Ebenen

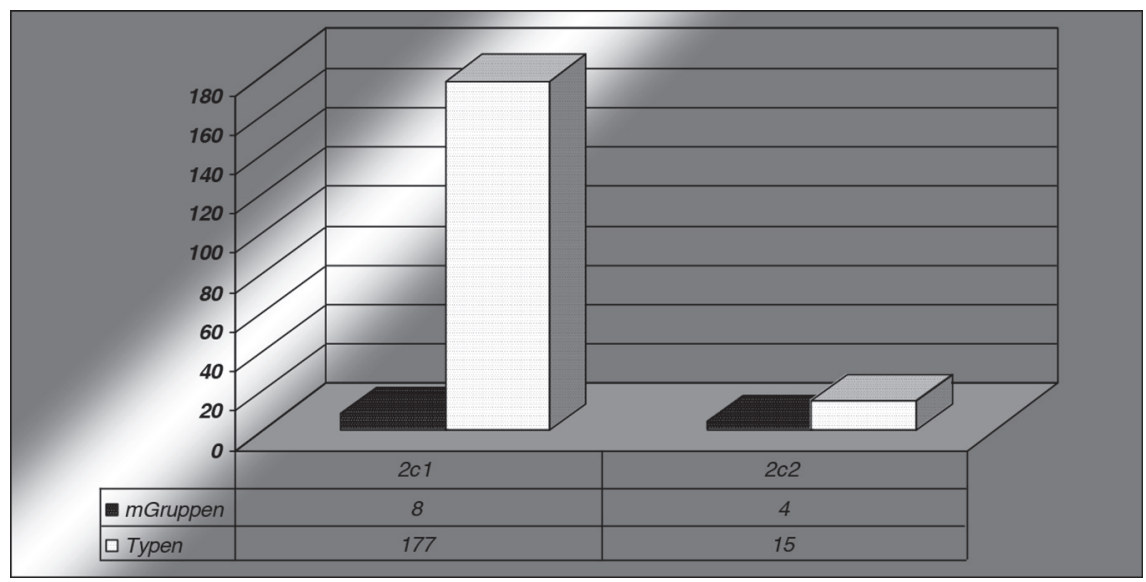

Diagramm 7. Verteilung der Serien, metrischen Gruppen und Typen innerhalb der Gattung 2c

Zur Serie 2c1 gehört die Mehrheit, 93,56 \% ( $\mathrm{n}=450)$, der Keramiken innerhalb der Gattung 2c. Die Exemplare dieser Schalen mit A2 Indices wurden in 8 metrische Gruppen und 177 Typen gruppiert. Die Serie 2c2 vertritt nur 6,44 \% $(n=31)$ der Schüsseln mit A3-4 Indexwerten innerhalb der Gattung. Sie bilden vier metrische Gruppen und 15 Typen.

\subsection{Klasse 3 - Sonderformen}

Hierher wurden 40 Grabgefäße zugeordnet, die Sonderformen zeigen und/oder nur selten auftreten. Die 40 Exemplare wurden 4 in Gattungen (Keramikgefäße, Gefäßdeckel, Tonlöffel sowie „konische Tonobjekte“), 7 Serien und 23 Typen zugeteilt (Diagramm 10). Diese Keramiken stammen aus 37 Gräbern von 11 Nekropolen 


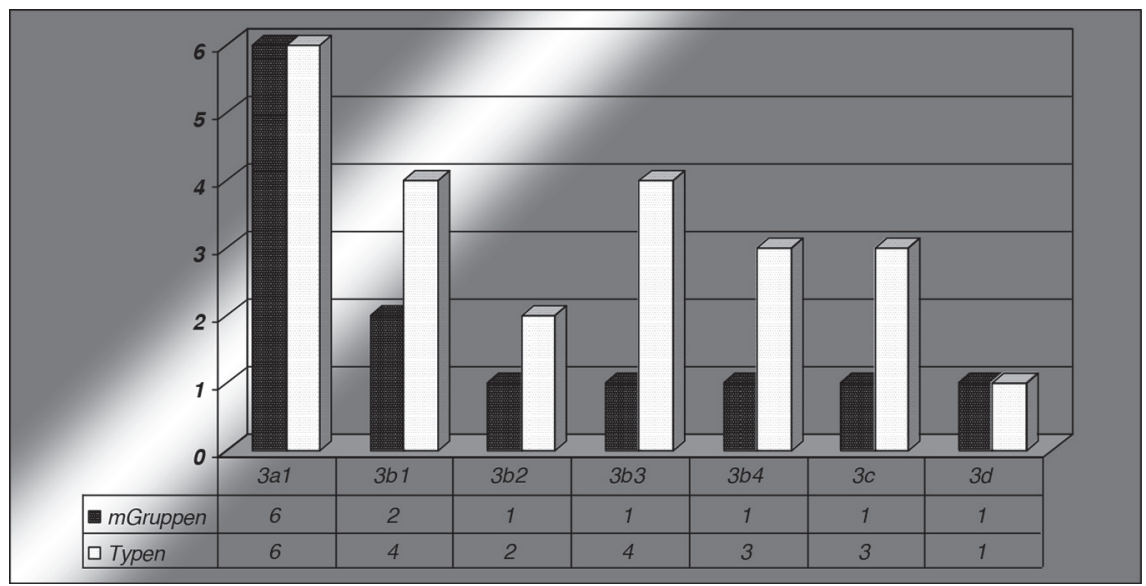

Diagramm 8. Verteilung der Keramiken der Klasse der Sonderformen nach Serien, metrischen Gruppen und Typen

(Tabelle 7). Die Verteilung der Keramiken der Klasse der Sonderformen zeigt Diagramm 8 nach den Serien, metrischen Gruppen und Typen.

Der Gattung 3a gehören Keramikgefäße von besonderer Gestalt zu. Sie erscheinen in einer einzigen Serie (3a1). Die Gattung 3b umfasst tönerne Gefäßdeckel. Sie treten in vier Serien auf (3b1 - konische Deckel, 3b2 zoomorphe, $3 b 3$ - prosopomorphe und 3b4 - zweigliedrige Gefäßdeckel). Der Gattung 3c ordneten wir die Serie $3 \mathrm{c} 1$ von Tonlöffeln und die Serie 3c2 von Tonlöffeln zu, während die „konischen Tonobjekte“ die Gattung 3d repräsentieren.

\section{ERGEBNISSE DER METRISCHEN ANALYSE}

Die chronologische Analyse dieser Keramiken nahmen wir in erster Linie mit Anwendung des Seriationsprogramms Winbasp (Bonner Seriation) vor. Die Basis dazu bildeten 818 Gefäßtypen, die 577 Gräber charakterisieren. Seriiert wurden 465 Typen aus 356 Gräbern. Auf diese Weise konnte die relativchronologische Lage von 330 Gräbern und 421 Typen eingesetzt werden. Die Seriation dient in diesem Fall als eine Krücke, damit man die Gefäßtypen und die Gräber mit ihnen sequenziert.

\subsection{Verteilung der Gräber und Typen nach künstlichen Perioden}

Mit Hilfe der oben angeführten Formanalyse wurden „künstliche Perioden“ nachgewiesen, also „künstliche Unterteilungen eines Formenkontinuus, ... die in erster Linie funktional zu deuten und eng mit Größe und Volumen verbunden sind. Daher erfolgt die Gliederung anhand der Analyse von Proportionen und nicht von Dimensionen. Aus diesem Grund werden keine absoluten Maße verwertet, sondern nur relative, die in Form von Indices angegeben werden“ - bestätigt B. Dammers. ${ }^{122}$

Als erster Schritt wurden die mittels der Seriation gegebenen künstlichen Perioden $(k P)$ auf Grund von 330 Bestattungen bestimmt. Es war möglich, insgesamt 12, maximal auf der Seriationstabelle basierende künstliche Perioden zu trennen.

322 der untersuchten 701 Typen können gleichzeitig nur in den jeweiligen Perioden nachgewiesen werden, d. h. sie treten in den Übergangsperioden nicht auf. 460 keramische Typen kommen in mehreren künstlichen Perioden vor: Sie können als „Übergangstypen“ behandelt werden. Die Hauptkoordinatenanalyse der Gräber gemäß den künstlichen Perioden zeigt Abbildung 6.

\footnotetext{
${ }^{122}$ Stehli-Zimmermann 1980, 151; Dammers 2005, 26-27.
} 


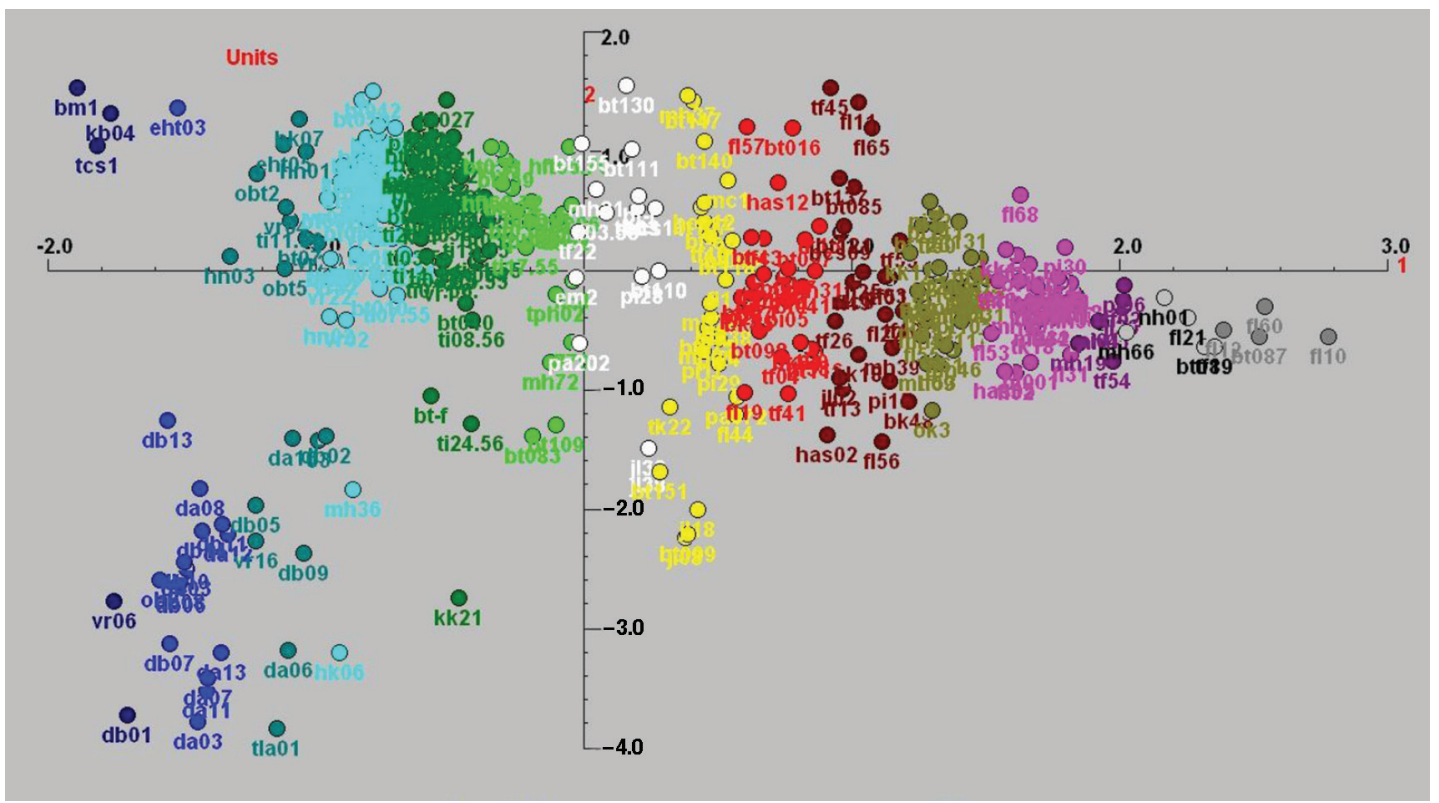

Abb. 6. Hauptkoordinatenanalyse der untersuchten kupferzeitlichen Befunde im östlichen Karpatenbecken gemäß 12 künstlichen Perioden

Die auf Grund der Untersuchung der künstlichen Perioden festgestellte relativchronologische Lage der Gräber konnten wir somit im Fall von 38 Fundorten herstellen (Tabelle 2).

kP 1: Diese Befunde treten nur in 2,88 \% $(n=8)$ der Gräber von acht Fundorten auf. In Bélmegyer, Deszk A, Deszk B, Endrőd-Hegedűs-tanya, Hódmezővásárhely-Kotacpart, Körösladány, Tiszaigar und Tápé-Lebő A ist je eine solche Bestattung belegt. 2,88 \% $(n=20)$ der Gefäßtypen ist für die künstliche Periode 1 typisch. Nur 40,0 \% $(\mathrm{n}=8)$ der Typen tritt innerhalb der diskutierten Zeitperiode während der kP 1 allein auf.

kP 2: Hierbei handelt es sich um 4,53 \% der Gräber $(n=14)$ der diskutierten Periode aus vier Nekropolen. $35,71 \%(\mathrm{n}=5)$ von ihnen stammt von Deszk A und die Hälfte, 50,00 \% $(\mathrm{n}=7)$, von Deszk B. Je ein solches Grab ist auch noch in Hódmezővásárhely-Népkert und Vel'ké Raškovce nachgewiesen. Bloß 5,33 \% ( $\mathrm{n}=37)$ der Gefäßtypen kann während dieser Periode festgestellt werden. 40,54 \% $(n=15)$ der Typen ist innerhalb der kP 2 nur für die diskutierte Periode typisch.

kP 3: 5,07 \% ( $\mathrm{n}=18)$ der Befunde, schon aus 12 Nekropolen, vertritt diese Zeitperiode. Die Mehrheit, also $16,67 \%(\mathrm{n}=3)$, stammt aus Vel'ké Raškovce und je $11,11 \%(\mathrm{n}=2-2)$ von Deszk A, Deszk B, Okány-Baromfitelep und Tibava. Endrőd, Hódmezővásárhely-Kotacpart, Hódmezővásárhely-Népkert, Oborín, Tiszabábolna-Szilpuszta und Tiszavalk-Tetes weisen je eine solche Bestattung auf. Bemerkenswert ist das Auftreten einer dieser Befunde in Tiszabábolna-Szilpuszta. Der Anteil der in dieser Periode nachgewiesenen keramischen Typen nimmt 7,35 \% ein. $37,25 \%(\mathrm{n}=19)$ der keramischen Typen mit kP 3 kann nur in der Zeit der diskutierten künstlichen Periode belegt werden. Im Kreis mit der erörterten $\mathrm{kP}$ beträgt ihr Anteil 37,25 \% (Diagramm 18, Abb. 7-9).

kP 4: Der Anteil der Gräber dieser Periode beträgt nun 20,56\% $(n=73)$. Sie sind in 14 Gräberfeldern nachgewiesen. Etwa die Hälfte, 46,58 \% ( $n=34)$, von ihnen stammt von Basatanya, 17,81 \% $(n=13)$ von Tibava und 15,07 \% $(\mathrm{n}=11)$ von Vel'ké Raškovce. Je 2,74 \% $(\mathrm{n}=2-2)$ dieser Befunde konnten wir in MagyarhomorogKónyadomb, Tiszabábolna, Hódmezővásárhely-Népkert und Deszk B bestimmen. Die Gräberansammlungen von Hódmezővásárhely-Laktanya, Köröstarcsa-Kossuth tér, Kisvárda, Tiszavalk-Tetes, Tápé-Lebő A, Panyola, Ószentiván VIII treten hierbei mit je einem Grab auf. Die Gefäßtypen erscheinen in der größten Proportion zu dieser Zeit; es handelt sich dabei um 31,84\%. Der Anteil der nur während dieser künstlichen Periode nachgewiesenen Typen nimmt schon 48,42\% $(\mathrm{n}=107)$ innerhalb der $\mathrm{kP} 4$ ein.

kP 5: $12,96 \%(n=46)$ der Bestattungen dieser Periode ist in 12 Nekropolen verteilt. In erster Linie zeichnen sich hier Polgár-Basatanya mit 36,96 \% $(\mathrm{n}=17)$ und Tibava mit 17,39\% $(\mathrm{n}=8)$ aus. In Vel'ké Raškovce er- 
scheint die diskutierte Periode nur mehr mit 10,87\% $(\mathrm{n}=5)$ der Befunde. Panyola und Tiszavalk-Tetes treten hier mit je 6,52 \% (n=3-3) der Befunde auf und je 4,35\% $(n=2-2)$ von solchen sind in Magyarhomorog-Kónyadomb, Polgár-Hajdúnánási út und Tiszakeszi bekannt. Je ein solches Grab kommt noch in Hajdúböszörmény-Ficsori-tódűlő, Hódmezővásárhely-Szakálhát, Polgár-Nagy-Kasziba und Mónosbél vor. 13,83 \% (n=96) aller Gefäßtypen tritt während der diskutierten Periode auf. Die hier belegten Gefäßtypen treten mit 53,13 \% ( $n=51)$ innerhalb der Typenansammlung der diskutierten künstlichen Periode auf.

kP 6: Hierher konnte 11,27 \% $(n=40)$ der seriierten Gräber eingeordnet werden. 32,50 \% $(n=13)$ der 19 Bestattungen der Periode kann in Basatanya festgestellt werden. Der Anteil solcher Bestattungen nimmt 22,50\% $(\mathrm{n}=9)$ in Tiszavalk-Tetes, $12,50 \%(\mathrm{n}=5)$ in Fényeslitke und 7,50\% $(\mathrm{n}=3)$ in Magyarhomorog-Kónyadomb ein. Je 5,0 \% ( $(\mathrm{n}=2-2)$ der Gräber ist in Tibava und Tiszavalk-Kenderföldek belegt, während wir je einen Befund in Deszk A, Emőd, Hajdúböszörmény-Ficsori-tó-dülő, Panyola, Kunszentmárton-Pusztaistvánháza und TiszabábolnaSzilpuszta registrieren konnten. 11,10 \% $(\mathrm{n}=77)$ der keramischen Typen kommt in dieser Zeit vor. Der Anteil der nur in dieser Zeit nachgewiesenen Typen beträgt 29,87\% $(\mathrm{n}=23)$.

kP 7: Etwa 9,58 \% $(\mathrm{n}=34)$ der Bestattungen von 14 Gräberfeldern vertreten diese Zeitperiode. Basatanya erhebt sich mit 32,35\% ( $\mathrm{n}=11)$ der Befunde und 14,71 \% $(\mathrm{n}=5)$ von ihnen stammt aus Tiszavalk-Tetes. In Tiszavalk-Kenderföldek ist der Anteil 2,94 \% ( $\mathrm{n}=3)$, in Fényeslitke, Jászladány, Polgár-Bacsókert und KunszentmártonPusztaistvánháza je 5,88\% (n=2-2). Je eine Bestattung kam in Kiskőrös, Magyarhomorog-Kónyadomb, Mezőkeresztes-Csincse-tanya, Mezőkövesd-Patakra járó-dűlő, Sárazsadány, Tiszakeszi und Vásárosnamény zum Vorschein. $7,78 \%(n=54)$ aller Gefäßtypen charakterisiert diese künstliche Periode. 42,59\% $(n=23)$ der Gefäßtypen der kP 7 ist nur hier vorhanden.

kP 8: 11,27\% $(\mathrm{n}=40)$ der Befunde von 12 Nekropolen stellt diese Periode dar. Polgár-Basatanya überwiegt mit 27,50 \% ( $\mathrm{n}=11)$. Der Anteil solcher Gräber nimmt in Kunszentmárton-Pusztaistvánháza 15,0 \% ( $\mathrm{n}=6)$, Magyarhomorog-Kónyadomb 12,50 \% (n=5), Fényeslitke, Tiszavalk-Kenderföldek und Tiszavalk-Tetes je 7,50 \% $(n=3-3)$ ein. Die Gräberansammlungen von Bodrogkeresztúr, Hajdúszoboszló und Tiszakeszi treten mit je 5,0 \% $(\mathrm{n}=2-2)$ solcher Befunde auf. Kiskőrös, Mezőkeresztes-Csincse-tanya und Mezőkövesd-Patakra járó-dűlő weisen je eine solche Bestattung auf. 8,65 \% $(n=60)$ der Typen kann in dieser Periode nachgewiesen werden. Der Anteil der nur für diese Periode typischen Varianten nimmt ab. Im Kreis der Typen dieser Periode erscheinen sie mit $50,0 \%(\mathrm{n}=30)$.

kP 9: Diese Periode wird durch 10,42 \% $(\mathrm{n}=37)$ der Gräber von 10 Fundorten vertreten. 37,84 \% ( $\mathrm{n}=14)$ von ihnen stammt von Tiszavalk-Kenderföldek, $19,0 \%(\mathrm{n}=7)$ von Magyarhomorog-Kónyadomb, 16,22 \% ( $\mathrm{n}=6)$ von Fényeslitke und 10,81\% ( $\mathrm{n}=4)$ aus Polgár-Basatanya. In Hajdúszoboszló, Kiskőrös, Mezőkövesd-Patakra járó-dűlő, Öcsöd-Kendereshalom, Polgár-Bacsókert und Kunszentmárton-Pusztaistvánháza fand man je eine solche Bestattung. 6,34 \% $(n=44)$ der Gefäßtypen kann in dieser Zeit nachgewiesen werden. Während dieser Zeit nimmt die Zahl der nur hier vorhandenen Typen weiter ab. Ihr Anteil beträgt 70,45 \% $(\mathrm{n}=31)$.

kP 10: Hierbei handelt es sich um 7,89\% $(\mathrm{n}=28)$ der Befunde von 8 Nekropolen. Das Gräberfeld von Fényeslitke zeichnet sich jetzt mit einem Anteil von 21,43\% ( $n=6)$, Magyarhomorog-Kónyadomb mit 21,43\% $(\mathrm{n}=6)$, Polgár-Basatanya und Tiszavalk-Kenderföldek mit je 17,86 \% $(\mathrm{n}=5-5)$ der Bestattungen aus. Solche Gräber erscheinen in Jászladány und Kunszentmárton-Pusztaistvánháza mit je 7,14\% $(\mathrm{n}=2-2)$ und je eine von ihnen stammt noch aus Hajdúszoboszló und Tiszakeszi-Fáy-kert. 3,03\% $(\mathrm{n}=21)$ der keramischen Typen ist in dieser Zeit zu registrieren. Die in dieser Zeit allein vorhandenen keramischen Typen sind nur durch $66,67 \%(n=14)$ vertreten.

kP 11: Die Gräberanzahl nimmt während dieser Periode ab. Es handelt sich nun um 2,25 \% $(n=8)$ der Bestattungen von 6 Nekropolen. Je 25,0 \% $(\mathrm{n}=2-2)$ stammt aus Tiszavalk-Kenderföldek und Polgár-Basatanya. Je ein solches Grab ist noch von Nagykörü-Hidashát, Hajdúszoboszló, Fényeslitke und Bodrogkeresztúr nachgewiesen. Die Anzahl der während dieser Periode belegten Gefäßtypen ist 6. Drei Typen sind nur für diese Zeitperiode typisch.

kP 12: Bei der finalen Periode handelt es sich um 2,54\% $(n=9)$ der seriierten Bestattungsobjekte von 3 Fundorten. Der Anteil solcher Befunde nimmt in Fényeslitke 55,56 \% $(n=5)$ und in Tiszavalk-Kenderföldek 33,33\% $(n=3)$ ein. Eine der Bestattungen konnte auch in Magyarhomorog-Kónyadomb registriert werden. 1,01 \% $(n=7)$ der Typen erscheint in dieser Periode. 7 Gefäßtypen können nur in der finalen künstlichen Periode belegt werden. 
Tabelle 2. Entwicklungsschema der kupferzeitlichen Gräberfelder gemäß künstlichen Perioden (mit Anzahl der Bestattungen)

\begin{tabular}{|c|c|c|c|c|c|c|c|c|c|c|c|c|}
\hline \multirow{2}{*}{ Gräberfelder } & \multicolumn{12}{|c|}{ Künstliche Perioden } \\
\hline & kP 1 & kP 2 & kP 3 & kP4 & kP 5 & kP 6 & kP 7 & kP 8 & kP9 & kP 10 & kP 11 & kP 12 \\
\hline Bélmegyer & 1 & & & & & & & & & & & \\
\hline Körösladány & 1 & & & & & & & & & & & \\
\hline Tiszaigar & 1 & & & & & & & & & & & \\
\hline Endrőd & 1 & & 1 & & & & & & & & & \\
\hline Hódmezővásárhely-Kotacpart & 1 & & 1 & & & & & & & & & \\
\hline Tápé-Lebő A & 1 & & & 1 & & & & & & & & \\
\hline Deszk B & 1 & 7 & 2 & 2 & & & & & & & & \\
\hline Deszk A & 1 & 5 & 2 & & & 1 & & & & & & \\
\hline Hódmezővásárhely-Népkert & & 1 & 1 & 2 & & & & & & & & \\
\hline Vel'ké Raškovce & & 1 & 3 & 11 & 5 & & & & & & & \\
\hline Oborín & & & 1 & & & & & & & & & \\
\hline Okány & & & 2 & & & & & & & & & \\
\hline Tiszabábolna & & & 1 & 2 & & 1 & & & & & & \\
\hline Tibava & & & 2 & 13 & 8 & 2 & & & & & & \\
\hline Tiszavalk-Tetes & & & 1 & 1 & 3 & 9 & 5 & 3 & & & & \\
\hline Polgár-Basatanya & & & 1 & 34 & 17 & 13 & 11 & 11 & 4 & 5 & 2 & \\
\hline Ószentiván VIII & & & & 1 & & & & & & & & \\
\hline Hódmezővásárhely-Laktanya & & & & 1 & & & & & & & & \\
\hline Köröstarcsa & & & & 1 & & & & & & & & \\
\hline Kisvárda & & & & 1 & & & & & & & & \\
\hline Panyola & & & & 1 & 3 & 1 & & & & & & \\
\hline Magyarhomorog-Kónyadomb & & & & 2 & 2 & 3 & 1 & 5 & 7 & 6 & & 1 \\
\hline Hódmezővásárhely-Szakálhát & & & & & 1 & & & & & & & \\
\hline Polgár-Nagy-Kasziba & & & & & 1 & & & & & & & \\
\hline Polgár-Hajdúnánás & & & & & 2 & & & & & & & \\
\hline Mónosbél & & & & & 1 & & & & & & & \\
\hline Hajdúböszörmény & & & & & 1 & 1 & & & & & & \\
\hline Tiszakeszi & & & & & 2 & & 1 & 2 & & 1 & & \\
\hline Emöd & & & & & & 1 & & & & & & \\
\hline Pusztaistvánháza & & & & & & 1 & 2 & 6 & 1 & 2 & & \\
\hline Tiszavalk-Kenderföldek & & & & & & 2 & 3 & 3 & 14 & 5 & 2 & 3 \\
\hline Fényeslitke & & & & & & 5 & 2 & 3 & 6 & 6 & 1 & 5 \\
\hline Vásárosnamény & & & & & & & 1 & & & & & \\
\hline Sárazsadány & & & & & & & 1 & & & & & \\
\hline Mezőkeresztes-Csincse & & & & & & & 1 & 1 & & & & \\
\hline Polgár-Bacsókert & & & & & & & 2 & & 1 & & & \\
\hline Mezőkövesd-Patakra járó-dülő & & & & & & & 1 & 1 & 1 & & & \\
\hline Kiskőrös & & & & & & & 1 & 1 & 1 & & & \\
\hline Jászladány & & & & & & & 2 & & & 2 & & \\
\hline Hajdúszoboszló & & & & & & & & 2 & 1 & 1 & 1 & \\
\hline Bodrogkeresztúr & & & & & & & & 2 & & & 1 & \\
\hline Öcsöd & & & & & & & & & 1 & & & \\
\hline Nagykörü & & & & & & & & & & & 1 & \\
\hline
\end{tabular}




\subsection{Verteilung der „,ikonischen Gefäßformen“ nach künstlichen Perioden}

Die von den früheren Autoren als Grundformen diskutierten „,breiten und tiefen Schüsseln mit zwei großen seitlichen Bandhenkeln“, die „Vierfußgefäße“, die „,breiten Schüsseln mit zwei Henkeln“, „Milchtöpfe“ und die „,blumentopfförmigen Gefäße“ treten in unserer Analyse in mehrere Typen gruppiert auf. Aus chronologischer Sicht ist auch die Ritzverzierung neben anderen Verzierungsarten von hervorragender Bedeutung. Das Vorkommen dieser „Grundformen“ gemäß künstlichen Perioden kann folgenderweise skizziert werden.

Diese Erscheinungen konnten wir im Fall von 23 Gefäßtypen mit Ritzverzierung und 132 Typen der ,keramischen Grundformen“ erörtern. Man kann feststellen, dass die ritzverzierte Dekoration in der künstlichen Periode 2 zuerst auf dem Fußgefäß da7.6 von Deszk A erscheint. Dasselbe kann in der Periode 4 auf dem Becher bt69.1 von Polgár-Basatanya beobachtet werden. Diese Verzierungsart scheint ab der künstlichen Periode 6 allgemein verbreitet zu sein. Auf den Keramiken der künstlichen Periode 12 kann sie dagegen nicht registriert werden.

Bei den „tiefen und breiten Schüsseln mit zwei großen Bandhenkeln“ handelt es sich um Schalentypen. I. Bognár-Kutzián nannte diese Keramiken „depas amphikypellon“. ${ }^{123}$ Dieser „Typ“, obwohl er in der ganzen Zeit eine Eigenschaft der Bodrogkeresztúr-Kultur aufweist, lebt auch in der Hunyadihalom-Kultur weiter - stellt P. Patay fest. ${ }^{124}$ Diese Keramiken treten zuerst während der „Mischperiode 4-6“ in der Keramik mh31.5 von Magyarhomorog-Kónyadomb auf und leben bis in die Periode 8 weiter, wie darauf die Gefäße $m h 72.1$ von MagyarhomorogKónyadomb, pi15.1 und pi5.7 von Kunszentmárton-Pusztaistvánháza, tvt5.1, tvt13.5 und tvt15.4 von Tiszavalk-Tetes, pa72.2 von Panyola und $t k 1.2$ von Tiszakeszi hinweisen. P. Patay setzt voraus, dass diese Schalen mit großen Henkeln die jüngere Stufe der BK vertreten dürften. „Es ist möglich, aus all diesen zu schließen, dass die südliche Welle (Volk?), durch welche die großhenkeligen Schalen im Karpatenbecken erschienen sind, am Anfang der Hochkupferzeit ankam. Das hat die Herausbildung der Bodrogkeresztúr-Kultur gerade vielleicht verursacht. " ${ }^{125}$

P. Patay bestätigt, dass Vierfußgefäße in der Bestattungszeremonie nur am Ende der BodrogkeresztúrKultur benutzt waren. ${ }^{126}$ Diese Keramiken wurden in unserer Analyse in drei Typen der Gattung 1d von den Schultergefäßen klassifiziert. Sie können zuerst in der „Mischperiode“ 5-6 registriert werden und das jüngste Stück stammt aus der Periode 9. Es handelt sich dabei um die Artefakte $f l 34.2$ und $f l 44.2$ von Fényeslitke, bk45.3 von Bodrogkeresztúr, $t k 22.1$, $t k 9.2$ und $t k 21.2$ von Tiszakeszi, $t f 57.1$ und $t f 28.2$ von Tiszavalk-Kenderföldek sowie pi30.1 von Kunszentmárton-Pusztaistvánháza.

Das allgemeine Auftreten der ,breiten konischen Schüsseln mit zwei Henkeln am Rand“ kann ab der Zeit der künstlichen Periode 4 belegt werden. Sie kommen in 33 Typen vor und die Letzte stammt aus der „Mischperiode“ 10-11.

Dasselbe sehen wir auch im Fall von 63 Typen der „Milchtöpfe” und 24 Typen der ,blumentopfförmigen Gefäße“. Je eine Variante ist in den künstlichen Perioden 2-5 und 3 nachgewiesen. Ihre allgemeine Verbreitung kann dagegen von der künstlichen Periode 4 an datiert werden. Sie wurden dann bis zum Ende der Benutzung der untersuchten kupferzeitlichen Gräberfelder ins Grab gelegt. Die Formänderungen der „Milchtöpfe“ der Tiszapolgár- und der Bodrogkeresztúr-Kultur skizzierte P. Patay. ${ }^{127}$

Auf der Grundlage der Obigen kommt man zu dem Schluss, dass die aufgezählten Erscheinungen mit einem Zeitraum verbunden sind, dessen Anfang auf die künstliche Periode 4 datiert werden kann. Diese Erscheinungen und Gefäßtypen sind während der Zeit der künstlichen Perioden 1 bis 3 nicht vorhanden oder sind wenigstens nicht typisch.

\subsection{Verteilung der Gräber nach Belegungsphasen}

Auf die Ergebnisse der Hauptkoordinatenanalyse basiert betrachten wir die Zusammenhänge zwischen Gräbern und keramischen Typen - als den zweiten Schritt - auf Grund von vier Belegungsphasen, den Kreis der möglichen Kontexte weiter beschränkend und die Anzahl der Befunde steigernd. In diese Analyse zogen wir auch die Befunde ein, die durch die Seriation nicht zugeteilt werden konnten, ihre relativchronologische Lage konnten

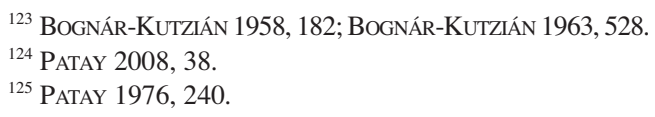

${ }^{126}$ Patay 2008, 37.
${ }^{127}$ Patay 2008, 34-35.

Acta Archaeologica Academiae Scientiarum Hungaricae 67, 2016 


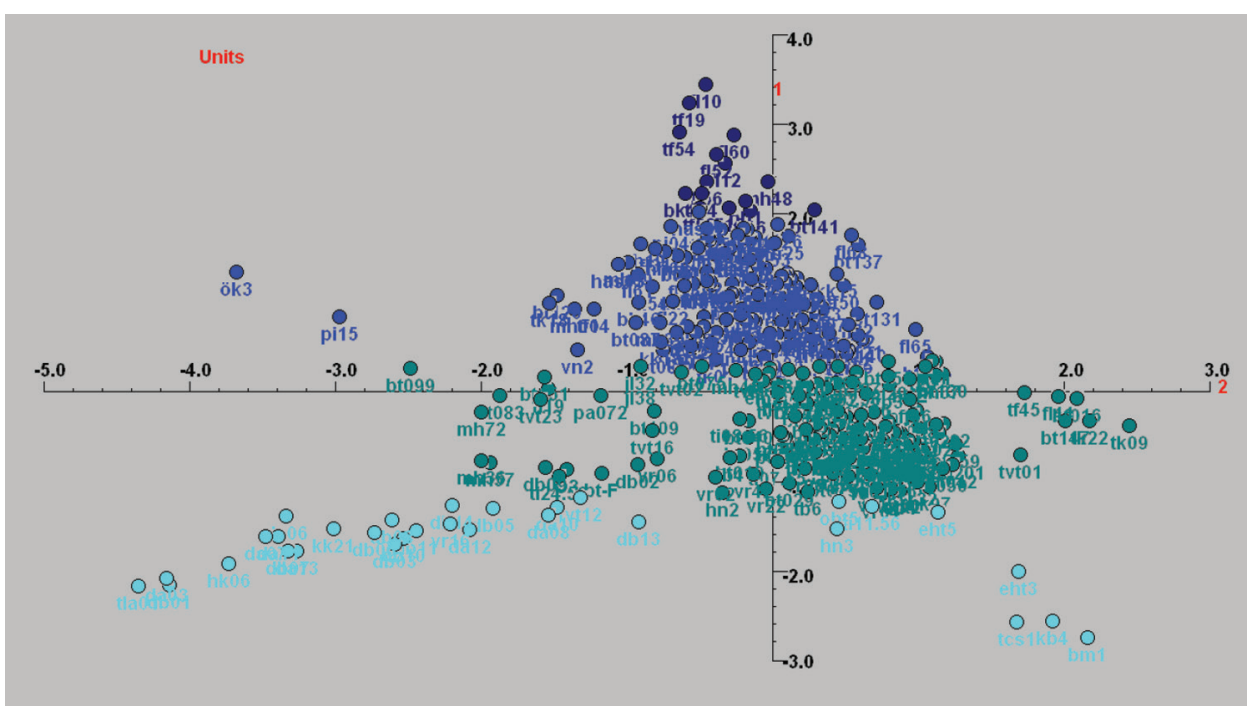

Abb. 7. Hauptkoordinatenanalyse der untersuchten kupferzeitlichen Befunde im westlichen Karpatenbecken nach Belegungsphasen

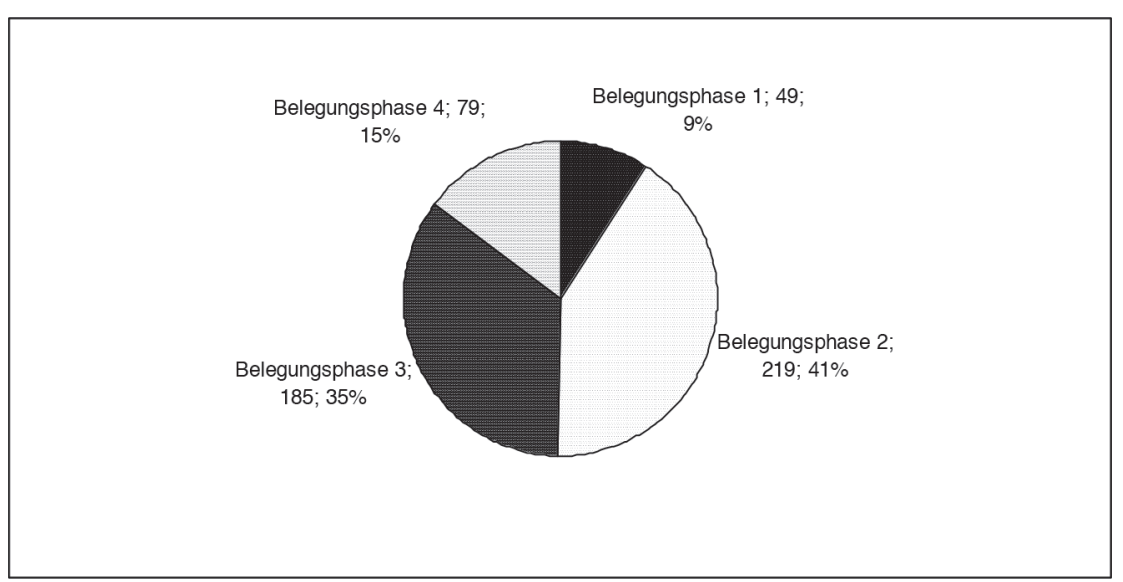

Diagramm 9. Verteilung und Vorkommen der Gräber in den einzelnen Belegungsphasen

wir aber durch Typenergänzungen und mittels archäologischer vergleichender Methode bestimmen. Auf die Ergebnisse der Hauptkoordinatenanalyse basiert können die Befunde vier Belegungsphasen zugeordnet werden. Die Verteilung der Gräber gemäß Belegungsphasen stellen Abbildung 7 und Diagramm 9 dar.

Belegungsphase 1:9,19\% $(n=49)$ der Bestattungen von 18 Fundorten kann hier zugeteilt werden. Es handelt sich dabei um die Befunde der künstlichen Perioden 1, 2 und 3. Die Gräberfelder von Deszk B und Deszk A zeichnen sich mit 26,43\% $(n=9)$ bzw. 18,37 \% $(n=9)$ der Gräber aus. Der Anteil solcher Bestattungen nimmt $10,20 \%(n=5)$ in Vel'ké Raškovce ein. Aus den Nekropolen von Polgár-Basatanya, Endrőd-Hegedűs-tanya, Hódmezővásárhely-Kotacpart, Hódmezővásárhely-Népkert, Okány-Baromfitelep, Tibava und Tápé-Lebő A kennen wir je 2 Befunde der diskutierten Zeitspanne. Die Gräberansammlungen von Oborín, Bélmegyer, KörösladányBikeri, Tiszaigar, Tiszabábolna-Szilpuszta, Tiszakeszi-Fáy-kert, Vésztő-Bikeri und Tiszavalk-Tetes weisen je einen solchen Befund auf (Diagramm 10, Tabelle 3).

In den Tabellen sind die durch Typenersetzen und die vergleichende archäologische Methode datierten Befunde mit $\bullet$ markiert. 


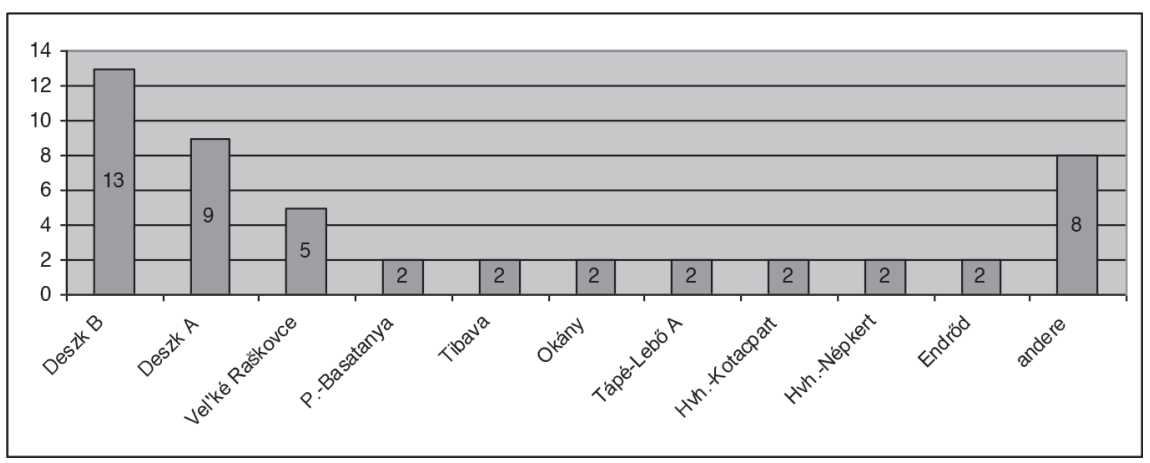

Diagramm 10. Vorkommen der Befunde der Belegungsphase 1 nach Nekropolen

(andere $=$ Gräberfelder von Oborín, Bélmegyer, Körösladány-Bikeri, Tiszacsege, Tiszabábolna-Szilpuszta, Tiszakeszi und Vésztő-Bikeri mit je einer Bestattung)

Tabelle 3. Gräber der Belegungsphase 1

\begin{tabular}{|c|c|c|}
\hline Fundorte & Grabnummer & Gräberanzahl \\
\hline Bélmegyer & bm1 & 1 \\
\hline Deszk A & da3, da6, da7, da11, da12, da13, da8, da10, •da9 & $9(26,53 \%)$ \\
\hline Deszk B & $\begin{array}{l}\text { db1, db3, db6, db7, db8, db10, db11, db13, db5, db14, •db12, •db15, } \\
\bullet \mathrm{db} 4\end{array}$ & $13(26,53 \%)$ \\
\hline Vel'ké Raškovce & vr16, vr4, vr5, vr22, •vr41 & $5(10,20 \%)$ \\
\hline Polgár-Basatanya & $\bullet$ bt49, •bt84 & $2(4,08 \%)$ \\
\hline Okány-Baromfitelep & obt 2 , obt5 & $2(4,08 \%)$ \\
\hline Endrőd-Hegedüs-tanya & eht3, eht5 & $2(4,08 \%)$ \\
\hline Hódmezővásárhely-Kotacpart & hk6, hk7 & $2(4,08 \%)$ \\
\hline Hódmezővásárhely-Népkert & hn3, hn2 & $2(4,08 \%)$ \\
\hline Tibava & ti11.56, ti15.56 & $2(4,08 \%)$ \\
\hline Tápé-Lebő A & tla1, •tla12 & $2(4,08 \%)$ \\
\hline Tiszaigar-Csikóstanya & tcs 1 & 1 \\
\hline Oborín & ob1 & 1 \\
\hline Körösladány-Bikeri & kb4 & 1 \\
\hline Vésztö-Bikeri & $\mathrm{vb} 2$ & 1 \\
\hline Tiszavalk-Tetes & tvt12 & 1 \\
\hline Tiszabábolna-Szilpuszta & tb6 & 1 \\
\hline Tiszakeszi-Fáy-kert & tk10 & 1 \\
\hline
\end{tabular}

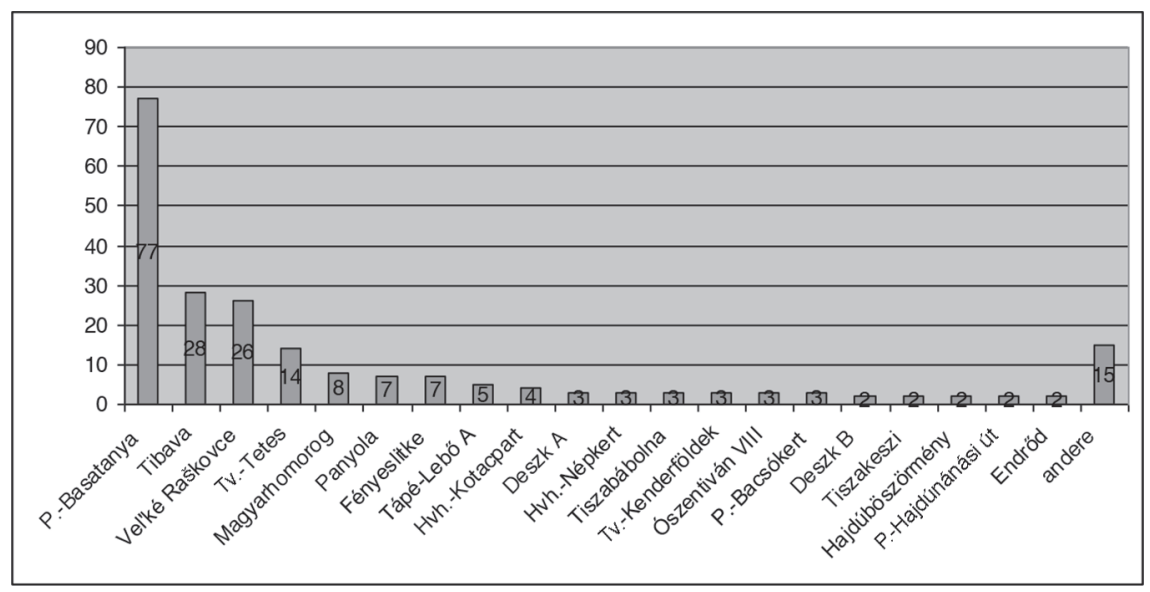

Diagramm 11. Vorkommen der Befunde der Belegungsphase 2 nach Nekropolen

(andere $=$ Gräberfelder von Emőd, Hajdúszoboszló, Hódmezővásárhely-Szakálhát, Hódmezővásárhely-Laktanya, Körösladány-Bikeri, Kiskőrös, Köröstarcsa, Kisvárda, Mónosbél, Oborín, Polgár-Nagy-Kasziba, Újvár, Vésztő-Bikeri und Vásárosnamény mit je einer Bestattung) 
Belegungsphase 2: Diese Zeitperiode vertritt fast die Hälfte, also etwa 41,09 \% $(n=219)$, der Befunde von 36 Fundorten. Es handelt sich dabei um die Bestattungen der künstlichen Perioden 4, 5 und 6. Die überwiegende Mehrheit dieser Gräber, 35,94 \% ( $\mathrm{n}=78)$, stammt aus Polgár-Basatanya. Sie treten in Tibava und Vel'ké Raškovce mit je einem Prozentsatz von 11,98 \% $(n=26-26)$ auf. Der Anteil solcher Befunde nimmt in Magyarhomorog-Kónyadomb 3,65\% $(n=8)$ ein. In Tiszavalk-Tetes ist es durch 6,45\% $(n=14)$, in Panyola und Fényeslitke durch je $3,23 \%(\mathrm{n}=7-7)$ dieser Gräber vertreten. In Hódmezővásárhely-Kotacpart ist 1,87 \% $(\mathrm{n}=4)$ solcher Gräber vorhanden. In Polgár-Bacsókert, Deszk A, Hódmezővásárhely-Népkert, Ószentiván VIII, Tiszabábolna-Szilpuszta und Tiszavalk-Kenderföldek beträgt der Anteil der Befunde der diskutierten Belegungsphase je 1,38 \% $(n=3-3)$. Je $0,92 \%(n=2-2)$ solcher Gräber ist in Endrőd-Hegedűs-tanya, Hódmezővásárhely-Szakálhát, Kiskőrös, Köröstarcsa,

Tabelle 4. Gräber der Belegungsphase 2

\begin{tabular}{|c|c|c|}
\hline Fundorte & Grabnummer & Gräberanzahl \\
\hline Deszk A & da2, $\bullet$ da $4, \bullet$ da33 & $3(1,37 \%)$ \\
\hline Deszk B & $\mathrm{db} 2, \mathrm{db} 9$ & $2(0,91 \%)$ \\
\hline Vel’ké Raškovce & 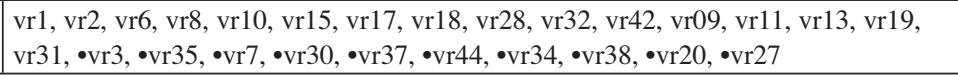 & $26(11,87 \%)$ \\
\hline Polgár-Basatanya & 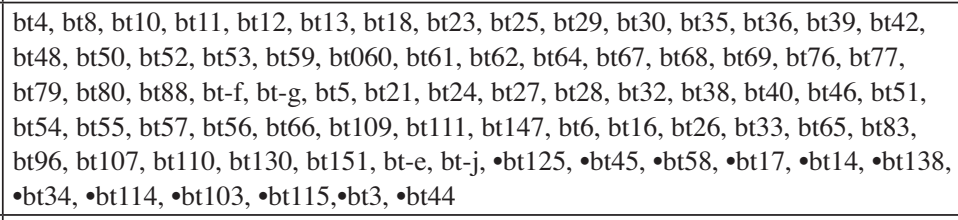 & $77(35,16 \%)$ \\
\hline Polgár-Nagy-Kasziba & pnk39 & 1 \\
\hline Polgár-Bacsókert & $\bullet$ bcs $1, \bullet b c s 13, \bullet b c s 8$ & $3(1,37 \%)$ \\
\hline Polgár-Hajdúnánási út & $\operatorname{tph} 2, \operatorname{tph} 4$ & $2(0,91 \%)$ \\
\hline Endrőd-Hegedűs-tanya & $\bullet$ eht6, •eht2 & $2(0,91 \%)$ \\
\hline Hódmezővásárhely-Kotacpart & $\bullet$ hk12, •hk17, •hk9, •hk4 & $4(1,83 \%)$ \\
\hline Hódmezővásárhely-Népkert & hn1, hn4, •hn5 & $3(1,37 \%)$ \\
\hline Hódmezővásárhely-Szakálhát & hsz1 & 1 \\
\hline Hódmezővásárhely-Laktanya & hv190 & 1 \\
\hline Tibava & $\begin{array}{l}\text { ti3.55, ti06.56, ti7.55, ti8.55, ti10.55, ti14.55, ti14.56, ti22.56, ti24.56, ti10.56, } \\
\text { ti15.55, ti19.56, ti21.56, ti1.55, ti1.56, ti4.55, ti4.56, ti8.56, ti11.55, ti16.56, ti18.55, } \\
\text { ti3.56, ti17.55, •ti20a.56, •ti6.55, •ti9.56, •ti18.56, •ti5.56 }\end{array}$ & $28(12,79 \%)$ \\
\hline Tápé-Lebő A & tla15, •tla10, •tla11, •tla4, •tla14 & $5(2,28 \%)$ \\
\hline Ószentiván VIII & ó3, •ó1, •ó2 & $3(1,37 \%)$ \\
\hline Oborín & $\bullet$ ob2 & 1 \\
\hline Körösladány-Bikeri & $\bullet \mathrm{kb} 3$ & 1 \\
\hline Vásárosnamény & $\bullet$ vn1 & 1 \\
\hline Vésztő-Bikeri & $\bullet \mathrm{vb} 1$ & 1 \\
\hline Panyola & pa201, pa202, pa203, pa204, pa72, •pa200, •pa205 & $7(3,20 \%)$ \\
\hline Tiszavalk-Tetes & tvt1, tvt2, tvt7, tvt9, tvt10, tvt11, tvt13, tvt17, tvt21, tvt23, tvt8, tvt16, tvt25, •tvt5 & $14(6,39 \%)$ \\
\hline Tiszavalk-Kenderföldek & $\mathrm{tf} 22, \mathrm{tf} 45, \bullet \mathrm{tf} 57$ & $3(1,37 \%)$ \\
\hline Tiszabábolna-Szilpuszta & tb1, tb4, tb3 & $3(1,37 \%)$ \\
\hline Tiszakeszi-Fáy-kert & tk9, tk22 & $2(0,91 \%)$ \\
\hline Hajdúböszörmény-Ficsori-tó-dülő & hft68, hft66 & $2(0,91 \%)$ \\
\hline Magyarhomorog-Kónyadomb & $\mathrm{mh} 36, \mathrm{mh} 57, \mathrm{mh} 21, \mathrm{mh} 72, \mathrm{mh} 28, \mathrm{mh} 37, \mathrm{mh} 46, \cdot \mathrm{mh} 54$ & $8(3,65 \%)$ \\
\hline Fényeslitke & $\mathrm{fl} 19, \mathrm{fl} 34, \mathrm{fl} 44, \mathrm{fl} 57, \mathrm{fl} 70, \bullet \mathrm{fl} 23, \bullet \mathrm{fl} 36$ & $7(3,20 \%)$ \\
\hline Mónosbél & mb1 & 1 \\
\hline Emőd & em2 & 1 \\
\hline Kunszentmárton-Pusztaistvánháza & pi29 & 1 \\
\hline Köröstarcsa-Kossuth tér & ktk1 & 1 \\
\hline Kisvárda & kv1 & 1 \\
\hline Kiskőrös & $\bullet \mathrm{kk} 16$ & 1 \\
\hline Újvár & •uv2 & 1 \\
\hline Hajdúszoboszló & •has1 & 1 \\
\hline
\end{tabular}


Kisvárda, Magyarhomorog-Kónyadomb, Oborín, Vésztő-Bikeri und Polgár-Nagy-Kasziba bekannt. Je eine Bestattung kam noch in Emőd, Hajdúszoboszló, Hódmezővásárhely-Szakálhát, Hódmezővásárhely-Laktanya, Körösladány-Bikeri, Kiskőrös, Köröstarcsa, Kisvárda, Mónosbél, Oborín, Polgár-Nagy-Kasziba, Újvár, Vésztő-Bikeri und Vásárosnamény zum Vorschein (Diagramm 11, Tabelle 4).

Belegungsphase 3: 34,71\% $(\mathrm{n}=185)$ der diskutierten Befunde, nunmehr von 24 Fundorten, kann hier aufgezählt werden (künstliche Perioden 5, 6 und 7). Die überwiegende Mehrheit, d. h. 33,33\% ( $\mathrm{n}=21)$, dieser

Tabelle 5. Gräber der Belegungsphase 3

\begin{tabular}{|c|c|c|}
\hline Fundorte & Grabnummer & Gräberanzahl \\
\hline Polgár-Basatanya & 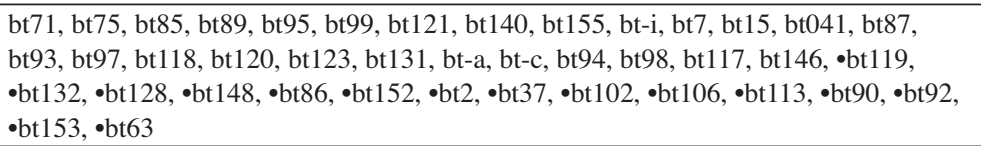 & $41(22,16 \%)$ \\
\hline Polgár-Bacsókert & bcs11, bcs12, bcs9, •bcs6, $\bullet$ bcs $4, \bullet b c s 10-11$ & $6(3,24 \%)$ \\
\hline Endröd-Hegedűs-tanya & •eht1 & 1 \\
\hline Hódmezővásárhely-Kotacpart & •hk5 & 1 \\
\hline Hódmezővásárhely-Bodzáspart & •hb2 & 1 \\
\hline Tibava & •ti23.56 & 1 \\
\hline Tápé-Lebő A & •tla13 & 1 \\
\hline Körösladány-Bikeri & •kb2 & 1 \\
\hline Vásárosnamény & vn2 & 1 \\
\hline Tiszavalk-Tetes & tvt14, tvt15, tvt20, tvt22, tvt24, tvt 3, tvt 18, tvt19 & $8(4,32 \%)$ \\
\hline Tiszavalk-Kenderföldek & 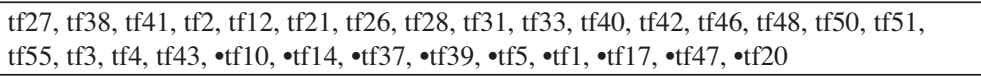 & $29(15,68 \%)$ \\
\hline Tiszakeszi-Fáy-kert & tk1, tk15, tk18, •tk4, •tk11, •tk21 & $6(3,24 \%)$ \\
\hline Magyarhomorog-Kónyadomb & $\begin{array}{l}\mathrm{mh} 31, \mathrm{mh} 1, \mathrm{mh} 34, \mathrm{mh} 39, \mathrm{mh} 41, \mathrm{mh} 47, \mathrm{mh} 5, \mathrm{mh} 6, \mathrm{mh} 9, \mathrm{mh} 10, \mathrm{mh} 51, \mathrm{mh} 74, \mathrm{mh} 78, \\
\bullet\end{array}$ & $25(13,51 \%)$ \\
\hline Fényeslitke & $\begin{array}{l}\mathrm{fl11}, \mathrm{fl} 15, \mathrm{fl} 22, \mathrm{fl} 32, \mathrm{fl} 65, \mathrm{fl} 17, \mathrm{fl} 25, \mathrm{fl} 50, \mathrm{fl} 54, \mathrm{fl} 55, \mathrm{fl} 61, \bullet \mathrm{fl} 35, \bullet \mathrm{fl} 38, \bullet \mathrm{fl} 43, \bullet \mathrm{fl} 20, \\
\bullet \mathrm{fl} 14, \bullet \mathrm{fl} 151, \bullet \mathrm{fl} 64, \bullet \mathrm{fl} 42, \bullet \mathrm{fl} 41, \bullet \mathrm{fl} 13\end{array}$ & $21(11,35 \%)$ \\
\hline Mezökövesd-Patakra járó-dülő & mkp6, mkp4, mkp5, •mkp1 & $4(2,16 \%)$ \\
\hline Bodrogkeresztúr & bk45, bk46 & $2(1,08 \%)$ \\
\hline Kunszentmárton-Pusztaistvánháza & pi24, pi26, pi3, pi5, pi15, pi17, pi28, pi32, pi30 & $9(4,86 \%)$ \\
\hline Mezőkeresztes-Csincse-tanya & $\mathrm{mc} 1, \mathrm{mc} 3$ und $\bullet \mathrm{mc} 2$ & $3(1,62 \%)$ \\
\hline Kiskőrös & kk18, kk15, kk17, •kk21, •kk-c & $5(2,70 \%)$ \\
\hline Jászladány & j132, j138, • j18, •j118, •j129, •fl17, • j15, • j113, • j116, • j137, • j128, • j121 & $12(6,49 \%)$ \\
\hline Öcsöd-Kendereshalom & ök3 & 1 \\
\hline Sárazsadány & sz1 & 1 \\
\hline Nagykörü-Hidashát & $\bullet$-nh2 & 1 \\
\hline Hajdúszoboszló & has4, has12, has5, •has3 & $4(2,16 \%)$ \\
\hline
\end{tabular}

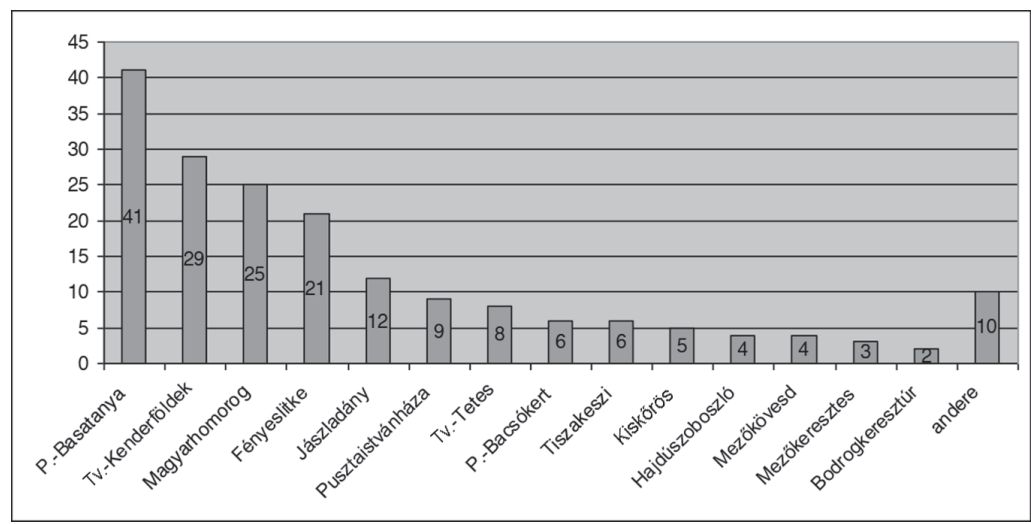

Diagramm 12. Vorkommen der Befunde der Belegungsphase 3 nach Nekropolen

(andere Gräberfelder mit je einem Grab: Deszk A, Endrőd-Hegedűs-tanya, Emőd, Hajdúszoboszló, Hódmezővásárhely-Népkert, KörösladányBikeri, Pusztaistvánháza, Sárazsadány, Tiszabábolna, Tiszavalk, Tápé-Lebő A, Újvár und Vésztő-Bikeri) 
Gräber ist in Basatanya nachgewiesen. Ihr Anteil beträgt in Tibava 14,29\% $(n=9)$, in Fényeslitke 6,35 \% $(n=4)$ und in Vel'ké Raškovce 4,76 \% (n=3). Die Gräberfelder von Polgár-Bacsókert, Hajdúböszörmény, Jászladány, Magyarhomorog-Kónyadomb, Panyola und Polgár-Hajdúnánási út kennzeichnet je 3,17\% $(n=2-2)$ und je eine Bestattung stammt auch noch aus Deszk A, Endrőd-Hegedűs-tanya, Emőd, Hajdúszoboszló, HódmezővásárhelyNépkert, Körösladány-Bikeri, Pusztaistvánháza, Sárazsadány, Tiszabábolna, Tiszavalk, Tápé-Lebő A, Újvár und Vésztő-Bikeri (Diagramm 12, Tabelle 5).

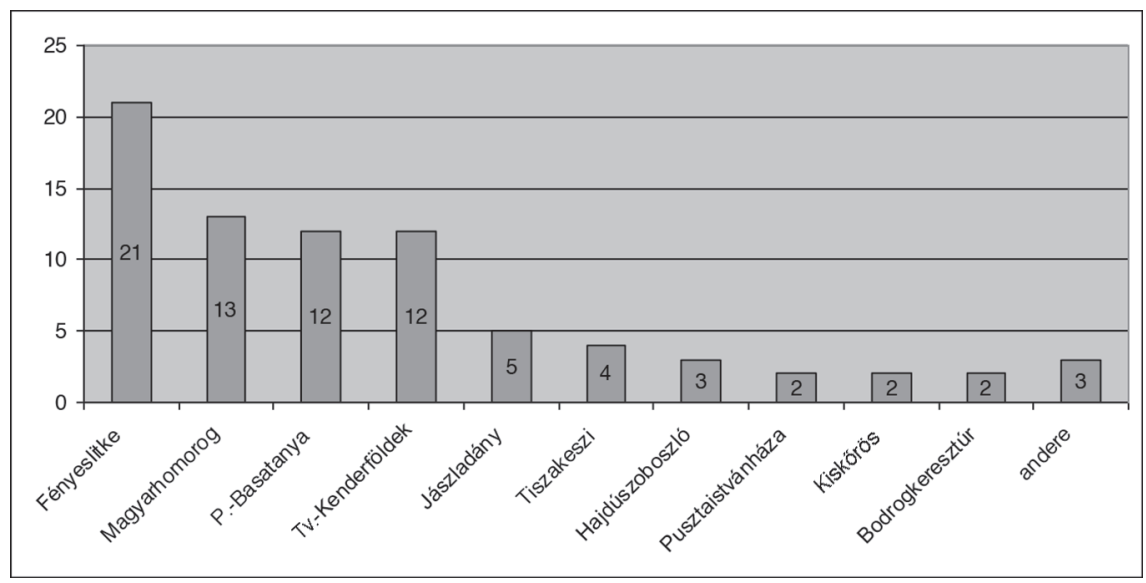

Diagramm 13. Vorkommen der Befunde der Belegungsphase 4 nach Nekropolen (andere $=$ Tiszabábolna-Szilpuszta, Gelej, Nagykörü-Hidashát)

Belegungsphase 4: Es geht um 15,01\% $(n=80)$ der untersuchten Bestattungen, die in 14 Nekropolen geborgen wurden. Die Zahl der Fundorte nimmt in dieser Zeitperiode also stark ab. Derzeit dominiert Basatanya mit 33,66 \% (n=34). Fényeslitke erscheint mit 15,84\% $(n=16)$, Tiszavalk mit 10,89\% $(n=11)$, MagyarhomorogKónyadomb mit 8,91 \% ( $\mathrm{n}=9)$, Pusztaistvánháza mit 5,94 \% $(\mathrm{n}=6)$ und Tiszakeszi bzw. Jászladány mit je 4,95 \% $(n=5-5) .2,97 \%(n=3)$ dieser Befunde gehört dem Gräberfeld von Polgár-Bacsókert zu und je 1,98 \% $(n=2-2)$ von ihnen wurde in Bodrogkeresztúr, Hajdúszoboszló und Mezőkeresztes-Csincse-tanya entdeckt. Je ein solches Grab ist noch in Endrőd-Hegedüs-tanya, Hódmezővásárhely-Bodzáspart, Kiskőrös, Panyola, Nagykörü und Mónosbél belegt (Diagramm 13, Tabelle 6).

Tabelle 6. Gräber der Belegungsphase 4

\begin{tabular}{|c|c|c|}
\hline Fundorte & Grabnummer & Gräberanzahl \\
\hline Polgár-Basatanya & $\begin{array}{l}\text { bt1, bt105, bt116, bt129, bt137, bt126, bt141, •bt112, •bt74, •bt154, •bt144, •bt136, } \\
\bullet \text { bt142 }\end{array}$ & $13(15,19 \%)$ \\
\hline Tiszabábolna-Szilpuszta & $\cdot \operatorname{tb} 2$ & 1 \\
\hline Tiszavalk-Kenderföldek & $\mathrm{tf} 7, \mathrm{tf} 13, \mathrm{tf} 18, \mathrm{tf} 25, \mathrm{tf} 52, \mathrm{tf} 16, \mathrm{tf} 53, \mathrm{tf} 19, \mathrm{tf} 44, \mathrm{tf} 54, \bullet \mathrm{tf} 6, \bullet \mathrm{tf} 23$ & $12(15,19 \%)$ \\
\hline Tiszakeszi-Fáy-kert & tk11, •tk13, •tk19 und •tk8 & $4(5,06 \%)$ \\
\hline Magyarhomorog-Kónyadomb & $\begin{array}{l}\mathrm{mh} 4, \mathrm{mh} 18, \mathrm{mh} 19, \mathrm{mh} 38, \mathrm{mh} 50, \mathrm{mh} 66, \mathrm{mh} 48, \bullet \mathrm{mh} 67, \bullet \mathrm{mh} 69, \bullet \mathrm{mh} 11, \bullet \mathrm{mh} 43, \\
\bullet \mathrm{mh} 40, \bullet \mathrm{mh} 22\end{array}$ & $13(16,46 \%)$ \\
\hline Fényeslitke & $\begin{array}{l}\text { fl31, fl39, fl49, fl53, fl63, fl68, fl16, fl10, fl12, fl52, fl56, fl60, •f158, •fl28, •fl48, } \\
\bullet f 167, \bullet f 121, \bullet f 133, \bullet f 135, \bullet f l 27, \bullet f 111\end{array}$ & $21(26,58 \%)$ \\
\hline Bodrogkeresztúr & bk48, •bk47 & $2(2,53 \%)$ \\
\hline Kunszentmárton-Pusztaistvánháza & pi4, pi6 & $2(2,53 \%)$ \\
\hline Kiskőrös & $\bullet \mathrm{kk} 14, \bullet \mathrm{kk} 23$ & $2(2,53 \%)$ \\
\hline Jászladány & $\mathrm{j} 12, \mathrm{j} 136, \bullet \mathrm{j} 123, \bullet \mathrm{j} 126, \bullet j 115$ & $5(6,33 \%)$ \\
\hline Gelej & •ge1 & 1 \\
\hline Nagykörü-Hidashát & nh1 & 1 \\
\hline Hajdúszoboszló & has11, has2, •has9 & $3(3,80 \%)$ \\
\hline
\end{tabular}




\section{LAUFZEITEN DER UNTERSUCHTEN GRÄBERFELDER}

Als Ergebnisse der kleinräumig-regionalen Untersuchungen können Folgende resümiert werden. Im Verlauf der Behandlung der Belegungsgeschichte der untersuchten Nekropolen wurde die Hauptaufmerksamkeit dem Vorkommen der Bestattungen zueinander gemäß Belegungsphasen sowie Belegungsperioden gewidmet. Die Fragen der Kontinuität oder Diskontinuität werden dann auch mit Rücksicht auf die Verteilung der Gräber auf den Gräberfeldplänen und die Grab- bzw. Typensequenzdaten besprochen.

Es ist notwendig, die Tatsache zu erwähnen, dass die hier vorgestellten Ergebnisse die Belegungsgeschichte der Gräberfelder nicht unvermeidlich in allen Fällen widerspiegeln. Die Mehrheit der untersuchten Gräberfelder ist nämlich nur in einem unvollständigen Maß freigelegt und nur wenige Bestattungen sind für einige Nekropolen dennoch bekannt.

Die archäologischen Forschungen behandeln die prähistorischen Kulturen gewöhnlich als Gruppen von Gemeinschaften/Gesellschaften ähnlicher oder gleicher Identität, einschließlich der Sprache, der Religion, der Gewohnheiten und des Bestattungsritus. Jedoch können wir J. Müller zustimmen, dass sich „mit archäologischen Mitteln keine ethnischen Identitäten nachweisen lassen. Mit archäologischen Mitteln lassen sich dagegen Raumstrukturen darstellen und z. B. auch Terrotorialität im Sinne ökonomischer oder politischer ,Grenzziehungen` rekonstruieren. “ ${ }^{128}$ In der vorliegenden Arbeit wurden nur die Nekropolen mit größerer Gräberanzahl behandelt.

\subsection{Verbreitungsregion 1 - untere Theißgegend}

Hierbei handelt es sich um die südliche Gruppe von Fundorten der diskutierten kupferzeitlichen Gräberfelder. Die Fundorte Deszk A, Deszk B und Ószentiván VIII befinden sich im Bereich des Theiß-Maros-Zwischenstromlands. Auch die Gräberfelder von Hódmezővásárhely-Bodzáspart, -Kotacpart-Vata-tanya, -Népkert, -Szakálhát und -Laktanya liegen in der Nähe der Theiß. Der Fundort Tápé-Lebő A ist bei der Maros-Mündung zu finden. Der Fundort Uivar/Újvár (Serbien) liegt im Banat, weit südlich von dieser Verbreitungsregion. ${ }^{129}$

\subsubsection{Deszk A (Kom. Csongrád, Bez. Szeged)}

Auf diesem Fundplatz wurden 13 Gräber der Tiszapolgár-Kultur ausgegraben. Alle dieser Bestattungen wurden mit insgesamt 48 Keramikgefäßen ausgestattet. ${ }^{130}$ Wir konnten hier insgesamt 47 Keramikgefäße aus 8 Gräbern untersuchen. Die Gräber vertreten die Deszk-Gruppe nach I. Bognár-Kutzián. ${ }^{131}$ Diese Gefäße erscheinen hier in 35 Typen von vier Gattungen: Fußgefäße sind in 20,0\% $(n=7)$ vorhanden. Mit dem größten Anteil, in $45,71 \%(n=16)$, treten die Becherformen auf. Schüsseln kommen nur in 5,71 \% $(n=2)$ vor, der Anteil von Schalentypen beträgt dagegen $28,57 \%(\mathrm{n}=10)$.

Zeitbestimmung gemäß Belegungsphasen: Die Belegung der Gräberansammlung in Deszk A beginnt zur Zeit der Belegungsphase 1. Die Mehrheit der Befunde $(75,0 \%, \mathrm{n}=9)$ vertritt diese Phase und zwei andere $(25,0 \%)$ können in die Belegungsphase 2 datiert werden. Jüngere Bestattungsobjekte wurden hier nicht belegt (Tabelle 7, Diagramm 14).

Zeitbestimmung gemäß Belegungsperioden: Anhand der Verteilung der Gräber gemäß Belegungsperioden ist feststellbar, dass die Bestattung da3 als die älteste in dieser Gräberansammlung behandelt werden kann, sie stammt nämlich aus der Zeit der Belegungsperiode 1a (Abb. 35). Die Gräber da6, da7, da11, da12 und da13 repräsentieren die Belegungsperiode 2 und die Gräber da8 bzw. da10 können der Belegungsperiode 3 zugeordnet werden. Die Belegung des behandelten Gräberfeldes dürfte dann mit der Bestattung da2 aus der Belegungsperiode 2 beendet haben (Tabelle 2).

Das Gräberfeld kann auch dadurch charakterisiert werden, dass die Keramik der Bestattungen da7, da11, da6 und da8 der Belegungsphase 1 und der Gräber da4 und da33 der Belegungsphase 2 sowie des Grabs da1 typologische Merkmale von spätneolithischen Traditionen darstellen dürften. Die diskutierte Gräbergruppe kann gleichmäßig also in den Formenkreis 1 datiert werden.

\footnotetext{
${ }^{128}$ MÜLLER 2009, 105.

${ }^{129}$ SCHIER 2008; SCHIER 2014; SCHIER-DraşOVEAN 2014.
}

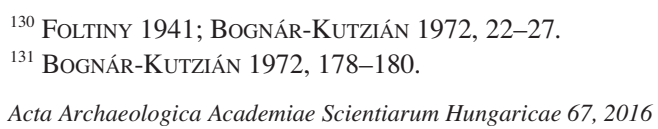




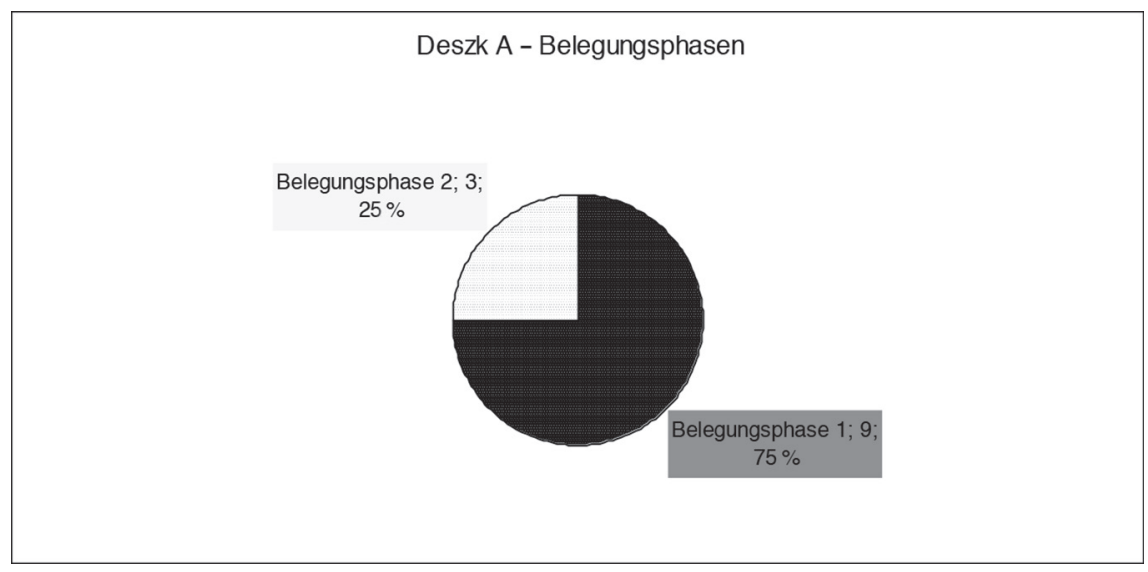

Diagramm 14. Verteilung der Gräber von Deszk A nach Belegungsphasen

\subsubsection{Deszk B (Kom. Csongrád, Bez. Szeged)}

15 Bestattungen wurden von hier veröffentlicht. Sie enthielten insgesamt 78 Keramiken. ${ }^{132}$ Davon wurden 71 Artefakte der Grabkeramik aus 16 Bestattungen in die Deszk-Gruppe nach I. Bognár-Kutzián aufgenommen. ${ }^{133}$ In diesen Gräbern konnten 42 Gefäßtypen von fünf Gattungen bestimmt werden. Fußgefäßtypen sind in 30,95\% ( $\mathrm{n}=13$ ) repräsentiert und fast die Hälfte, 42,86 \% $(n=18)$, der Typen gehört der Gattung der Becher an. In 9,52 \% ( $n=4)$ wurden hier noch Schultergefäßtypen, in 4,76 \% $(n=2)$ Schüsseltypen und in 11,90 \% $(n=5)$ Schalentypen nachgewiesen.

Zeitbestimmung gemäß Belegungsphasen: Die Mehrheit der Befunde, d. h. 13 Bestattungen (86,67\%) dieser Gräbergruppe kann in die Belegungsphase 1 eingeordnet werden. Zwei andere Gräber (13,33\%) stammen aus der Belegungsphase 2. Es gibt keine Daten für eine noch jüngere Belegungszeit der diskutierten Gräberansamm-

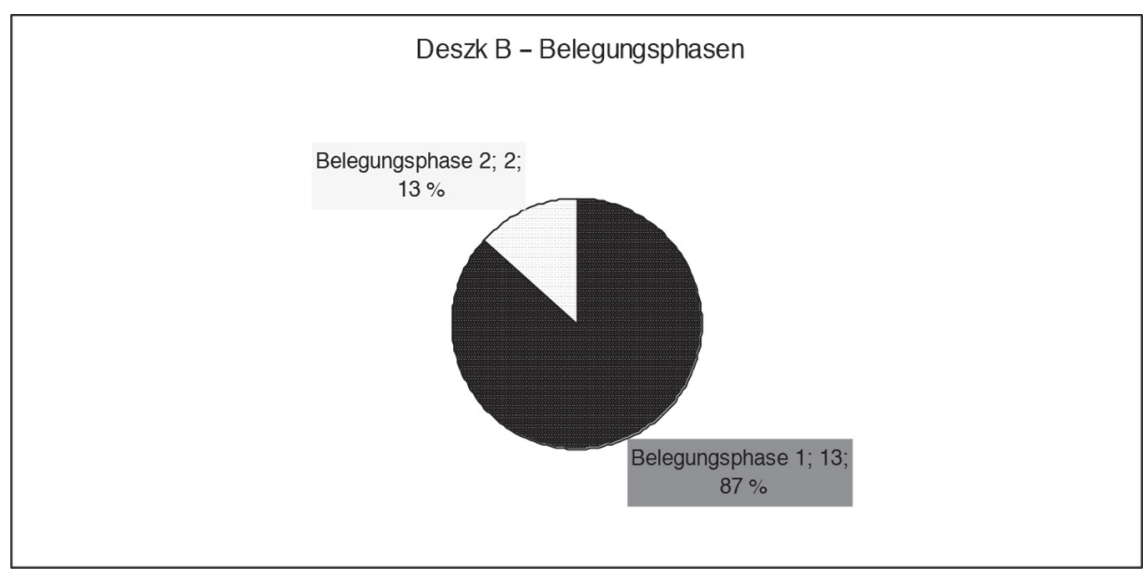

Diagramm 15. Verteilung der Gräber von Deszk B nach Belegungsphasen

lung (Tabelle 7, Diagramm 15).

Zeitbestimmung gemäß Belegungsperioden: Die Verteilung der seriierten Gräber gemäß Belegungsperioden weist darauf hin, dass die Benutzung dieser Gräberansammlung zur Zeit der Periode 1a mit der Bestattung db1 angefangen hatte $(A b b .37)$. Der Anteil der Befunde der Periode $1 \mathrm{~b}$ beträgt $58,33 \%(\mathrm{n}=7)(\mathrm{Grab} \mathrm{db} 3, \mathrm{db} 6, \mathrm{db}$, $\mathrm{db} 8, \mathrm{db} 10, \mathrm{db} 11, \mathrm{db} 13)$. Die Belegungsperioden 1c (Grab db5, db14) und 2a (Grab db2, db9) werden durch je

${ }^{132}$ BÁlint 1941, 36; Foltiny 1941, 69-88; BognÁR-

${ }^{133}$ BOGNÁR-KuTZIÁN 1972, 178-180. KUTZIÁN 1972, 27-34. 
$16,67 \%(n=2-2)$ der Gräber vertreten. Die Benutzung dieses Gräberfeldes begann also mit der ältesten Belegungsperiode und endete während der Belegungsperiode 2a (Tabelle 3).

Die Gräber db1, db7, db3, db10, db6, db11, db13, db8, db5, db14, db12, db15 und db4 der Belegungsphase 1 können zeitlich in die frühe und entwickelte Tiszapolgár-Kultur eingeordnet werden. Die Bestattungen db9 und db2 der Belegungsphase 2 vertreten den Formenkreis 2. Das Gefäß db9.2 im Grab db9 dürfte eventuell in die Übergangsphase gesetzt werden.

\subsubsection{Hódmezövásárhely-Kotacpart-Vatatanya (Kom. Csongrád)}

M. Párducz grub hier 25 Gräber in den Jahren 1932 und 1933 aus. In der Nähe der Befunde der Bodrogkeresztúr-Kultur sind auch frühkupferzeitliche Bestattungen vorhanden. ${ }^{134}$ Nur 8 von den hier geborgenen 17 Gräbern ergaben Keramikgefäße, insgesamt 15 Stück. Die Zahl der analysierten Keramiken beträgt 14, sie stammen aus 8 Gräbern. Hier handelt es sich um die Deszk-Gruppe nach I. Bognár-Kutzián. ${ }^{135}$ Die frühkupferzeitlichen keramischen Beigaben des Gräberfeldes gehören zweifellos in den Formenkreis der Tiszapolgár-Kultur und die hochkupferzeitlichen in die Bodrogkeresztúr-Kultur - bestätigte P. Patay. Auf die Hunyadihalom-Kultur hinweisende typologische Elemente sind hier nicht vorhanden. P. Patay datierte deswegen diesen Abschnitt der Nekropole in die Phase A der Bodrogkeresztúr-Kultur. ${ }^{136}$

In der Nähe der hochkupferzeitlichen Befunde lagen 16 Bestattungen der Tiszapolgár-Kultur. ${ }^{137} 14$ Gefäßtypen von fünf Gattungen sind in den untersuchten Bestattungen vorhanden. Fußgefäßtypen und Schalentypen sind durch je 21,43\% $(n=3-3)$, Bechertypen durch 35,71 \% $(n=5)$ und Schultergefäße durch 14,29 \% (n=2) repräsentiert. Es gibt hier auch einen Schüsseltyp.

Zeitbestimmung gemäß Belegungsphasen: Die Entwicklung dieses Gräberfeldes kann in die Zeit der Belegungsphase 1 datiert werden. Es handelt sich dabei nur um zwei Bestattungen $(28,57 \%)$. Die Benutzung des Bestattungsplatzes setzte sich während der Belegungsphase 2 mit vier Befunden $(51,14 \%)$ fort und endete mit einem einzigen Grab aus der Belegungsphase 3 (Tabelle 7, Diagramm 16).

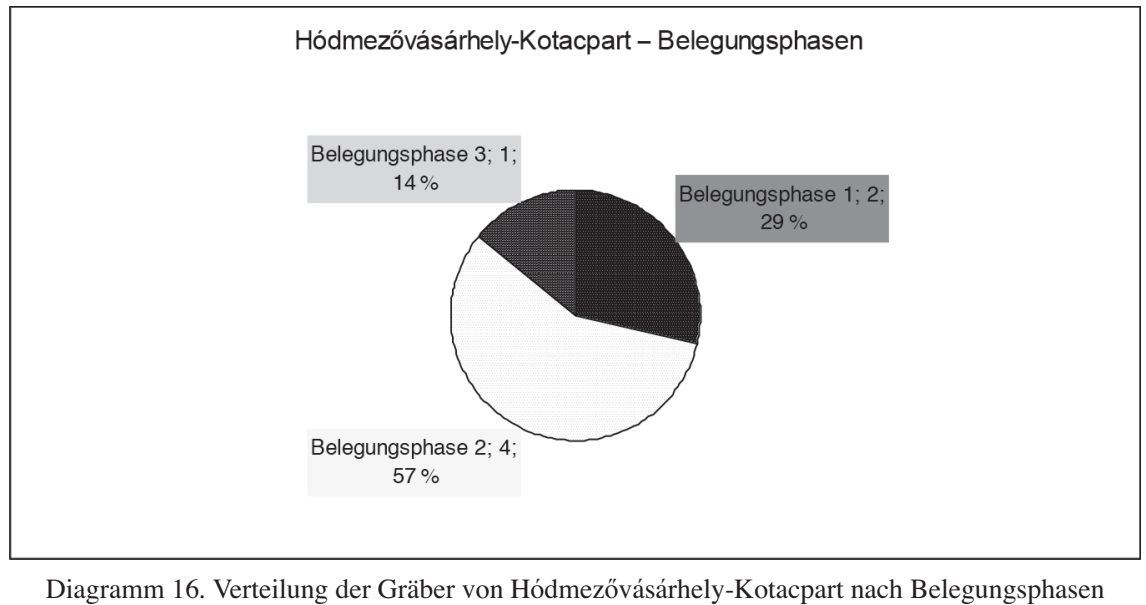

Zeitbestimmung gemäß Belegungsperioden: Die Verteilung der seriierten Gräber dürfte darauf hindeuten, dass das Grab hk6 die früheste Belegungsperiode (Abb.39) und das Grab hk7 die Belegungsperiode 1c repräsentiert (Tabelle 2).

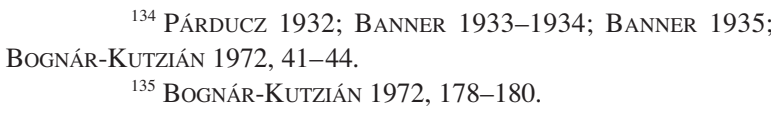

${ }^{134}$ PÁRduCZ 1932; BANNer 1933-1934; BANNER 1935 BOGNÁR-KuTZIÁN 1972, 41-44.

${ }^{135}$ Bognár-KutZián 1972, 178-180.

\author{
${ }^{136}$ PATAY 2008, 29 \\ ${ }^{137}$ PÁRduCZ 1932, 106-110, PATAY 1961, 31.
}


Die Gräber der Belegungsphase 1 und der Belegungsphase 2 können dem Formenkreis 1 zugeordnet werden. Die Keramik der Bestattung hk6 weist auch spätneolithische Traditionen auf. Das Gefäß des Grabes hk5 konnte nur mit Vorbehalt in den Übergang zwischen dem Formenkreis 1 und dem Formenkreis 2 eingeordnet werden.

\subsubsection{Hódmezövásárhely-Népkert (Kom. Csongrád)}

In sechs Bestattungen dieser Fundstelle kamen nur 22 Grabgefäße zum Vorschein. ${ }^{138}$ Davon untersuchten wir 22 Artefakte von 21 Varianten aus fünf Bestattungen. I. Bognár-Kutzián datiert diese Gräber in die Deszk-Gruppe. ${ }^{139}$ Diese Gräber charakterisieren 21 Gefäßtypen von fünf Gattungen. Fußgefäßtypen sind in 38,10\% ( $\mathrm{n}=8)$, Becherformen und Schalentypen in je 19,05\% ( $n=4-4)$, Schultergefäßtypen in 14,29 \% $(n=3)$ und Schüsseltypen in 9,52\% $(n=2)$ belegt.

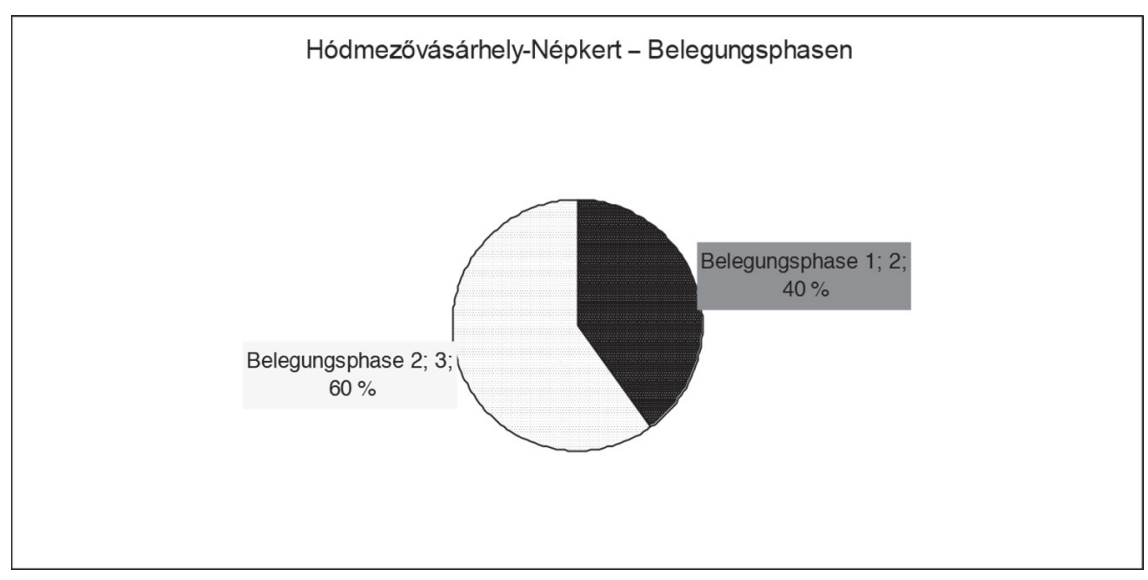

Diagramm 17. Verteilung der Gräber von Hódmezővásárhely-Népkert nach Belegungsphasen

Zeitbestimmung gemäß Belegungsphasen: An dieser Fundstelle kann man feststellen, dass zwei Gräber mit der Belegungsphase 1 und drei andere mit der Belegungsphase 2 als zeitgleich angesehen werden können (Tabelle 7, Diagramm 17).

Zeitbestimmung gemäß Belegungsperioden: Das Vorkommen der seriierten Gräber nach Belegungsperioden beweist, dass die Benutzung dieser Gräberansammlung nur in der Zeit der Belegungsperiode 1b, und zwar mit dem Grab hn3, begonnen haben dürfte (Abb. 40). Das Grab hn2 stammt aus der Periode 1c und die Benutzung des Bestattungsplatzes hörte auch in diesem Fall in der Belegungsperiode 2a mit zwei anderen Befunden auf (Tabelle 2).

Die Mehrheit der Gräber vertritt also den Formenkreis 1. Bei der Keramik des Grabes hn1 und des Grabes hn5 der Belegungsphase 2 sind typologische Merkmale zu sehen, die in die Richtung des Übergangs zwischen den beiden Formenkreisen zeigen.

\subsubsection{Hódmezövásárhely-Laktanya (Kom. Csongrád)}

Auf dem Fundplatz 47/1 wurden auch Objekte der Tiszapolgár-Kultur entdeckt. Die Funde aus dem Grab 90 wurden von R. Patay veröffentlicht. ${ }^{140}$ In die Analyse nahmen wir drei Keramiken auf. Nur zwei Gefäßtypen, Fußgefäße zweimal und Schalen einmal, sind hier vorhanden.

Zeitbestimmung gemäß Belegungsphasen und -perioden: Das Grab hv190 stammt aus der Zeit der Belegungsphase 2 und konnte in die Belegungsperiode 2a eingeordnet werden (Abb. 42, Tabellen 10 und 3).

Die Bestattung hv190 aus der Phase 2 datiert in den Formenkreis 1, mit typologischen Merkmalen der Keramik des Übergangs.

${ }^{138}$ Gazdapusztai 1964, 251; Bognár-KutZián 1972, $\quad{ }^{139}$ BognáR-KutZián 1972, $178-180$. $44-47$.

${ }^{140}$ R. PATAY 2008. 


\subsubsection{Tápé-Lebö A (Szeged, Kom. Csongrád)}

Von hier sind insgesamt 18 Grabgefäße belegt, die aus 15 Bestattungen stammen. Ein Grab enthielt keine Keramik. ${ }^{141}$ In die Analyse wurden 17 Keramiken aus 14 Bestattungen einbezogen.

Nach der Meinung von N. Kalicz gehören hier alle drei Grabungsstellen (A, B und C) zu einem einzigen Siedlungsplatz: Es ließ sich feststellen, dass der Fundplatz aus einer nördlichen „A“-Grabungsstelle mit einem 2,0-2,5 m starken Tell und einer zusammenfassenden horizontalen Siedlung, ferner aus den auf der ganzen Fläche auftretenden Bestattungen besteht. ${ }^{142}$ Er datierte alle Bestattungen der Grabungsstellen A, B und C in die späte, ,sogar späteste Phase der Theiß-Kultur (Gorzsa-Gruppe und Prototiszapolgár-Phase) “. ${ }^{143}$ In den Bestattungen von TápéLebő A wurden 17 Gefäßtypen von fünf Gattungen festgestellt. Fußgefäßtypen fehlen hier. Fast die Hälfte, 41,18 \% $(\mathrm{n}=7)$, vertritt die Gattung von Bechern. Der Anteil der Schultergefäßtypen ist zugleich 23,53\% $(n=4)$ und der der Schalen $17,65 \%(n=3)$. Schüsseltypen kommen in $11,76 \%(n=2)$ vor und man findet hier auch einen Napftyp.

Zeitbestimmung gemäß Belegungsphasen: Die Benutzung des Bestattungsplatzes von Tápé-Lebő A begann mit zwei Gräbern (25,0 \%) der Belegungsphase 1. Die Mehrheit der Befunde, 5 Gräber (62,50 \%), stammen dagegen aus der Belegungsphase 2. Die Belegung der Gräberansammlung endete mit einem Grab in der Belegungsphase 3 (Tabelle 7, Diagramm 18).

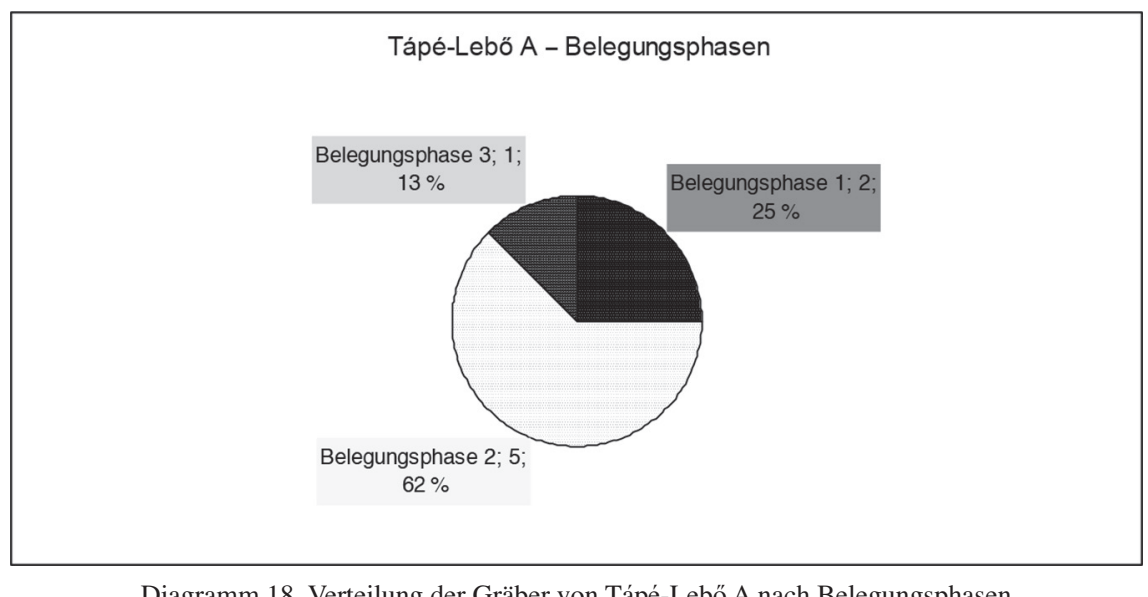

Diagramm 18. Verteilung der Gräber von Tápé-Lebő A nach Belegungsphasen

Zeitbestimmung gemäß Belegungsperioden: Mittels Seriation konnte die chronologische Lage nur im Fall von zwei Gräbern festgestellt werden (Tabelle 2).

Die Gräberansammlung vertritt den Formenkreis 1. Im keramischen Bestand der Gräber tla1 und tla12 der Belegungsphase 1 und der Gräber tla15, tla10 und tla4 der Belegungsphase 2 können auch die typologischen Merkmale von früheren, spätneolithischen Traditionen entdeckt werden. Im Fall des Grabs tla13 der Belegungsphase 3 kann man nicht mit Sicherheit entscheiden, ob die Keramik den Übergang oder den Formenkreis 2 repräsentiert.

\subsubsection{Uivar/Újvár (Rumänien, Kom. Temes)}

Auf dem spätneolithischen Tell von Újvár (Uivar, Serbien) wurden jüngst auch Funde der TiszapolgárKultur entdeckt. ${ }^{144}$ Bei zwei Bestattungen setzte man voraus, dass sie die Prototiszapolgár-Phase vertreten dürften. ${ }^{145}$ Das einzige Grab von hier enthielt fünf Gefäße, die analysiert werden konnten.

Im Fall der Frauenbestattung 2 bemerkte W. Schier Folgendes: „According to both relative ... and absolute chronology ... the late Neolithic sherds in this burial are at least 400-500 years older than the complete vessels

\footnotetext{
${ }^{141}$ ReIZNER 1899; ReIZNER 1904; KoreK 1958, 132; PATAY 1938, 103; BogNÁR-KuTZIÁN 1972, 86-89.

${ }^{142}$ KaLICZ 2013, 365.
}

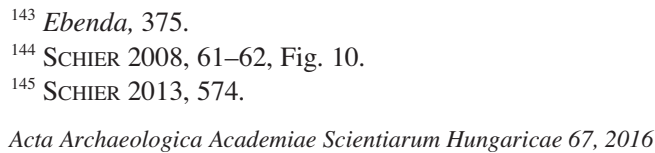


deposited as grave good that date the burial chronologically. “146 Das Gefäß mit S-Profil aus diesem Grab ${ }^{147}$ hat seinen Parellelfund im Grab 8 von Deszk B, während die typologischen Analogien der anderen Keramiken ${ }^{148}$ im Grab 1 von Kisvárda gesucht werden dürften. W. Schier hebt hervor, dass die hohe Fußschüssel - der Leittyp der Tiszapolgár-Kultur - im Grab 2 von Uivar fehlt. ${ }^{149}$

Auf Grund der Radiokarbondaten wurde festgestellt, dass es einen Altersunterschied von nicht mehr als dreißig Jahren zwischen den in diesen Uivarer Gräbern bestatteten beiden Frauen gibt. „They are older then the dated Tiszapolgár burials published by Nándor Kalicz und Pál Raczky, ${ }^{150}$ but their dating corresponds quite well with five recently published radiocarbon dates from the Tiszapolgár cemetery at Hajdúböszörmény-Ficsori-tó-dülö, whose combined calibrated time span (at the $68 \%$ probability level) is $4350-4420$ cal BC. " 151 Das Grab uv1 von Újvár wurde in eine Zeit von 4340-4255 cal BC bzw. 4360-4230 cal BC und das Grab uv2 von 4355-4260 cal BC bzw. 4450-4230 cal BC datiert. ${ }^{152}$ F. Draşovean veröffentlichte jüngst neun Radiokarbondaten von Uivar: Mit einer Ausnahme (Phase Vinča C1) vertreten sie die Phase Vinča C2. ${ }^{153}$ Die Keramiken des Grabes uv2 vertreten vier Typen (Typen 1b2d5 und 1b3b2 von Bechern, 2b1f2 von Schüsseln, 2c2b1 von Schalen) von drei Gattungen.

Zeitbestimmung gemäß Belegungsphasen und -perioden: Das Grab db8 von Deszk B datierten wir in die Periode $1 \mathrm{~b}$ bzw. in die Belegungsphase 1. Das Grab kv1 von Kisvárda dürfte dagegen die Periode 2a bzw. die Belegungsphase 2 vertreten (Kat. 99). Im Fall der am weitesten südlich liegenden untersuchten Fundstelle mit Befunden der Tiszapolgár-Kultur kann man nur so viel voraussetzen, dass das Grab uv2 in die Zeit der Belegungsphase 2 datierbar sein dürfte (Tabellen 7 und 2).

Das Grab uv2 der Belegungsphase 2 von Uivar/Újvár kann auf Grund der Ergebnisse der Analyse und der oben angeführten Daten zeitlich dem Formenkreis 2 zugeordnet werden.

\subsection{Verbreitungsregion 2 - Theißwinkel und Körösgegend}

Das Gräberfeld von Kunszentmárton-Pusztaistvánháza wurde im Theißwinkel entdeckt. Die Fundorte Öcsöd-Kendereshalom, Endrőd-Hegedűs-tanya, Köröstarcsa-Kossuth tér, Körösladány-Bikeri, Bélmegyer-Monokidomb, Vésztő-Bikeri, Okány-Baromfitelep und Magyarhomorog-Mogyorós-tanya wurden entlang der Körös-Flüsse angesetzt.

\subsubsection{Endröd-Hegedüs-tanya (Kom. Békés, Bez. Gyomaendröd)}

Neun Grabgefäße stammen aus fünf hier ausgegrabenen Bestattungen. ${ }^{154}$ Die Gräber dieser Fundstelle charakterisieren acht Gefäßtypen von drei Gattungen. Fußgefäße fehlen auch in diesem Fall. Die Hälfte, 50,0 \% $(\mathrm{n}=4)$, gehört der Gattung von Schalen an, 37,50 \% $(\mathrm{n}=3)$ der von Bechern und der Typ 1d4b3 vertritt die Gattung der Schultergefäße.

Zeitbestimmung gemäß Belegungsphasen: Die chronologische Lage nach Belegungsphasen ist hier bei fünf Befunden bekannt. Je zwei davon (40,0-40,0 \%) stammen aus der Belegungsphase 1 und der Belegungsphase 2. Die Belegung des Bestattungsplatzes endete mit einer Bestattung der Belegungsphase 3 (Tabelle 7, Diagramm 19).

Zeitbestimmung gemäß Belegungsperioden: Die Ergebnisse der durch Seriation vollendeten Untersuchungen weisen darauf hin, dass die Belegung der Gräbergruppe auf die früheste Belegungsperiode fällt (Grab eht3), während ein anderer Befund (Grab eht5) in die Zeit der Belegungsperiode 1c gesetzt werden kann (Tabelle 2).

Die Gräber eht 3 und eht 5 der Belegungsphase 1 sowie die Gräber eht 6 und eht 2 der Belegungsphase 2 repräsentieren den Formenkreis 1 eindeutig. Die Bestattung eht 3 der Belegungsphase 3 dürfte in den Übergang zum Formenkreis 2 zugeordnet werden.

\footnotetext{
${ }^{146}$ Ebenda, 573.

${ }^{147}$ BOGNÁR-KutZiÁn 1972, Pl. 25.5; SCHIER 2013, Fig. 6.3.

${ }^{148}$ BognÁr-KutZián 1972, Pl. 49.1-5; SCHIER 2013, Fig.

6.2, 4 .

${ }^{149}$ SCHIER 2013, 573
}

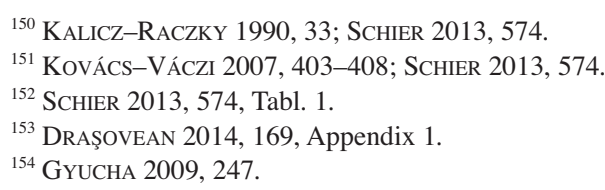

Acta Archaeologica Academiae Scientiarum Hungaricae 67, 2016 


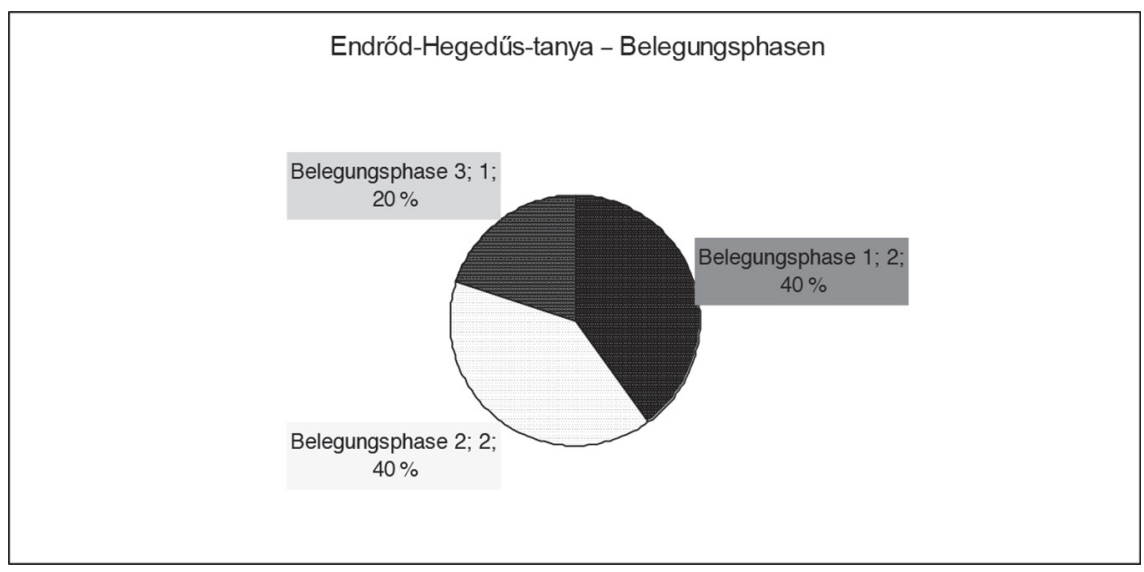

Diagramm 19. Verteilung der Gräber von Endrőd-Hegedűs-tanya nach Belegungsphasen

\subsubsection{Körösladány-Bikeri (Kom. Békés, Bez. Szeghalom)}

Die Bedeutung dieses Fundortes liegt darin, dass zwei Siedlungsphasen auch anhand von zehn Holzkohleproben bestimmt werden konnten. Eine davon kann in den Zeitraum von 4445-4341 cal BC und die zweite in die Zeitspanne von 4336-4173 cal BC datiert werden. ${ }^{155}$ Aus der anderen Seite legte man hier ebenfalls auch vier Gräber mit insgesamt fünf Gefäßen frei. ${ }^{156}$ In die Analyse wurden 5 Gefäße aus 3 Bestattungen einbezogen. Die Entwicklung dieser Siedlung wird von A. Gyucha in den Zeitraum zwischen 4336 und 4173 cal BC datiert und die Mehrheit der Gräber dürfte aus der späteren Phase der Siedlung gestammt haben. ${ }^{157}$ Nur vier Gefäßtypen konnten hier bestimmt werden.

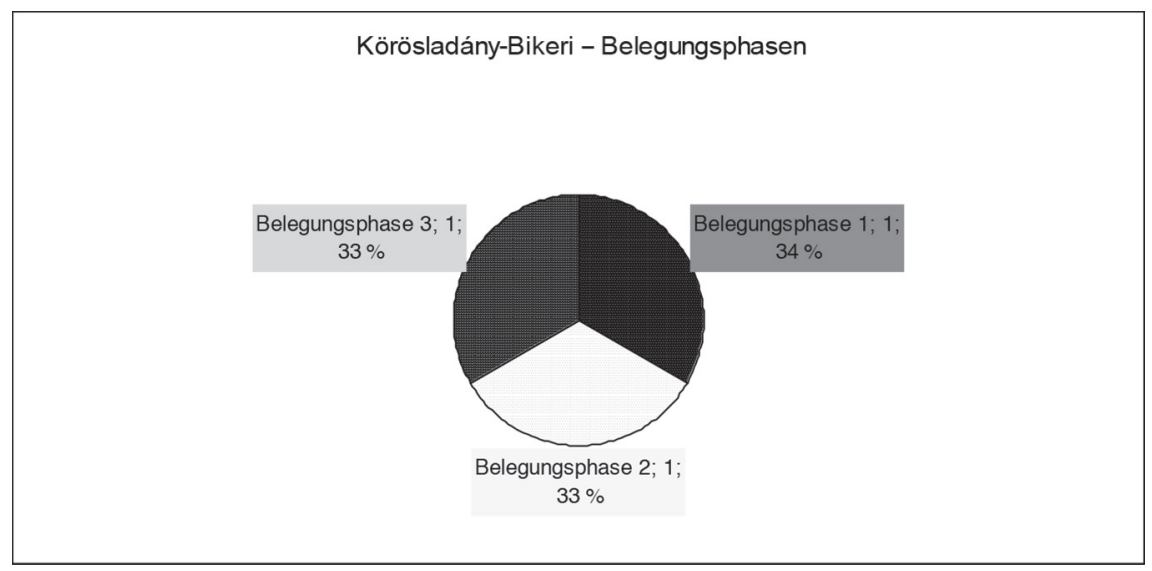

Diagramm 20. Verteilung der Gräber von Körösladány-Bikeri nach Belegungsphasen

Zeitbestimmung gemäß Belegungsphasen: Ein Grab kann hier in die Belegungsphase 1 datiert werden, während zwei andere die Belegungsphase 2 repräsentieren. Die Benutzung des Bestattungsplatztes hatte dann in der Zeit der Belegungsphase 3 mit einem Grab beendet (Tabelle 7, Diagramm 20).

Zeitbestimmung gemäß Belegungsperioden: Mittels Seriation ist es feststellbar, dass das Grab kb4 in der Anfangsperiode angelegt wurde (Tabelle 2).

\footnotetext{
${ }^{155}$ YeRKES et al. 2009; GYUCHA 2009, 286, 306, Tab. 6.1.

${ }^{156}$ GYUCHA 2009, 250.
}

${ }^{157}$ Ebenda, 287. 
Die Gräber kb4 der Belegungsphase 1 und kb3 der Belegungsphase 3 datieren in den Formenkreis 1. Im Fall des Gefäßes im Grab kb2 kann man nur mit Vorbehalt voraussetzen, dass es eventuell den Übergang zwischen den Formenkreisen 1 und 2 repräsentiert haben dürfte.

\subsubsection{Kunszentmárton-Pusztaistvánháza (Kom. Jász-Nagykun-Szolnok)}

J. Hillebrand führte hier systematische Ausgrabungen von 1925 bis 1927 durch und legte 33 Gräber frei. ${ }^{158}$ Die Grabbeschreibungen stammen von P. Patay. ${ }^{159}$ Das Grab 15 ist tiefer als die anderen. 63 untersuchten Keramiken waren Funde von 14 Bestattungen.

Der Ansicht von P. Patay nach sind hier zahlreiche Gefäße vorhanden, die die charakteristische Verzierung der Tiszaug-Gruppe der Tiszapolgár-Kultur an sich tragen. Sie stammen aus einander nahe liegenden Bestattungen. Die Gefäßformen und -verzierungen sind in mehreren Fällen mit denen der Tiszaug-Kisrét-Gruppe übereinstimmend. Es werden dabei die Gräber 17 und 31 vom Tiszapolgár-Charakter erwähnt. ${ }^{160} \mathrm{P}$. Patay bemerkte, dass dieses Phänomen aus Sicht der Entwicklung der kupferzeitlichen Keramik und der Herausbildung der BodrogkeresztúrKultur bedeutend ist. ${ }^{161}$ Das Phänomen von Pusztaistvánháza erklärt er auf zweierlei Art. 1. Die Tiszaug-Gruppe retardierte und blühte nach der Zeit, als die Einflüsse der Hunyadihalom-Gruppe (Salcuţa-Kultur) und die LasinjaBalaton-Gruppe bereits in die Tiefebene eingedrungen waren, also bis zum Anfang der zweiten Phase der Bodrogkeresztúr-Kultur. 2. Das Gräberfeld wurde schon in der ersten Phase der Bodrogkeresztúr-Kultur belegt. ${ }^{12}$ P. Patay schreibt dem Eindringen der Hunyadihalom-Gemeinschaft in die Tiefebene eine entscheidende Bedeutung für die Entwicklung der Bodrogkeresztúr-Kultur zu: „Durch ihren Einfluss haben sich die Formen der zweiten Phase der Bodrogkeresztúr-Kultur ausgebildet. “ ${ }^{\text {163 }}$ Das Fundmaterial des diskutierten Gräberfeldes weist also bestimmte Dualität auf, es gibt hier nämlich Funde und Elemente der Tiszapolgár-Kultur, der Übergangsperiode und der Bodrogkeresztúr-Kultur. P. Patay stellt fest, dass man nicht entscheiden kann, ob die Benutzung des Gräberfeldes in der Hochkupferzeit kontinuierlich oder abschnittsweise stattfand. Die jüngsten Gräber bilden keine zusammenhängende Ansammlung. ${ }^{164}$

In den Bestattungen dieses Fundortes stellten wir 56 Gefäßtypen von fünf Gattungen dar. Die Fußgefäßtypen erscheinen hier in nur 5,36 \% ( $n=3)$. Fast die Hälfte, 46,43\% $(n=26)$, der hier vorhandenen Gefäßtypen kann der Gattung der Becher zugeordnet werden. Schüsseltypen und Schalentypen treten in je 23,21 \% $(n=13)$ auf. Auch ein Typ von Schultergefäßen kann hier beobachtet werden.

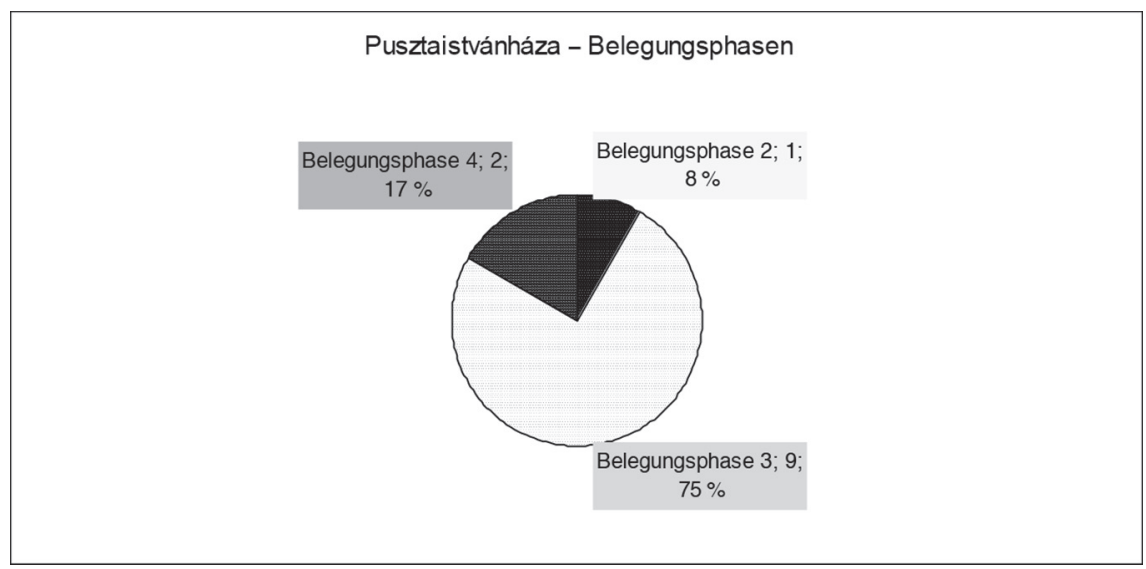

Diagramm 21. Verteilung der Gräber von Kunszentmárton-Pusztaistvánháza nach Belegungsphasen

\footnotetext{
${ }^{158}$ Hillebrand 1929.

${ }^{159}$ PATAY 1961, 40-54.

${ }^{160}$ Patay 1976, 239.

${ }^{161}$ Patay 1961, 53.
}

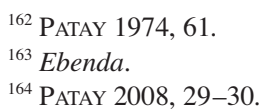


Zeitbestimmung gemäß Belegungsphasen: Die chronologische Stellung konnte hier nach Belegungsphasen und nach Perioden bei 12 Befunden bestimmt werden. Die Daten deuten darauf hin, dass die Belegung dieses groBen Gräberfeldes mit einem Grab (8,0 \%) aus der Zeit der Belegungsphase 2 begann. Die Mehrheit der Bestattungen $(75,0 \%, \mathrm{n}=9)$ wurde dagegen in der Belegungsphase 3 angelegt und die Benutzung des Bestattungsplatzes hörte dann zur Zeit der finalen Phase mit zwei Gräbern (16,67 \%) auf (Tabelle 7, Diagramm 21).

Zeitbestimmung gemäß Belegungsperioden: Auf die Ergebnisse der Seriation gestützt kann man annehmen, dass die Benutzung des Bestattungsplatzes während der Belegungsperiode 2c mit dem Grab pi29 anfing $(8,33 \%)$. Die Gräber pi24 und pi26 stammen schon aus der Belegungsperiode 3a (16,67\%). Die Mehrheit der Befunde (Grab pi5, pi3, pi15, pi17, pi28, pi32) kann dagegen zeitlich in die Belegungsperiode $3 b$ gesetzt werden $(50,0 \%)$. Bloß eine Bestattung (Grab pi30) vertritt dann die Belegungsperiode $3 \mathrm{c}(8,33 \%)$ und das Ende der Belegungszeit fällt hier in die Belegungsperiode $4 \mathrm{a}$ (Grab pi4, pi6) (16,67\%) (Tabelle 2).

Das Grab pi29 der Belegungsphase 2 und die Gräber pi26, pi24, pi28, pi5, pi15, pi32, pi17, pi3 und pi30 der Belegungsphase 3 bzw. alle anderen der Belegungsphase 4 vertreten den Formenkreis 2. Das Gefäß pi17.4 weist typologische Merkmale des Formenkreises 3 (Hunyadihalom) auf. Diese Bestattung befindet sich genau in der Mitte des Gräberfeldes.

\subsubsection{Magyarhomorog-Kónyadomb (Kom. Hajdú-Bihar, Bez. Berettyóújfalu)}

Dieses kupferzeitliche Gräberfeld kann mit 84 registrierten Bestattungen als vollkommen freigelegt angesehen werden. ${ }^{165}$ Die große Zahl, 150 analysierte Artefakte der Grabkeramik stammen aus 51 Bestattungen. Aus Sicht der Chronologie hat das Gräberfeld besondere Bedeutung, weil das hier geborgene Fundmaterial typochronologisch nicht einheitlich ist. ${ }^{166}$

Die Bedeutung dieses Gräberfeldes sieht P. Patay darin, dass seine vollständige Freilegung die Bestimmung der inneren Chronologie der Bodrogkeresztúr-Kultur ermöglichte. Er beobachtete, dass dieses Gräberfeld hinsichtlich des Fundmaterials nicht einheitlich ist und es kann in einen nördlichen und einen südlichen Teil geteilt werden. Es sind Gefäßformen besonders im Süden vorhanden, die im Norden fehlen - solche, die für die Tiszapolgár-Kultur typisch sind. ${ }^{167}$ Als der älteste Teil der Nekropole wird demnach die Mitte des südlichen Bereichs behandelt, aber auch diese Gräber vertreten die Hochkupferzeit. Wirklich frühe Formen erscheinen hier nur in einem kleinen Anteil. ${ }^{168}$ P. Patay bestätigt, dass die Belegung in diesem Gräberfeld kontinuierlich war, unabhängig davon, dass chronologische Unterschiede sowohl typologisch als auch stratigraphisch nachweisbar sind. ${ }^{169}$ Was in PolgárBasatanya fehlt, kann in Magyarhomorog-Kónyadomb gefunden werden, d. h. die Anfangsphase der Bodrogkeresztúr-Kultur. ${ }^{170}$ Jüngst datierte P. Patay die nördliche Gräbergruppe und die jüngeren Gräber der südlichen Gruppe in diesem Gräberfeld in die Phase A der Bodrogkeresztúr-Kultur. ${ }^{171} \mathrm{M}$. Meisenheimer bestätigt, dass nur die frühe Phase der Periode II in Magyarhomorog und Tiszakeszi zu fassen ist. ${ }^{172}$

Unabhängig davon, dass chronologische Unterschiede sowohl typologisch als auch stratigraphisch zwischen den bestimmten Gräbern von Magyarhomorog-Kónyadomb ausweisbar sind, hielt P. Patay ihre Belegung für kontinuierlich, ununterbrochen. Im Gegensatz zu Polgár-Basatanya, wo zwischen den Gräberfeldschnitten der Tiszapolgár- und der Bodrogkeresztúr-Kultur ,in der Kontinuität unbedingt ein Bruch erfolgt werden sollte“ - bestätigt er. Die wenigen Gräber von Übergangscharakter liegen nicht zwischen den früh- und mittelkupferzeitlichen Teilen. ${ }^{173}$

110 Gefäßtypen von fünf Gattungen sind in diesen Gräbern vorhanden. Der große Anteil, 15,32 \% ( $n=17)$, von Fußgefäßtypen ist auch für dieses Gräberfeld charakteristisch. Fast die Hälfte, 42,34 \% (n=47), der Gefäßtypen vertritt zugleich die Gattung der Becher, 20,72 \% $(n=23)$ die der Schalen und 19,82 \% $(n=22)$ die der Schüsseln. Die Sonderformen treten hier in zwei Typen auf.

Zeitbestimmung gemäß Belegungsphasen: Dieses kupferzeitliche Gräberfeld bietet gute Möglichkeiten zur typologischen Analyse der untersuchten Nekropolen, da hier man nicht weniger als 46 Bestattungen nach Belegungs-

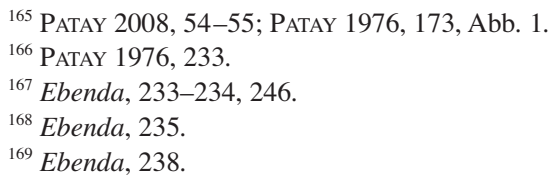

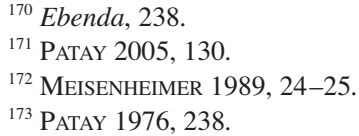


phasen und 27 andere nach Perioden einordnen konnte. Die Benutzung des Gräberfeldes begann in der Belegungsphase 2 mit 8 Bestattungen (17,39\%). Mehr als die Hälfte der analysierten Gräber $(54,35 \%, \mathrm{n}=25)$ gehört der Belegungsphase 3 an und 13 Gräber (28,26 \%) stammen aus der spätesten Belegungsphase (Tabelle 7, Diagramm 22).

Zeitbestimmung gemäß Belegungsperioden: Die Daten der mittels Seriation vorgenommenen Analyse weisen darauf hin, dass die Benutzung der Nekropole in der Belegungsperiode 2a mit den Befunden mh36 und mh57 begonnen haben dürfte (7,41 \%). Ebenso zwei Gräber (mh21, mh22) können in die Belegungsperiode 2b eingeord-

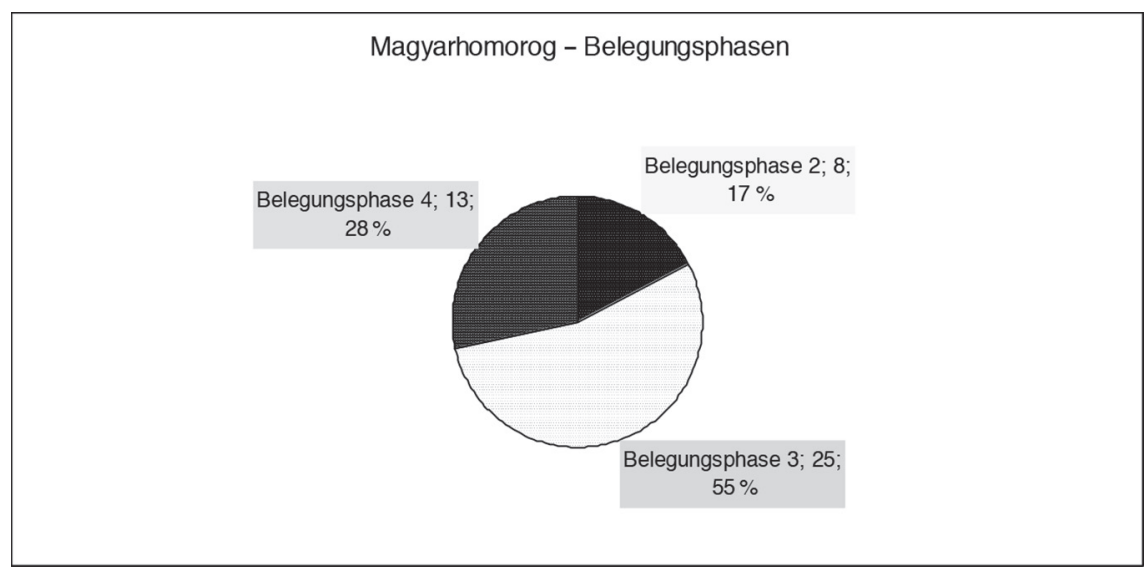

Diagramm 22. Verteilung der Gräber von Magyarhomorog-Kónyadomb nach Belegungsphasen

net werden (7,41\%). Die Benutzung des Bestattungsplatzes setzte sich auch im Weiteren ununterbrochen fort: Drei Bestattungen (mh28, mh37, mh46) vertreten die Belegungsperiode 2c (11,11\%). Allein das Grab mh31 gehört der Belegungsperiode 3a an (3,70 \%), während fünf andere Befunde (mh1, mh34, mh39, mh41, mh47) die Belegungsperiode $3 b$ charakterisieren $(18,52 \%)$. Sieben Gräber (mh5, mh6, mh9, mh10, mh51, mh74, mh78) stammen aus der Belegungsperiode 3c (25,93\%) und sechs weitere (mh4, mh18, mh19, mh38, mh50, mh66) aus der Belegungsperiode $4 \mathrm{a}(22,22 \%)$. Am Ende der Belegungszeit kann nur das Grab mh48 allein bestätigt werden (Tabelle 2).

Zwischen den ältesten Gräbern mh56 und mh57 der Belegungsperiode 2a und den mh21 und mh72 der Belegungsperiode $2 \mathrm{~b}$ sowie den $\mathrm{mh} 37$, mh46, mh28 und mh54 der Belegungsperiode $2 \mathrm{c}$ kann eine ununterbrochene Entwicklung angenommen werden. Die Bestattungen mh57, mh21, mh72, mh37, mh46 und mh28 der Belegungsphase 2 vertreten den Formenkreis 2, wie alle anderen Befunde der Belegungsphase 3 und der Belegungsphase 4. Die Gräber mit Gefäßformen, die als typologische Prämissen des Formenkreises 3 zu behandeln sind, konzentrieren sich in der südlichen Hälfte des Gräberfeldes (Grab mh38, mh39, mh21, mh31, mh46) und bilden eine kleinere Ansammlung untereinander.

\subsection{Verbreitungsregion 3 - mittlere Theißgegend}

Die Fundorte von Jászladány, Nagykörü-Hidashát, Tiszaigar-Csikóstanya, Tiszabábolna-Szilpuszta, Tiszavalk-Kenderföldek, Tiszavalk-Tetes, Tiszakeszi-Fáy-kert, Polgár-Basatanya, Polgár-Hajdúnánási út, Nagy-KaszibaBacsókert, Mezőkeresztes-Csincse-tanya, Mezőkövesd-Patakra járó-dűlő, Gelej-Füzeshát und Emőd befinden sich in der Theißgegend. Die Gräberfelder von Hajdúböszörmény-Ficsori-tó-dủlő und Hajdúszoboszló wurden weiter von der Theiß entfernt angelegt und die Fundstelle von Mónosbél liegt schon am südlichen Verlauf des Bükkgebirges. Der Fundplatz von Kiskőrös liegt im Sandgebiet Kiskunság zwischen der Donau und Theiß, westlich von den Verbreitungsregionen 1 und 3. 


\subsubsection{Mezökövesd-Patakra járó-dülö (Kom. Csongrád)}

R. Patay grub hier auch sechs Gräber der Bodrogkeresztúr-Kultur im Jahre 2000 an einer Rettungsgrabung aus. In die Analyse wurden 16 Keramikgefäße aus diesen Bestattungsobjekten einbezogen. ${ }^{174}$ Die da bekannten sechs Bestattungen wurden in die Zeit der Bodrogkeresztúr-Kultur datiert. ${ }^{175}$ Typisch ist die große Anzahl der in diesen Gräbern belegten keramischen Gattungen und Typen. 13 Gefäßtypen erscheinen nämlich in sechs Gattungen. Es gibt nur einen Fußgefäßtyp. Bechertypen treten in 23,08 \% $(n=3)$, Näpfe und Schalen in je 15,38 \% (n=2-2) und Schüsseln in sogar 30,77 \% ( $n=4)$ auf. Der Typ 3b3a2 gehört der Gattung der Sonderformen an.

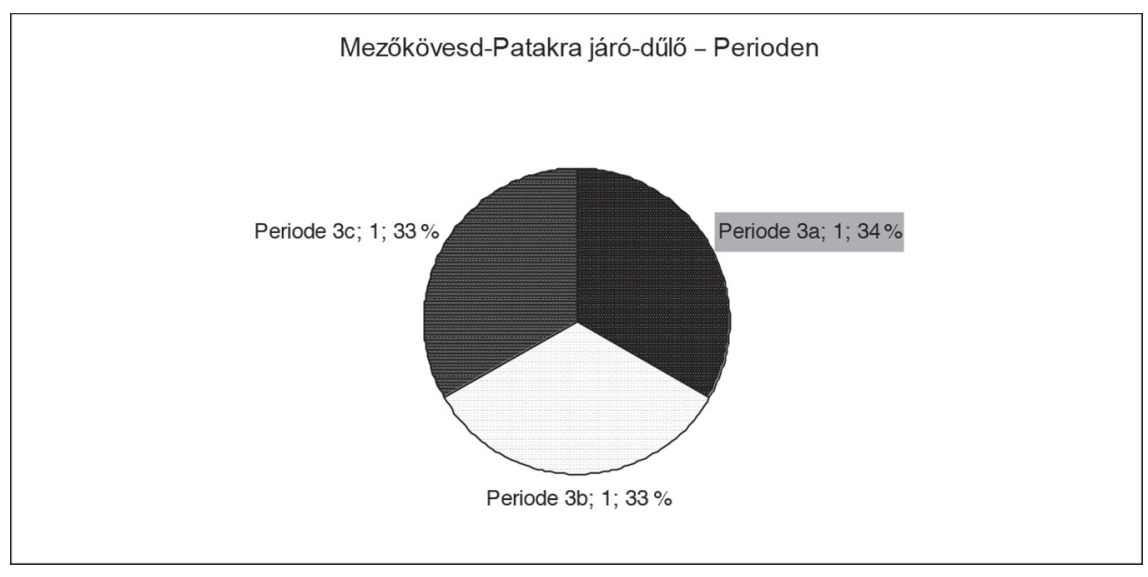

Diagramm 23. Verteilung der Gräber von Mezőkövesd-Patakra járó-dűlő nach Belegungsperioden

Zeitbestimmung gemäß Belegungsphasen und -perioden: Die da untersuchten vier Bestattungen können in die Belegungsphase 3 datiert werden. Die chronologische Stellung nach Perioden ist bei drei Befunden bekannt. Je eine Bestattung (Grab mkp6) vertritt die Belegungsperiode 3a, die Belegungsperiode 3b (Grab mkp4) und die Belegungsperiode 3c (Grab mkp5) (Tabellen 7 und 3, Diagramm 23).

Das Grab mkp6 der Belegungsphase 3 kann auf Grund des Charakteristikums der keramischen Typologie in den Übergang zwischen den beiden Formenkreisen und dem Formenkreis 2 eingereiht werden.

\subsubsection{Jászladány (Kom. Jász-Nagykun-Szolnok, Bez. Jászberény)}

Im Laufe einer nicht fachmäßigen Ausgrabung wurden hier 10 bis 12 Gräber zerstört. S. Gallus legte dann 40 Gräber frei. Die Funde und Befunde von 37 Bestattungen veröffentlichte P. Patay. ${ }^{176}$ Die untersuchten 30 Keramiken kamen in 20 Bestattungen zum Vorschein. Die keramischen und anderen Funde dieser Gräber stellen das allgemein bekannte Bild dar, bemerkt P. Patay, und er ordnete sie an das Ende der Bodrogkeresztúr-Kultur ein. ${ }^{177}$ Er ist der Meinung, dass die Brandbestattung 28 Wirkungen fremder Kulturen bezeichnet. ${ }^{178}$ Jüngst datierte er die Gräber von Jászladány in die Phase B der Bodrogkeresztúr-Kultur. ${ }^{179} 25$ Typen der Grabkeramik von drei Gattungen konnten hier bestimmt werden. Fußgefäße fehlen. Im größten Anteil 48,0 \% $(n=12)$ sind Bechertypen nachzuweisen, aber auch die Proportion der Schüsseln ist groß $(32,0 \%, n=8) .20,0 \%(n=5)$ der Typen gehört der Gattung von Schalen zu.

Zeitbestimmung gemäß Belegungsphasen: Nach Belegungsphasen konnte die chronologische Lage im Fall von 17 Gräbern und nach Belegungsperioden nur bei vier Gräbern festgestellt werden. Das Gräberfeld wurde überwiegend zur Zeit der Belegungsphase 3 benutzt; die Zahl der Gräber beträgt nun 12 (70,59 \%). Die letzte Etappe
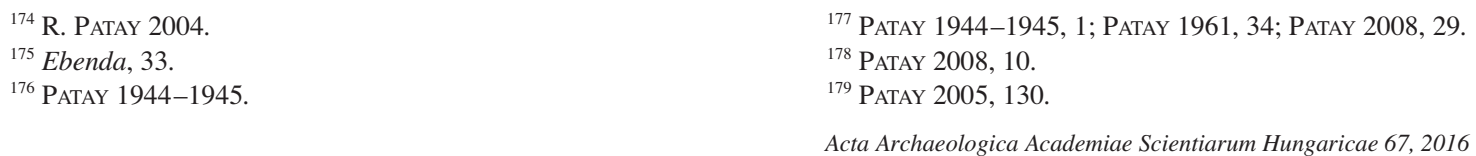


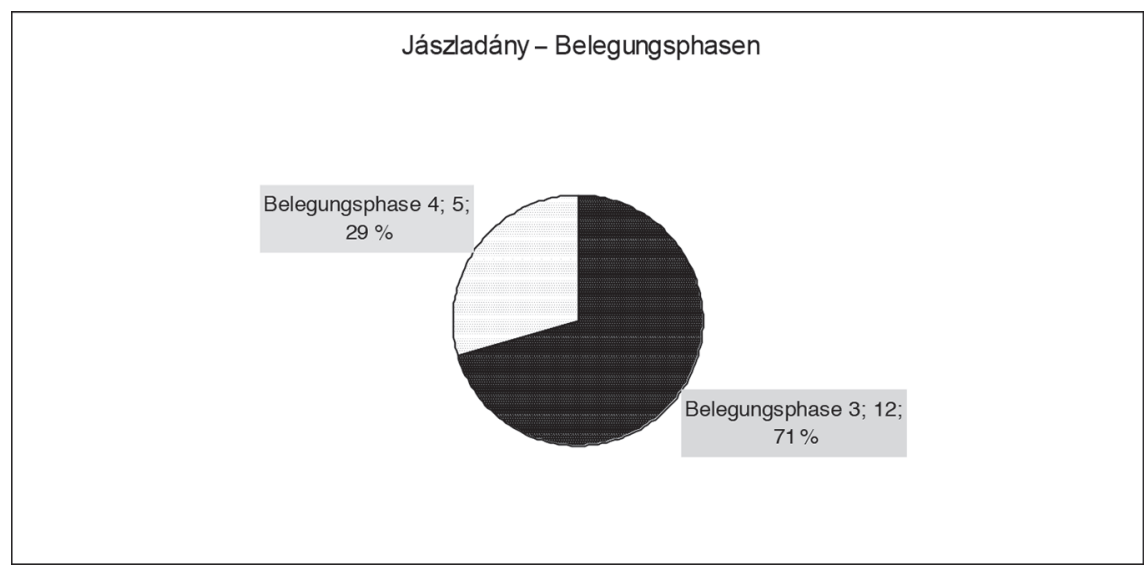

Diagramm 24. Verteilung der Gräber von Jászladány nach Belegungsphasen

der Belegungszeit fällt gleichzeitig in die Belegungsphase 4 mit fünf Bestattungen $(29,41 \%)($ Tabelle 7 , Diagramm 24).

Zeitbestimmung gemäß Belegungsperioden: Die Verteilung der Gräber nach Perioden zeigt, dass der Anfang der Benutzung dieses Bestattungsplatzes in den Zeitraum der Belegungsperiode 3a fällt (Grab j132, j138). Zeitlich können die Gräber j12 und j136 in die Belegungsperiode 4a gesetzt werden (Tabelle 2).

Die Gräber j138, j132, j18, j118, j129, j15, j113, j116, j137, j128 und j121 der Belegungsphase 3 sowie alle anderen Bestattungsobjekte der Belegungsphase 4 können diesem Formenkreis zugeordnet werden.

\subsubsection{Hajdúböszörmény-Ficsori-tó-dülö (Kom. Hajdú-Bihar, Bez. Hajdúböszörmény)}

„The cemetery of Hajdúböszörmény is the first authentically excavated material indicating the Early Copper Age occupation of the northern part of the Hajdúság“ - schreiben K. Kovács und G. Váczi. ${ }^{180}$ Von den 34 da geborgenen kupferzeitlichen Bestattungen wurden bislang nur zwei veröffentlicht. ${ }^{181}$ Von diesen Gräbern konnten wir 16 Keramiken in die Analyse aufnehmen. In den Bestattungen dieses Fundortes wurden 11 Gefäßtypen von nur drei Gattungen nachgewiesen. Mehr als die Hälfte der Typen, also 63,64 \% (n=7), vertritt die Gattung der Becher. Die Fußgefäße und die Schalen sind hier durch je 18,18 \% (n=2-2) der Typen repräsentiert.

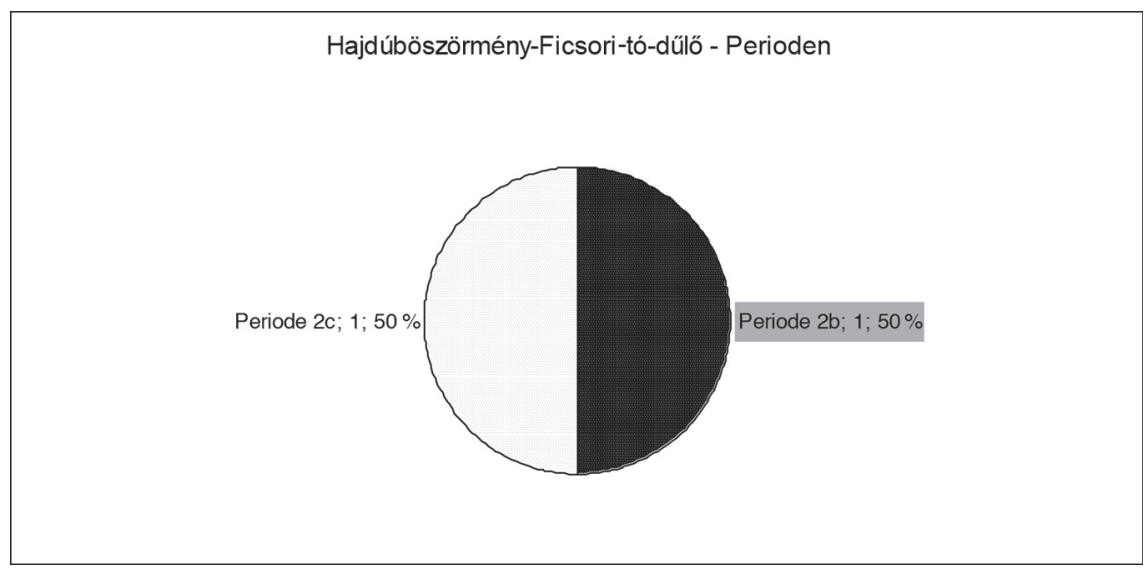

Diagramm 25. Verteilung der Gräber von Hajdúböszörmény-Ficsori-tó-dủlő nach Belegungsperioden

\footnotetext{
${ }^{180}$ KovÁCS-VÁCZI 2007, 397-398.
}

${ }^{181}$ Ebenda, 398-402. 
Zeitbestimmung gemäß Belegungsphasen und -perioden: Der Anfang der Belegung dieser Gräberansammlung kann in die Belegungsphase 2 datiert werden. Die Ergebnisse der Seriation deuten darauf hin, dass die Bestattung hft68 aus der Belegungsperiode $2 \mathrm{~b}$ und die Bestattung hft66 aus der Belegungsperiode $2 \mathrm{c}$ gestammt haben dürften (Tabellen 7 und 2, Diagramm 25).

Die Gräber hft68.72 und hft66.70 der Belegungsphase 2 können in den Formenkreis 1 datiert werden. Die nach K. Kovács und G. Váczi veröffentlichten Radiokarbondaten von drei Gräbern datieren den Anfang der Belegung des Gräberfeldes in den Zeitraum zwischen $4350 \mathrm{cal} \mathrm{BC}(68,2 \%)$ und $4260 \mathrm{cal} \mathrm{BC}$ bzw. an das Ende von $4310 \mathrm{cal} \mathrm{BC}$ und $4210 \mathrm{cal} \mathrm{BC} .{ }^{182}$

\subsubsection{Hajdúszoboszló (Kom. Hajdú-Bihar, Bez. Hajdúszoboszló)}

Die ersten Funde von 12 Gräbern wurden hier im Jahre 1928 gefunden. ${ }^{183}$ Zwei weitere Bestattungen wurden hier 1971 entdeckt. Aus acht Gräbern wurden 23 Gefäße analysiert. Sie vertreten die Basatanya-Gruppe nach I. Bognár-Kutzián. ${ }^{184}$

Die hier ausgegrabenen 12 Gräber wurden in die Bodrogkeresztúr-Kultur gestellt. ${ }^{185}$ Die 1971 dokumentierten zwei neueren Bestattungen gehören dagegen in die Tiszapolgár-Kultur. M. Sz. Máthé war der Meinung, dass sowohl die frühkupferzeitlichen als auch die hochkupferzeitlichen Gemeinschaften diese Nekropole belegt hatten. ${ }^{186}$ Die Parallelfunde des Fußgefäßes aus dem Grab 1 sind in der Tiszapolgár-Kultur bekannt. ${ }^{187}$ In diesem Grab kamen zugleich auch ein „Milchtopf“ und eine Schüssel vor, die für die Keramik der Bodrogkeresztúr-Kultur typisch sind. ${ }^{188}$ Aus einigen Erscheinungen folgerte P. Patay darauf, dass diese Gräber am Anfang der BodrogkeresztúrKultur angelegt worden waren. ${ }^{189}$ „Das Gräberfeld dürfte aber auch einen Abschnitt der Tiszapolgár-Kultur gehabt haben“ - stellte P. Patay fest. ${ }^{190}$ In diesen Bestattungen konnten 22 Gefäßtypen von fünf Gattungen nachgewiesen werden. Der Anteil der Fußgefäßtypen und der Schüsseltypen nimmt hier je 13,64 \% (n=3-3) ein. Bechertypen sind

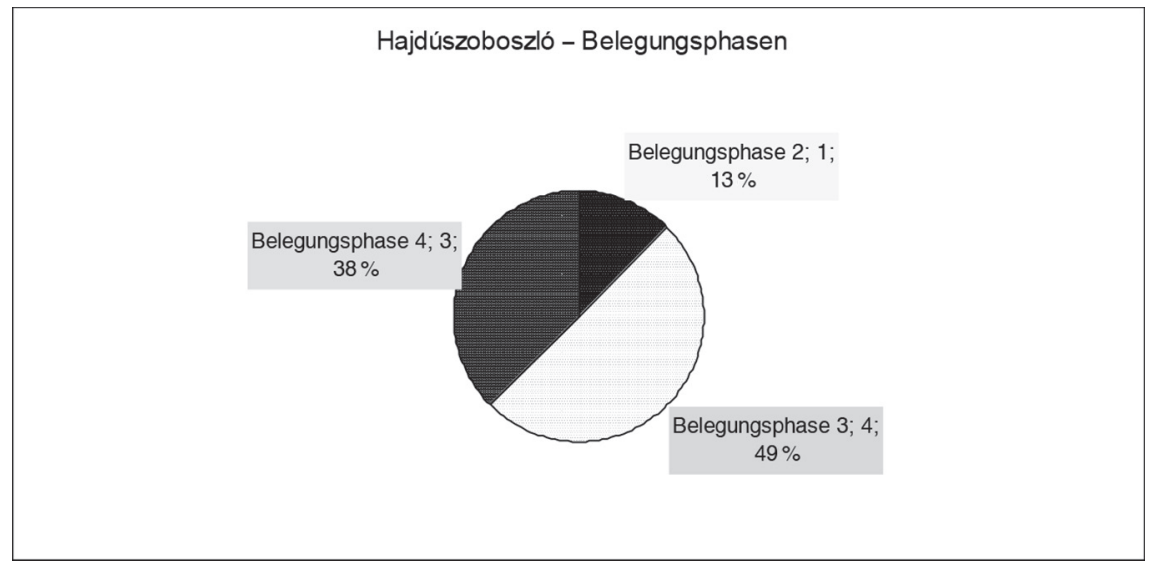

Diagramm 26. Verteilung der Gräber von Hajdúszoboszló nach Belegungsphasen

mit einem Prozentsatz von 45,45 \% $(n=10)$ belegt, während Schalentypen in 22,73 \% $(n=5)$ vorkommen. Kennzeichnend ist hier auch der Typ 3b4a3 der Sonderformen.

Zeitbestimmung gemäß Belegungsphasen: Gemäß Belegungsphasen konnte man acht Gräber in diesem Fall einordnen. Ein Grab gehört zur Belegungsphase 1, vier andere (50,0 \%) vertreten die Belegungsphase 3 und drei weitere Gräber (37,50 \%) die finale Belegungsphase (Tabelle 7, Diagramm 26).

$1972,36-37$

${ }^{182}$ KovÁcS-VÁCZI 2007; SZILÁGYI 2015, 28

${ }^{183}$ Zoltai 1928; MáthÉ 1974, 141; BognÁr-KutZián

${ }^{184}$ BOGNÁR-KuTZIÁN 1972, 173.

${ }^{185}$ Zoltai 1928; Patay 1961, 25-30.

\footnotetext{
${ }^{186}$ MÁthé 1974, 144.

${ }^{187}$ PATAY 1976, 239.

${ }^{188}$ PATAY 2008, 27.

${ }^{189}$ PATAY 1961, 30.

${ }^{190}$ PatAy 2008, 27.
}

Acta Archaeologica Academiae Scientiarum Hungaricae 67, 2016 
Tiszavalk-Tetes, nirgendwo fassbar.“204 Zur Frage der Kontinuität zwischen Periode I zu Periode II in Basatanya bemerkt M. Meisenheimer, dass „der Bruch zwischen den beiden Perioden, sowohl was die Keramikformen als auch was das Totenritual insgesamt betrifft, für ein einziges Gräberfeld ungewöhnlich klar ausgeprägt ist“ “ ${ }^{205}$

Die Benutzung des Gräberfeldes von Polgár-Basatanya datieren P. Raczky und Zs. Siklósi auf Grund der Bayesischen Analyse (bei 68,2 \%) in einen Zeitraum zwischen 4420-4280 BC und 4040-3910 BC, mit 300 bis 510 Jahren. Die Entwicklung der Tiszapolgár-Kultur wird in eine Zeit zwischen 4480-4270 BC und 4350-4170 BC datiert. Die Übergangsperiode zwischen der Tiszapolgár- und der Bodrogkeresztúr-Kultur umfasst einen Zeitraum von 4430-4040 BC bis 4060-3650 BC. Die Periode A der Bodrogkeresztúr-Kultur dürfte von 4420-4070 BC bis 4220-3840, über 580 Jahren, gedauert haben. Die Perioden A und B der Bodrogkeresztúr-Kultur wurden in einen Zeitraum zwischen 4290-4060 BC und 4160-3920 BC und die Entwicklung in Tiszalúc-Sarkadpuszta zwischen 3990-3810 BC und 3910-3700 BC datiert. ${ }^{206}$

In diesem Gräberfeld wurden 331 Gefäßtypen von 7 Gattungen festgestellt. Fußgefäßtypen erscheinen hier in 19,63\% ( $n=63)$. Der Anteil von Bechertypen beträgt 20,85 \% ( $n=69)$, der von Schultergefäßen $14,20 \%(n=47)$ und der von Schüsseln 14,80 \% ( $\mathrm{n}=49)$. Napftypen sind nur in 5,44 \% $(\mathrm{n}=18)$ vorhanden. Augenfällig ist der hohe

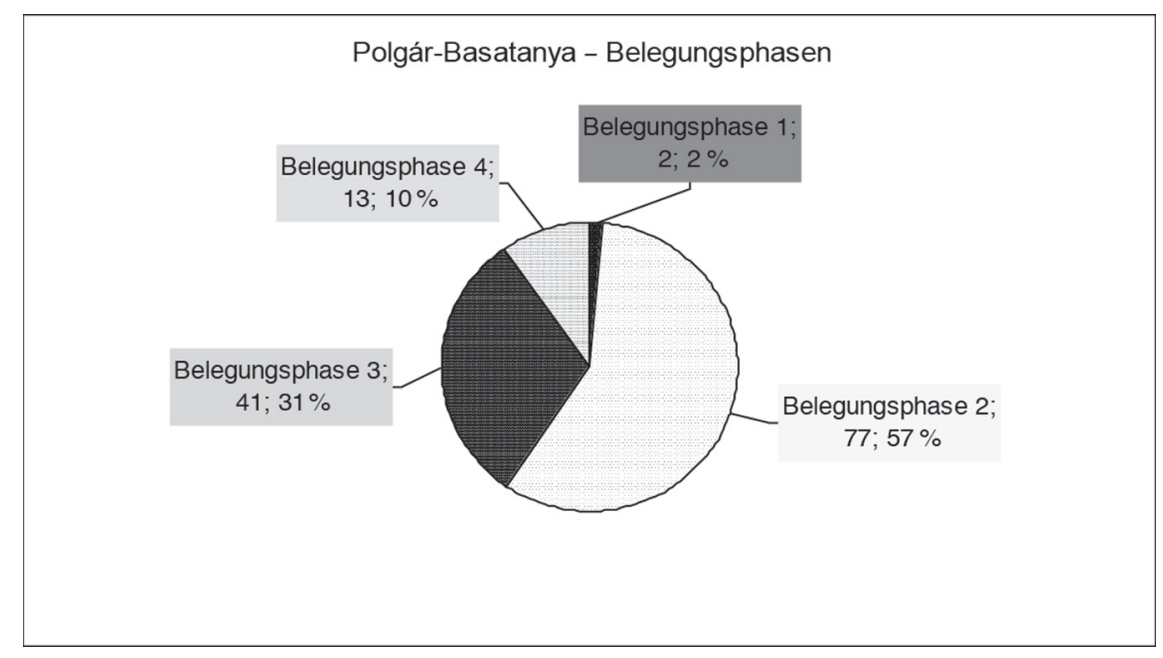

Diagramm 27. Verteilung der Gräber von Polgár-Basatanya nach Belegungsphasen

Anteil der Schalentypen: 24,47 \% ( $n=81)$. Die Sonderformen der Keramik treten nur in 1,21\% $(n=4)$ auf.

Zeitbestimmung gemäß Belegungsphasen: In diesem kupferzeitlichen Gräberfeld mit der größten Gräberanzahl konnte man die relativchronologische Lage nach Belegungsphasen insgesamt bei 133 Gräbern bestimmen. Auf Grund der Analyse kann festgestellt werden, dass die Benutzung des Gräberfeldes während des Zeitraumes der Belegungsphase 1 mit den Gräbern bt49 und bt84 (1,50\%) begann. Die Belegung setzte sich dann zur Zeit der Belegungsphase 2 mit 77 Gräbern (57,89\%) fort. Aus der Belegungsphase 3 stammen 41 Gräber $(31,83 \%)$ und auch die finale Belegungsphase wird noch durch 13 Bestattungen repräsentiert (9,77 \%) (Tabelle 7, Diagramm 27).

Im Fall von 3,09 \% der Bestattungen kann man voraussetzen, dass sie einen Übergang zwischen den Belegungsperioden 2c und 3a darstellen dürften (Grab bt75, bt99, bt155). Das Grab bt75 datiert M. Meisenheimer in ihre Übergangsperiode. Es befindet sich an der Grenze der Tiszapolgár- und der Bodrogkeresztúr-Bereiche der Nekropole. Die Gräber der Belegungsperiode $3 \boldsymbol{a}$ treten in 8,25 \% $(\mathrm{n}=8)$ der untersuchten Fälle auf (Grab bt71, bt85, bt89, bt95, bt118, bt121, bt140, bt-I). Diese Bestattungen der Bodrogkeresztúr-Kultur sind ebenfalls für den mittleren Teil des Gräberfeldes typisch; sie bilden zugleich keine dichtere Grabansammlung untereinander. Das Grab bt71 liegt genau an der Grenze der Tiszapolgár- und der Bodrogkeresztúr-Bereiche bei Bestattungen der Belegungsperioden 2a und 2c. In die Belegungsperiode $3 \boldsymbol{b}$ datieren $11,34 \%(\mathrm{n}=11)$ der Bestattungsobjekte der Bodrogkeresztúr-Kultur (Grab bt7, bt15, bt41, bt87, bt93, bt97, bt120, bt123, bt131, bt-A, bt-C). Auch sie verteilen sich einerseits an der Grenze der Bereiche der beiden Kulturen, andererseits im mittleren Teil des Gräberfeldes nicht

${ }^{205}$ MEISENHEIMER 1989, 54.

${ }^{206}$ RACZKY-SiKLÓSI 2013, Tab. 2.

Acta Archaeologica Academiae Scientiarum Hungaricae 67, 2016 


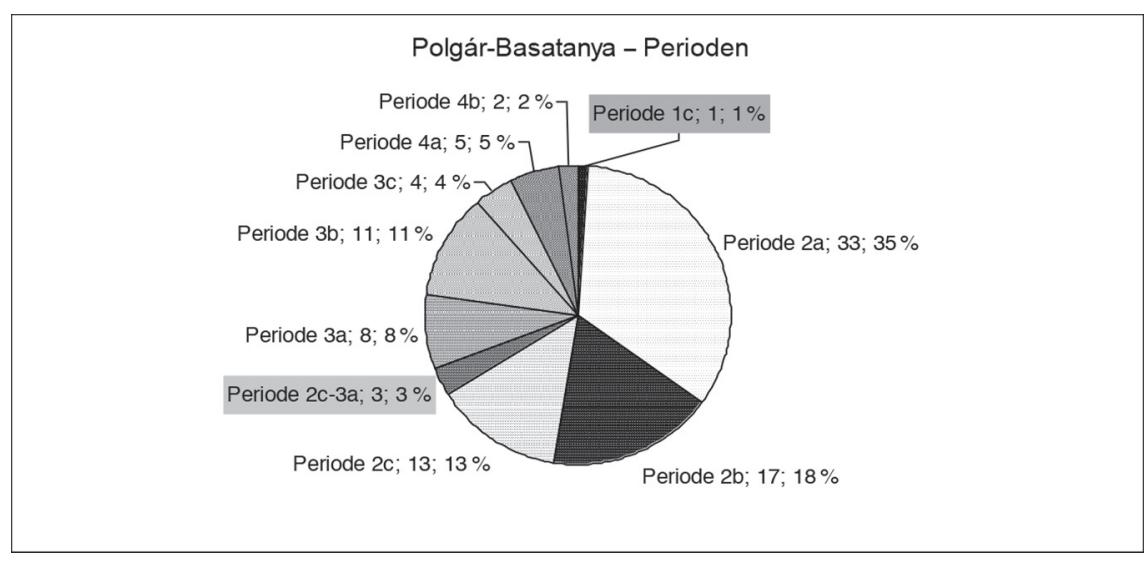

Diagramm 28. Verteilung der Gräber von Polgár-Basatanya nach Belegungsperioden

weit voneinander. Der Anteil der Befunde der Belegungsperiode $3 \boldsymbol{c}$ beträgt 4,12 \% $(n=4)(G r a b$ bt94, bt98, bt117, bt146) und auch sie sind für die Grenze und das mittlere Gebiet der Nekropole typsich. Das Grab bt41 dieser Periode kommt dagegen auf dem nördlichen Teil, neben Tiszapolgár-Bestattungen vor. Gräber der Belegungsperiode $4 \boldsymbol{a}$ erscheinen in 5,15\% ( $n=5)$ (Grab bt1, bt105, bt116, bt129, bt137). Die Gräber bt126 und bt142 der Belegungsperiode $4 \boldsymbol{b}(2,06 \%)$ dürften als die jüngsten Befunde des kupferzeitlichen Friedhofs von Polgár-Basatanya behandelt werden. Drei von diesen liegen im mittleren Bereich, das Grab bt105 und das Grab bt116 sogar einander nahe, wie die bt127 und bt137 in der südlichsten Gruppierung des Gräberfeldes.

Die Gräber bt129, bt137, bt133 und bt142 der Perioden 4a und 4b wurden mit Gefäßen ausgestattet, die die typologischen Merkmale der Hunyadihalom-Kultur aufweisen.

Die Verteilung der kupferzeitlichen Gräber von Polgár-Basatanya auf dem Gräberfeldplan studierend kann man annehmen, dass die Benutzung dieses Bestattungsplatzes in der Belegungsphase 1 begonnen haben dürfte. Die Bestattungen der Belegungsphase 1 des Gräberfeldes konnten gemäß Belegungsperioden nicht datiert werden. Das Grab bt84 wurde nach M. Meisenheimer zeitlich in ihre Periode II gesetzt und 14C-Daten setzen diese Bestattung zugleich in das 5. Jahrtausend. Ein wichtiges Phänomen ist es weiterhin, dass dieses Grab an der Peripherie der nordwestlichen Gräbergruppierung, mit Bestattungen der Belegungsperiode 2a, liegt und die Keramik dieses Befundes einen spätneolithischen Charakter aufweist.

Die Ansammlung der Gräber der Belegungsphase 2 kann sowohl kulturell als auch gebietlich in zwei Unterphasen geteilt werden. Die Gräber der Unterphase 2a verteilen sich auf dem Nordteil des Gräberfeldes und datieren in den Formenkreis 1. Die Bestattungen der Unterphase $2 b$ konzentrieren sich dagegen in der Mitte des südlichen Teiles und vertreten schon den Formenkreis 2.

Die Gräber der Belegungsphase 3 ergeben zwei größere und zusammenhängende Grabreihen in der Südhälfte der Nekropole. Die Bestattungen bt37 und bt 41 befinden sich dagegen inmitten der Nordhälfte, im Kreis von Bestattungen der Belegungsphase 2a. Vier weitere Gräber der Belegungsphase 3 charakterisieren die südliche Gräbergruppe. Alle Befunde der diskutierten Belegungsphase wurden von M. Meisenheimer in ihre Periode II gesetzt.

Das Grab 74 der Belegungsphase 4 befindet sich an der nördlichen Peripherie der Südhälfte des Gräberfeldes. Die Gräber dieser finalen Belegungsphase bilden untereinander eine lockere Ansammlung in der südlichen Gruppierung des Gräberfeldes. Auch die Befunde der Belegungsphase 4 wurden von M. Meisenheimer ihrer Periode II zugeordnet. ${ }^{207}$

Auf dem nördlichen Teil des Gräberfeldes kann man mit Recht eine ununterbrochene Belegung zur Zeit des Formenkreises 1 annehmen. Es handelt sich dabei um die Belegungsperioden 2a, 2b und 2c. Die typologischen Merkmale der Keramiken aus den Gräbern der Belegungsperiode $2 b$ werfen einige Fragen auf. Die Befunde bt51, bt21, bt46, bt24 und bt5 bestehen noch aus Gefäßen des Formenkreises 1. Im Fall der keramischen Befunde der Bestattungen bt27, bt55, bt54, bt66, bt28, bt147, bt32 und bt40 können nunmehr typologische Merkmale des Formenkreises 2 entdeckt werden. Die Bestattung bt38 dürfte Keramiken sowohl des Formenkreises 1 als auch des Formenkreises 2 besitzen, während die Gräber bt111 und bt109 der diskutierten Belegungsperiode schon den For-

${ }^{207}$ MEISENHEIMER 1989, 54. 
menkreis 2 repräsentiert haben dürften.

Die von P. Raczky und Zs. Siklósi veröffentlichten Radiokarbondaten von Polgár-Basatanya können unsere Ergebnisse in Bezug auf die Bestimmungen der Belegungsperioden der Gräberfelder des Polgár-Komplexes bekräftigen. ${ }^{208}$

Die verschiedensten und merkwürdigsten Situationen der chronologischen Reihenfolge der Gräber können auf der mittleren Fläche der Nekropole beobachtet werden. P. Patay modifizierte bzw. änderte die Bestimmungen gemäß drei Perioden (Periode I, Übergangszeit, Periode II) von I. Bognár-Kutzián nach seinen Beobachtungen und stellte diese Bestattungen in fünf zeitliche Einheiten ein (Periode I, Periode I - möglicherweise schon Übergangszeit, Übergangszeit, Übergangszeit - möglicherweise schon Periode II, Periode II). ${ }^{209}$

Es ist notwendig, drei Phänomene in Zusammenhang mit den Ergebnissen der Seriation zu erwähnen.

1. Wie schon darauf hingedeutet, vertreten die Gräber der Periode $2 \mathrm{~b}$ einerseits den Formenkreis 1, andererseits den Formenkreis 2. Die Bestattungen mit solchen Keramiken erscheinen territorial voneinander getrennt.

2. Die Gräber bt26, bt33 und bt65 im nördlichen Tiszapolgár-Bereich des Gräberfeldes wurden durch die Seriation in die Belegungsphase 2c datiert. Sie vertreten zugleich den Formenkreis 1 mit ihrer Keramik.

3. Im mittleren Bereich des Gräberfeldes von Polgár-Basatanya treten Gräber von drei aufeinanderfolgenden Zeitabschnitten vermischt auf. Für dieses Phänomen erläutert P. Patay drei Optionen. Davon erwähnen wir hier die dritte: Ist es möglich, dass diese mit Funden unterschiedlichen Charakters ausgestatteten Gräber gleichzeitig sind und die hier begrabene Gemeinschaft sich aus drei verschiedenen Schichten zusammensetzte? Dies dürfte darauf hinweisen, dass die frühesten Gemeinschaften der Bodrogkeresztúr-Kultur völlig desselben Alters gewesen wären wie die letzten Dörfer - stellte P. Patay fest. ${ }^{210}$ Dafür gibt es aber kein Beispiel in den anderen kupferzeitlichen Gräberfeldern und die Anerkennung der Existenz der Übergangsphase zwischen der Tiszapolgár- und der Bodrogkeresztúr-Kultur widerspricht dieser Hypothese. P. Patay hält es für möglich, dass eine Pause im Begräbnis nach der Bestattung von sechs Personen folgte, weil sich die Gräber der Bodrogkeresztúr-Kultur nicht zeigen, um sich denen der Übergangsphase anzuschließen. Diese wurden jedoch unvermeidlich in Betracht gezogen, da der Platz der neueren Gräber vermieden genug zugeteilt wurde - setzte P. Patay fort. ${ }^{211}$

\subsubsection{Polgár-Bacsókert (Kom. Hajdú-Bihar, Bez. Hajdúnánás)}

Die in die Analyse einbezogenen 17 Keramiken stammen aus 9 Gräbern. ${ }^{212}$ P. Patay bemerkt, dass „die Keramik von hier weist nicht viel Abwechslung auf und unter ihnen die wohlbekannten Typen der BodrogkeresztúrKultur vertreten sind, die auch in anderen Gräberfeldern die üblichen Grabbeigaben bilden“ ${ }^{213}$ Er datiert diese

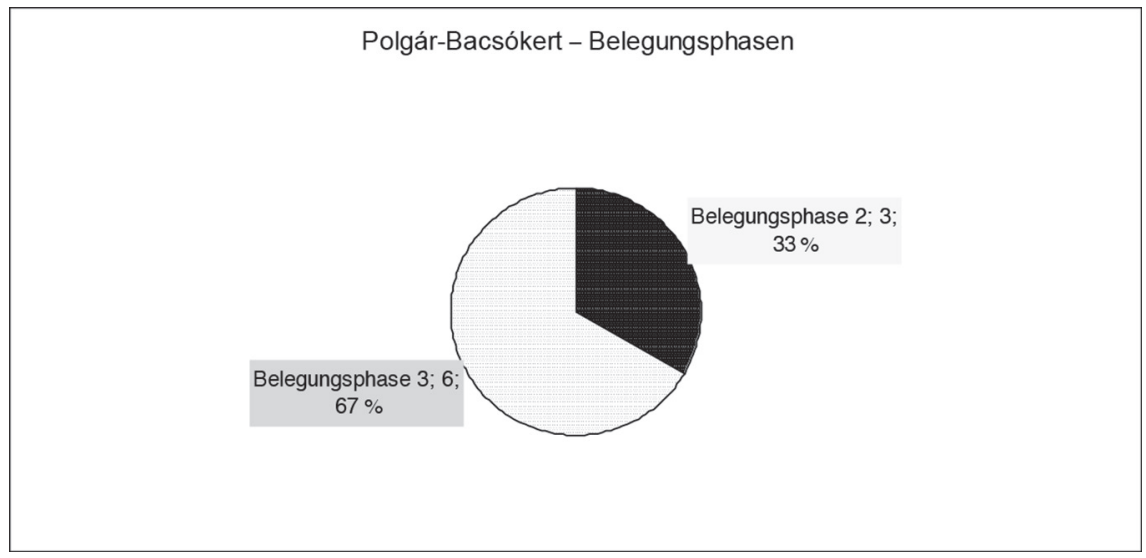

Diagramm 29. Verteilung der Gräber von Polgár-Bacsókert nach Belegungsphasen

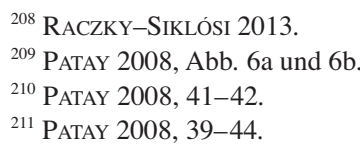

212 PATAY 1958.

${ }^{213}$ Ebenda, 141-146.

${ }^{214}$ HellebrandT-Patay 1977, 50. 
Gräber in die entwickelte Bodrogkeresztúr-Kultur. ${ }^{214}$ Die hier untersuchten Grabgefäße vertreten 14 Typen, aber von drei Gattungen. Aus chronologischer Sicht ist es wichtig, dass hier auch Fußgefäßtypen in 14,29\% $(n=2)$ nachgewiesen sind. Je 42,86 \% ( $n=6-6$ ) der Typen vertritt die Gattung der Becher und Schalen.

Zeitbestimmung gemäß Belegungsphasen: Diese Gräberansammlung ergibt neun Bestattungen, die nach Belegungsphasen eingeordnet werden können. Drei von ihnen (33,33 \%) stammen aus der Belegungsphase 2, während sechs andere (66,67 \%) zur Zeit der Belegungsphase 3 angelegt wurden (Tabelle 7, Diagramm 29).

Zeitbestimmung gemäß Belegungsperioden: Mittels Seriation konnte die relativchronologische Lage nur im Fall von drei Gräbern bestimmt werden. Zwei Befunde (bcs11, bcs12) vertreten die Belegungsperiode 3a $(66,67 \%)$ und das Grab bcs9 dürfte der Belegungsperiode 3c (33,33\%) angehört haben (Tabelle 2).

Das Grab bcs 13 der Belegungsphase 2 dürfte auf Grund des typologischen Charakters der Keramik dem Übergang zwischen dem Formenkreis 1 und dem Formenkreis 2 zugeordnet werden. Das Grab bcs8 der Belegungsphase 2 und die Gräber bcs11, bcs 12 und bcs9 der Belegungsphase 3 repräsentieren dagegen schon den Formenkreis 2. Die Bestattung bcs4 - mit einem Hohlfuß eines Fußgefäßes - kann man nur mit Vorbehalt in den Formenkreis 1 oder den Übergang datieren.

\subsubsection{Kiskörös-Seregélyes (Kom. Bács-Kiskun, Bez. Kiskörös)}

Im Jahre 1930 wurden hier zwei Gräber gefunden. An den ersten Ausgrabungen entdeckte J. Csalog 11 und dann weitere 15 Bestattungsobjekte. Ein Grab kam danach zum Vorschein. Die Gräberanzahl beträgt somit 29. J. Csalog veröffentlichte nur die Funde und Befunde der ersten Ausgrabung. ${ }^{215}$ Er bestätigte, dass die Grabkeramik von Kiskőrös wenige neue Typen der ungarischen Kupferzeit ergab. Der zweihenkelige Milchtopf wurde hier als Leitform bestimmt, ${ }^{216}$ die Fußgefäße fehlen gleichzeitig. ${ }^{217}$ Aus diesem Gräberfeld konnten wir 18 Gefäße aus neun Gräbern in die Merkmalanalyse einbeziehen. 17 Gefäßtypen von 4 Gattungen sind aus diesen Gräbern bekannt. Mehr als die Hälfte, 52,94 \% ( $n=9)$, vertreten die Becherformen. Die Schüsseltypen sind in 17,65 \% $(n=3)$ und

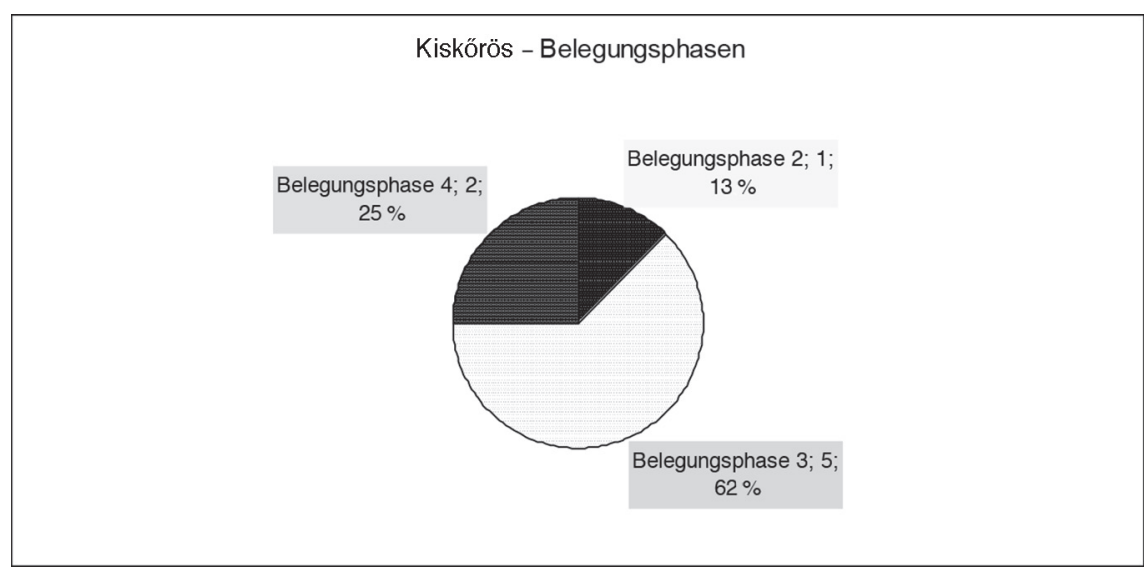

Diagramm 30. Verteilung der Gräber von Kiskőrös nach Belegungsphasen

die Schalentypen in $23,53 \%(n=4)$ belegt.

Zeitbestimmung gemäß Belegungsphasen: In dieser Gräbergruppe sind 8 Gräber vorhanden, die nach Belegungsphasen datiert werden können. Eine Bestattung (12,50 \%) stammt aus der Belegungsphase 2. Fünf andere Gräber (62,50 \%) vertreten gleichzeitig die Belegungsphase 3 und zwei weitere $(25,0 \%)$ die Belegungsphase 4 (Tabelle 7, Diagramm 30).

Zeitbestimmung gemäß Belegungsperioden: Mittels Seriation konnten nur drei Bestattungen nach Perioden eingeordnet werden. Die Gräber kk18, kk17 und kk15 dürften zeitlich den Belegungsperioden 3a, 3b und 3c entsprechen (Tabelle 2).

${ }^{215}$ Csalogovits 1931; Patay 1961, 34-35.

${ }^{217}$ PATAY 1961, 37.

${ }^{216}$ CSALOGOVITS 1931, 103-107. 
Das Grab kk16 der Belegungsphase 2, die Gräber kk18, kk17, kk15, kk21 und kk-c der Belegungsphase 3 sowie alle anderen Bestattungen der Belegungsphase 4 können dem Formenkreis 2 zugeordnet werden.

\subsubsection{Tiszabábolna-Szilpuszta (Kom. Borsod-Abaúj-Zemplén, Bez. Mezökövesd)}

Hier wurde eine Rettungsgrabung im Jahre 1976 vorgenommen. ${ }^{218}$ Die 27 untersuchten Keramiken sind für 7 Bestattungen typisch. Die Mehrheit der hier entdeckten Bestattungen (Grab tb1, tb2, tb4, tb6) wurde zeitlich in die frühe Tiszapolgár-Kultur zugewiesen, während andere (z. B. Grab tb3 und tb5) aus der entwickelten Bodrogkeresztúr-Kultur gestammt haben dürften. ${ }^{219}$ In diesem Gräberfeld stellten wir 25 Typen von fünf Gattungen der Grabkeramik fest. Der Anteil der Fußgefäßtypen ist verhältnismäßig hoch, 28,0 \% (n=7). Mehr als die Hälfte, $52,0 \%(\mathrm{n}=13)$, der Gefäßtypen vertritt gleichzeitig die Gattung der Becher. Schüsseln und Schalen erscheinen in je $8,0 \%(n=2-2)$ und auch der Typ 3a1e1 der Sonderformen taucht da auf.

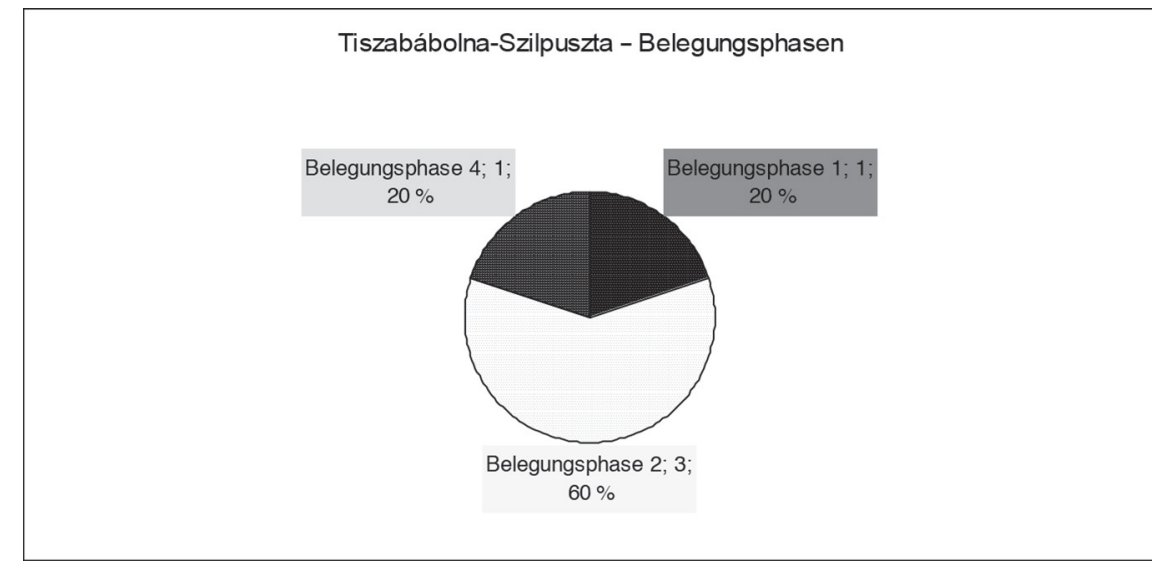

Diagramm 31. Verteilung der Gräber von Tiszabábolna-Szilpuszta nach Belegungsphasen

Zeitbestimmung gemäß Belegungsphasen: Die Benutzung dieses Bestattungsplatztes begann während der Belegungsphase 1 mit einem Grab (12,50\%). Drei andere (62,50\%) stammen aus der Belegungsphase 2 und auch die Belegungsphase 4 wird durch einen Befund (12,50 \%) vertreten (Tabelle 7, Diagramm 31).

Zeitbestimmung gemäß Belegungsperioden: Das Grab tb6 wurde in der Zeit der Belegungsperiode 1c angelegt (25,0 \%). Die Bestattungen tb1 und tb4 können in die Belegungsperiode 2a zugeordnet werden (50,0 \%), während das Grab tb3 die Belegungsperiode 2c repräsentiert haben dürfte $(25,0 \%)$ (Tabelle 2).

Das Inventar des Grabes tb6 der Belegungsphase 1 kann spätneolithische Traditionen zeigen. Die Bestattungen tb4, tb1 und tb3 der Belegungsphase 2 können in den Übergang zwischen dem Formenkreis 1 und dem Formenkreis 2 eingeordnet werden. Die Belegungsphase 3 ist hier nicht vertreten, während das Grab tb2 der Belegungsphase 4 den Formenkreis 2 repräsentiert. Das Gefäß tb7.1 aus dem Grab tb7 konnte mit den angewendeten analytischen Methoden zeitlich nicht eingeordnet werden. Form und Verzierung dieses Exemplars gelten im keramischen Bestand der untersuchten kupferzeitlichen Kulturen als Unikum.

\subsubsection{Tiszakeszi-Fáy-kert (Kom. Borsod-Abaúj-Zemplén, Bez. Mezöcsát)}

F. Tompa stellte in Tiszakeszi drei kupferzeitiche Fundorte fest und an der Fundstelle Fáy-kert grub er insgesamt 23 Bestattungen aus. Die Funde und Befunde veröffentlichte P. Patay. ${ }^{220}$ Er beobachtete, dass es auch Exemplare im keramischen Bestand des Gräberfeldes vorhanden sind, die die typologischen Merkmale der Früh-

${ }^{218}$ HeLlebrandT-PATAY 1977, 43-47.

${ }^{219}$ HellebrandT-PATAy 1977, 48-49.
${ }^{220}$ PATAY 1957.

Acta Archaeologica Academiae Scientiarum Hungaricae 67, 2016 
kupferzeit aufweisen. Von hier haben wir 27 Keramiken aus 16 Gräbern aufgenommen. I. Bognár-Kutzián datiert sie in die Basatanya-Gruppe. ${ }^{221}$ Im Grab befinden sich zwei Schüsseln, die in der Hochkupferzeit ungewöhnlich waren. Ihre Analogien sind zugleich von der Mitte des mittleren Teiles der Nekropole von Magyarhomorog-Kónyadomb bekannt. ${ }^{222} \mathrm{M}$. Meisenheimer konnte auch hier nur die frühe Phase der Periode II gemäß ihrer Datierung fassen. $^{223} 22$ Gefäßtypen sind hier bekannt. Fußgefäßtypen fehlen auch in diesem Fall. Fast die Hälfte, 45,45 \% $(\mathrm{n}=10)$, der Typen vertritt die Gattung der Becher, 27,27 \% $(\mathrm{n}=6)$ die Gattung der Schüsseln, $18,18 \%(\mathrm{n}=4)$ die der Schalen und nur 9,09\% $(\mathrm{n}=2)$ die der Schultergefäße.

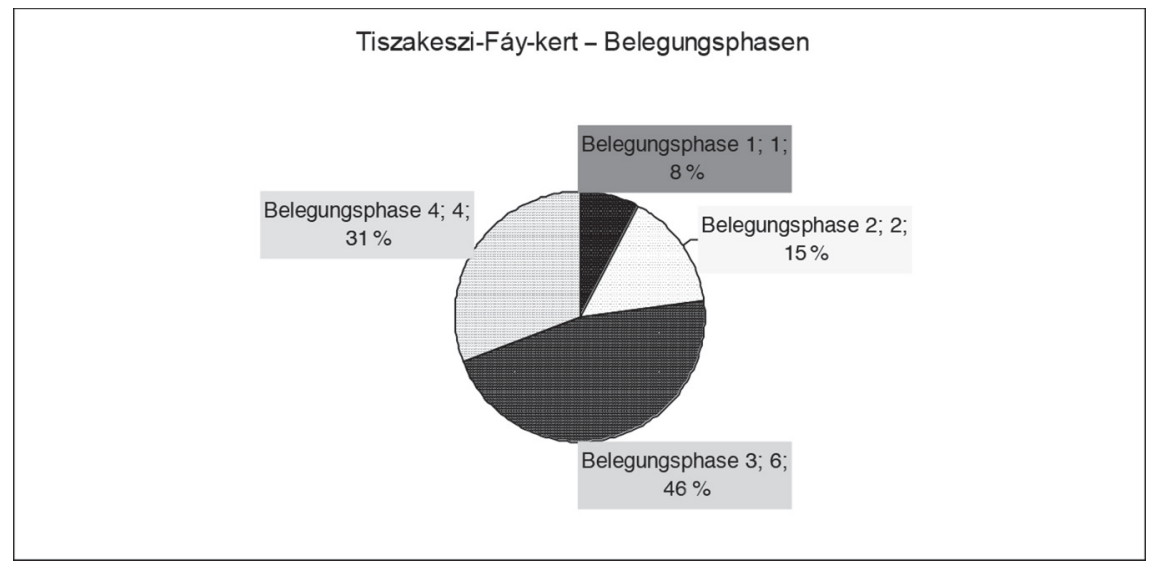

Diagramm 32. Verteilung der Gräber von Tiszakeszi-Fáy-kert nach Belegungsphasen

Zeitbestimmung gemäß Belegungsphasen: Die relativchronologische Stellung durch Belegungsphasen ist in diesem Fall bei 13 Gräbern bestimmt. Nur ein Grab (7,69\%) datiert in die Belegungsphase 1 und zwei andere $(15,38 \%)$ gehören der Belegungsphase 2 an. Es gibt zugleich sechs Befunde $(46,15 \%)$ aus der Belegungsphase 3 und vier (30,77\%) der Belegungsphase 4 (Tabelle 7, Diagramm 32).

Zeitbestimmung gemäß Belegungsperioden: Die chronologische Lage nach Perioden ist nur bei sechs Bestattungen bekannt. Die Gräber tk9 und tk22 sind mit der Belegungsperiode 2b verbunden (33,33 \%). Das Grab tk1 gehört der Belegungsperiode 3a an (16,67 \%). Die Befunde tk15 und tk18 wurden dann zur Zeit der Belegungsperiode $3 \mathrm{~b}$ angelegt $(33,33 \%)$ und das Grab tk11 dürfte aus der Belegungsperiode $4 \mathrm{a}$ gestammt haben $(16,67 \%)$ (Tabelle 2).

Das Grab tk10 der Belegungsphase 1 dürfte entweder den Übergang oder den Formenkreis 2 vertreten. Ein Gefäß des Grabes tk22 der Belegungsphase 2, etwa in der Mitte des Gräberfeldes, wurde mit Scheibenhenkeln verziert. Die Bestattung tk9 bzw. die anderen Gräber der Belegungsphase 3 und der Belegungsphase 4 kann man eindeutig in den Formenkreis 2 datieren.

\subsubsection{Tiszavalk-Kenderföldek (Kom. Borsod-Abaúj-Zemplén, Bez. Mezökövesd)}

Auf diesem Fundort wurde die erste Ausgrabung im Jahre 1954 durchgeführt, aber die überwiegende Mehrheit der kupferzeitlichen Gräber kam im Laufe systematischer Ausgrabungen zum Vorschein. ${ }^{224}$ Dieses Gräberfeld dürfte ursprünglich aus 80 bis 100 Bestattungen bestanden haben. 57 von ihnen wurden ausgegraben, ${ }^{225}$ „womit der freilegbare Teil des Gräberfeldes erschöpft war“. ${ }^{226}$ Die ursprüngliche Anzahl der Gräber schätzte P. Patay hier unbedingt auf über 100. Davon konnte man nur 54 Bestattungen retten und dokumentieren. ${ }^{227} 138$

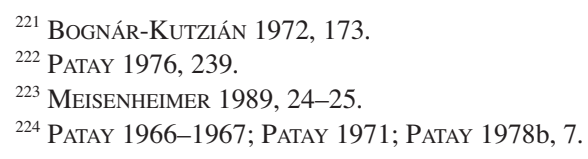

${ }^{225}$ Hellebrandt-Patay 1977, 49; Patay 1978b, 8.

${ }^{226}$ PATAY $1978 \mathrm{~b}, 8$.

${ }^{227}$ Ebenda, 54. 
Exemplare der Grabkeramik wurden hier untersucht, die in 48 Bestattungen zum Vorschein kamen. Die ersten Bestattungen dürften aus der Blütezeit der Bodrogkeresztúr-Kultur gestammt haben, die Mehrheit kann dagegen an das Ende der Phase B datiert werden. ${ }^{228}$ Die keramischen Funde der ausgegrabenen Bestattungen zeigen ein verhältnismäßig einheitliches Bild. P. Patay erklärte es damit, dass dieses Gräberfeld zur Zeit der Phase B der Bodrogkeresztúr-Kultur benutzt war. ${ }^{229}$ Als die jüngsten Bestattungsobjekte erwähnt er Befunde auch hier, „wo typologische Elemente der Hunyadihalom-Kultur schon in einer erheblichen Anzahl erscheinen" (Grab tf39, tf43, tf44, tf51). ${ }^{230}$ Die Zahl der hier festgestellten Gefäßtypen ist 94 von fünf Gattungen. Ein beachtenswertes Phänomen ist es, dass Fußgefäßtypen in diesem Gräberfeld durch 9,57 \% $(n=9)$ vertreten sind. Fast die Hälfte, 48,94 \% $(\mathrm{n}=46)$, der hier vorhandenen Typen gehört zugleich der Gattung der Becher zu. Der Anteil der Schalentypen nimmt 24,47\% $(n=23)$ und der von Schüsseltypen 14,89\% $(n=14)$ ein. Man findet hier auch noch zwei Typen von Schultergefäßen.

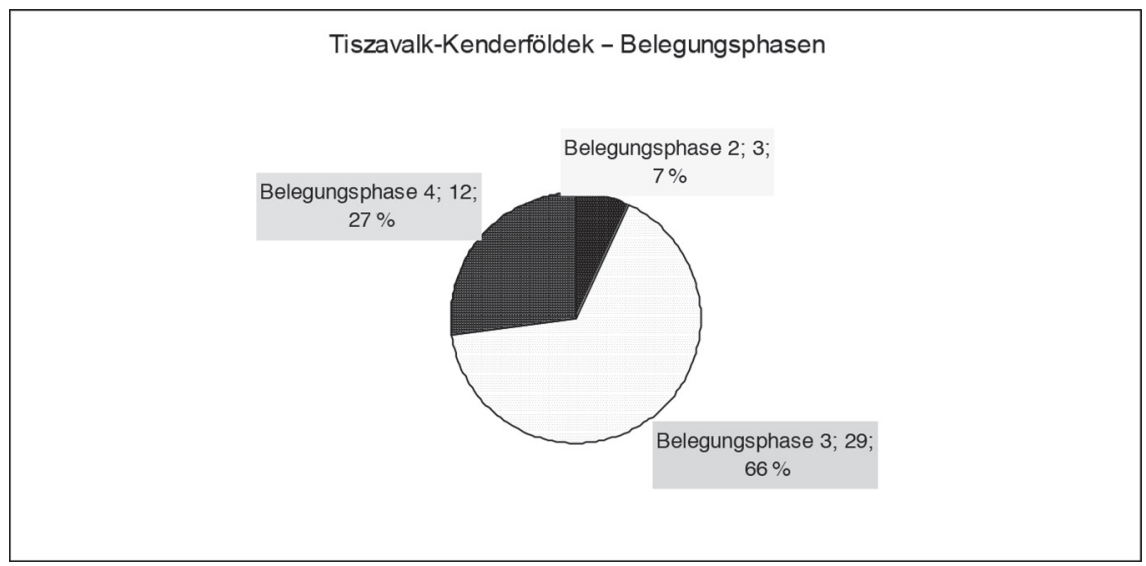

Diagramm 33. Verteilung der Gräber von Tiszavalk-Kenderföldek nach Belegungsphasen

Zeitbestimmung gemäß Belegungsphasen: In der Entwicklung des Gräberfeldes von Tiszavalk-Kenderföldek können drei Belegungsphasen im Fall von 44 Gräbern bestimmt werden. Die Belegungsphase 2 wird durch 3 Bestattungen (6,82 \%) vertreten. Die Mehrheit, 29 Bestattungen (65,91 \%), stammt dagegen aus der Belegungsphase 3. 12 Befunde (27,27 \%) datieren zugleich in die finale Belegungsphase (Tabelle 7, Diagramm 33).

Zeitbestimmung gemäß Belegungsperioden: Die relative chronologische Lage nach Perioden wurde hier bei 32 Bestattungen festgestellt. Auf die Ergebnisse der Seriation basierend ist es verifizierbar, dass die Belegung des Gräberfeldes zur Zeit der Belegungsperiode $2 \mathrm{c}$ mit den Befunden tf 22 und tf 45 begann $(6,25 \%)$. Die Benutzung des Bestattungsplatzes setzte sich dann mit drei Gräbern (tf27, tf38, tf41) der Belegungsperiode 3a $(9,38 \%$ ) und ebenso mit drei Bestattungen (tf3, tf4, tf43) der Belegungsperiode $3 \mathrm{~b}(9,38 \%$ ) fort. Fast die Hälfte (14) der seriierten Gräber der Fundstelle (Grab tf2, tf 12, tf21, tf26, tf28, tf31, tf33, tf40, tf42, tf46, tf48, tf50, tf51, tf55) stammt zugleich aus der Belegungsperiode 3c (43,75\%). Fünf Befunde (Grab tf7, tf13, tf18, tf25, tf52) können zeitlich in die Belegungsperiode 4a (15,63\%), zwei andere (Grab tf 16 , tf53) in die Belegungsperiode $4 \mathrm{~b}(6,25 \%)$ und zum Schluss drei Bestattungen (Grab tf 19, tf 44, tf54) in die Belegungsperiode $4 \mathrm{c}(9,38 \%)$ gesetzt werden (Tabelle 2).

Die Benutzung des diskutierten Gräberfeldes beginnt zur Zeit der Belegungsperiode 2c (Grab tf45 und tf22) und setzte sich während der darauffolgenden Perioden ununterbrochen fort. Alle Bestattungsobjekte der Belegungsphase 3 und der Belegungsphase 4 stammen also aus der Zeit des Formenkreises 2. Festgestellt werden kann weiterhin, dass die für die Hunyadihalom-Keramik kennzeichnenden Elemente nicht nur das als jüngste definierte Grab, sondern auch diejenige der letzten Periode der Belegungsphase 3 charakterisieren.

${ }^{228}$ HellebrandT-Patay 1977, 49; PAtay 2008, 32.

${ }^{229}$ PATAY 2008, 32.
${ }^{230}$ PATAY 1978b, 54; PATAY 2008, 39. 


\subsubsection{Tiszavalk-Tetes (Kom. Borsod-Abaúj-Zemplén, Bez. Mezökövesd)}

P. Patay grub hier 25 kupferzeitliche Gräber in den Jahren 1973 und 1975 aus. ${ }^{231}$ Das Gräberfeld war nach seiner Meinung in der Tiszapolgár-Bodrogkeresztúr-Übergangsphase benutzt. ${ }^{232}$ Die Funde einiger Bestattungen bewahren noch die Traditionen der Tiszapolgár-Kultur, es treten aber schon auch die charakteristischen Gefäßformen der Hochkupferzeit auf. ${ }^{233}$ Hinsichtlich der inneren Chronologie des Gräberfeldes ist es wichtig, dass 12 „Schalen mit zwei großen Henkeln“ in 8 Gräbern zum Vorschein kamen. ${ }^{234}$ M. Meisenheimer nimmt hier einen Bruch in der keramischen Entwicklung an und das Gräberfeld dürfte zu dem Kulturwechsel Tiszapolgár-Bodrogkeresztúr gehören. ${ }^{235}$ Von diesen Bestattungsobjekten konnten wir 113 Keramikgefäße in die Analyse aufnehmen.

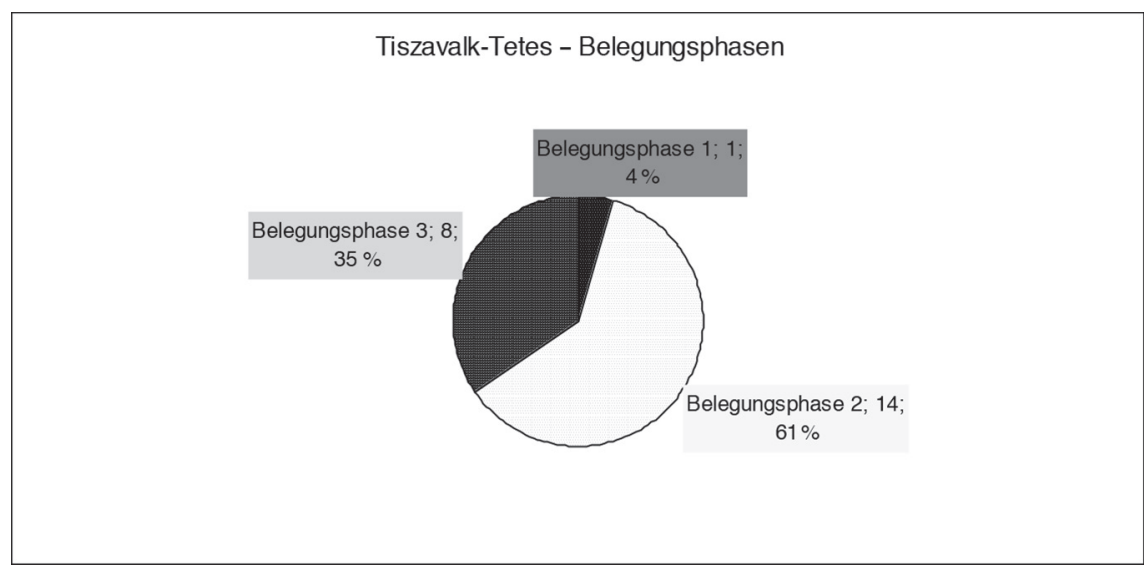

Diagramm 34. Verteilung der Gräber von Tiszavalk-Tetes nach Belegungsphasen

80 Typen der Grabkeramik sogar von acht Gattungen wurden in diesem Gräberfeld nachgewiesen. Die Proportion der Fußgefäßvarianten nimmt hier 22,50 \% $(\mathrm{n}=18)$ ein. Becher- und Schalentypen kommen dagegen in viel größerem Anteil, in 23,75 \% $(\mathrm{n}=19)$ und 26,25 \% $(\mathrm{n}=21)$, vor. Der Anteil der Schüsseltypen ist $11,25 \%(\mathrm{n}=9)$ und der der Näpfe und Schultergefäße nur mehr 7,50 \% $(n=6)$ bzw. 5,0 \% $(n=4)$. Ein Typ der Butmir-Gefäße und zwei andere der Sonderformen sind hier kennzeichnend.

Zeitbestimmung gemäß Belegungsphasen: In diesem Gräberfeld der Tiszapolgár-Kultur können drei Belegungsphasen bei 23 Gräbern getrennt werden. Nur ein Grab (4,35\%) vertritt die erste Belegungsphase, 14 andere $(60,87 \%)$ vertreten dagegen die Belegungsphase 2. Acht Bestattungen $(34,78 \%)$ stammen zugleich aus der Belegungsphase 3 (Tabelle 7, Diagramm 34).

Zeitbestimmung gemäß Belegungsperioden: Gemäß Perioden wurden 22 Gräber zeitlich geordnet. Die Ergebnisse der Seriation können darauf hinweisen, dass die Benutzung dieses Gräberfeldes zur Zeit der Belegungsperiode 1c mit dem Grab tvt12 anfing (4,55\%). Auch aus der Belegungsperiode 2a ist nur das Grab tvt1 bekannt $(4,55 \%)$, während drei andere (Grab tvt8, tvt16 und tvt25) die Belegungsperiode 2b charakterisieren (13,64\%). Der Belegungsperiode 2c können neun Bestattungen (40,91\%) zugeordnet werden (Grab tvt2, tvt7, tvt9, tvt10, tvt11, tvt13, tvt17, tvt21, tvt23). Fünf weitere Gräber (Grab tvt14, tvt15, tvt20, tvt22, tvt24) können der Belegungsperiode $3 \mathrm{a}(22,73 \%)$ und drei (Grab tvt3, tvt18, tvt19) der Belegungsperiode $3 \mathrm{~b}(13,64 \%)$ zugeordnet werden (Tabelle 2).

Das Grab tvt12 kann den Übergang vertreten. Anhand des typologischen Charakters der Befunde tvt16, tvt25, tvt2, tvt9, tvt21, tvt23, tvt7, tvt11, tvt10 und tvt17 der Belegungsperiode 2 könnten diese Bestattungen genauso dem Übergang, eventuell dem Formenkreis 2 näher zugeordnet werden. Die übrigen Gräber der Belegungsphase 3 stellen schon den Formenkreis 2 dar. Die Form des Fußgefäßes tvt 2.5 kann für eine der typologischen Prämissen der Hunyadihalom-Keramik gehalten werden.

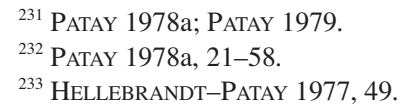

\author{
${ }^{234}$ PATAY 2008, 33. \\ ${ }^{235}$ MeISENHEIMER 1989, 55.
}




\subsection{Verbreitungsregion 4 - Oberlauf der Theiß, Bodrog-, Kraszna- und Szamosgegend}

Die Fundorte von Bodrogkeresztúr und Sárazsadány liegen entlang des Bodrog-Flusses. Am Oberlauf der Theiß wurden die Gräberfelder von Fényeslitke und Kisvárda angesetzt, während das von Vásárosnamény befindet sich südlich von den anderen Nekropolen bei der Kraszna-Mündung und das Gräberfeld von Panyola-Vásármeződomb am rechten Ufer der Szamos.

\subsubsection{Fényeslitke (Kom. Szabolcs-Szatmár-Bereg, Bez. Kisvárda)}

Im Jahre 1949 legte J. Korek hier acht Gräber frei. In den Jahren 1949 und 1951 bzw. 1954 setzten P. Patay und Gy. Nováki die Ausgrabungen fort. Insgesamt 68 Gräber sind hier bekannt: Es dürfte dabei um die vollständige Freilegung des Gräberfeldes gehandelt haben. ${ }^{236}$ Hier stellte es sich heraus, dass die kupferzeitlichen Nekropolen aus wesentlich mehreren Gräbern bestehen als bis dahin bekannt. Auf Grund des Grabungsplans kann auch die ursprüngliche Ausdehnung des Gräberfeldes bestimmt werden. Periodenunterschiede wurden hier nicht festgestellt: P. Patay bestätigt, dass die Benutzung des Gräberfeldes in der Zeit der Herausbildung der Bodrogkeresztúr-Kultur begann. ${ }^{237}$ 121 Keramiken aus 55 Bestattungen konnten von hier in die Analyse einbezogen werden. Typisch sind die große Zahl von Kupfergeräten und das Fehlen von Fußgefäßen. ${ }^{238}$ Im Fundmaterial des Gräberfeldes konnte P. Patay keine chronologischen Unterschiede beobachten. Befunde der Tiszapolgár-Kultur sind hier nicht belegt. Den Beginn der Benutzung des Gräberfeldes datiert P. Patay an das Ende der Bodrogkeresztúr-Kultur. ${ }^{239}$ Hier erscheinen dieselben Gefäßformen wie anderswo, nur die Krüge kommen in größerer Zahl vor. ${ }^{240}$ Beachtenswert ist auch der Mangel an Fußgefäßen. In Fényeslitke wurden 94 Gefäßtypen festgestellt. Die Fußgefäßtypen erscheinen hier mit einem Prozentsatz von 3,19\% (n=3). Mehr als die Hälfte, 52,13\% $(\mathrm{n}=49)$, vertritt die Gattung der Becher und nur 25,53\% $(\mathrm{n}=24)$ die Gattung von Schalen. 13,83\% $(\mathrm{n}=13)$ der Typen gehören der Gattung von Schüsseln zu. Der Anteil der Schultergefäßtypen ist hier minimal, 2,13\% $(n=2)$, und der der Sonderformen nimmt 3,19\% $(n=3)$ ein.

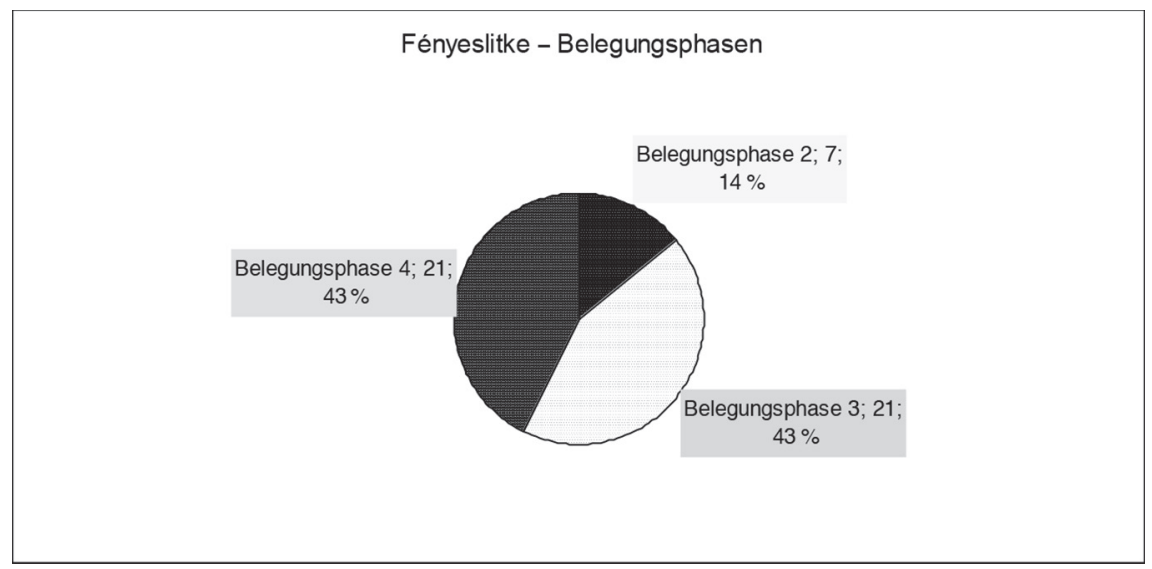

Diagramm 35. Verteilung der Gräber von Fényeslitke gemäß Belegungsphasen

Zeitbestimmung gemäß Belegungsphasen: Die Zeitstellung nach Belegungsphasen ist in diesem Gräberfeld bei 49 Gräbern bestimmt. 7 Bestattungen (14,29 \%) wurden in der Belegungsphase 2 und 21 (42,86 \%) dagegen in der Belegungsphase 3 angelegt. In der Belegungsphase 4 sind ebenfalls 21 Befunde bekannt (Tabelle 7, Diagramm 35).

Zeitbestimmung gemäß Belegungsperioden: Die Verteilung von 23 seriierten Gräbern nach Perioden zeigt Folgendes: Die Belegung des Gräberfeldes begann mit fünf Bestattungen (Grab fl19, fl34, fl44, fl57, fl70) in der Belegungsperiode 2c. In der Belegungsperiode 3a wurden zwei Gräber (Grab fl11, fl15), in der Belegungsperiode

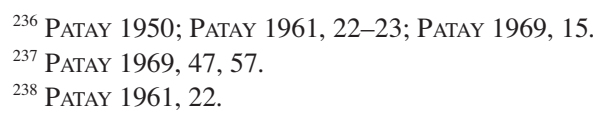

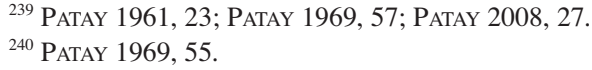


3b drei Gräber (Grab fl22, fl32, fl65) und in der Belegungsperiode 3c sogar sechs Befunde (Grab fl17, fl25, fl50, fl54, fl55, fl61) nachgewiesen. In der Belegungsperiode 4a wurden sechs Gräber (Grab fl31, fl39, fl49, fl53, fl63, fl68), in der Belegungsperiode 4b nur das Grab fl16 und in der finalen Periode fünf Bestattungen angelegt (Grab fl10, fl12, fl52, fl56, fl60) (Tabelle 2).

Im Fall des kupferzeitlichen Gräberfeldes kann festgestellt werden, dass die Bestattungsobjekte fl44, fl70, fl19, fl57, fl34, fl23 und fl36 der Belegungsphase 2 schon den Formenkreis 2 vertreten, ebenso wie alle anderen Gräber der Belegungsphasen 3 und 4. Die Inventare der Gräber fl31 und fl65 wiesen auch Keramiken auf, deren Form als Prämissen der Hunyadihalom-Keramik zu behandeln ist. Diese Gräber liegen im westlichen Bereich des Gräberfeldes.

\subsubsection{Panyola-Vásármezö-domb (Kom. Szabolcs-Szatmár-Bereg, Bez. Fehérgyarmat)}

R. Patay veröffentlichte die Funde und Befunde von sechs kupferzeitlichen Bestattungen. Er stellte fest, dass das Gräberfeld sowohl in der Zeit der Tiszapolgár- als auch der Bodrogkeresztúr-Kultur belegt war. ${ }^{241} 24$ Grabgefäße von sieben Bestattungen wurden in die Analyse einbezogen. Die Funde aus Panyola versuchten wir in unserer früheren Arbeit mit Hilfe der prähistorischen vergleichenden Methode zu datieren. Dabei handelte es sich um 21 ganze oder fragmentarisch erhaltene Grabgefäße aus sechs Gräbern. ${ }^{242}$ Festgestellt wurde, dass nur zwei von den untersuchten Gräbern in Palonya die „reine“ Tiszapolgár-Kultur vertreten. Die Grabgefäße der Bestattungen pa203 und pa205 besitzen nämlich Entsprechungen in den Gräbern anderer Tiszapolgár-Gräberfelder. Im Fall der Gräber pa204, pa201 und pa72 überwiegen noch die Beziehungen zu den Tiszapolgár-Belegungshorizonten, es treten aber auch schon Merkmale der Übergangsphase auf. Ein beachtenswertes Phänomen ist bei Grab pa202, dass sein Keramikinventar aus typologischer Sicht zwar noch mit der Tiszapolgár-Kultur verbunden ist, aber die Gepräge der Übergangsphase schon deutlich überwiegen und zum Schluss auch die typologischen Merkmale der Bodrogkeresztúr-Kultur erscheinen. ${ }^{243}$ Das Grab pa72, das südwestlich von der frühkupferzeitlichen Gräbergruppe $90 \mathrm{~m}$ weit entfernt lag, stammt nach der Bestimmung von R. Patay aus der Phase A der Bodrogkeresztúr-Kultur. Die anderen Bestattungen vertreten seiner Ansicht nach die Tiszapolgár-Kultur. ${ }^{244}$

Die Grabgefäße dieses Gräberfeldes vertreten 18 Typen von vier Gattungen. Fußgefäße und Schalen erscheinen in je 27,78 \% ( $n=5-5)$, Becherformen in 33,33\% $(n=6)$ und Schüsseln in nur 11,11 \% $(n=2)$.

Zeitbestimmung gemäß Belegungsphasen: Im Fall dieser Gräberansammlung kann man feststellen, dass die sieben nach Belegungsphasen bestimmten Gräber der Belegungsphase 2 angehört haben dürften (Tabelle 7).

Zeitbestimmung gemäß Belegungsperioden: Die Verteilung von fünf seriierten Gräbern dürfte darauf hinweisen, dass die Benutzung der Gräberansammlung in der Belegungsperiode 2a mit dem Grab pa201 begann

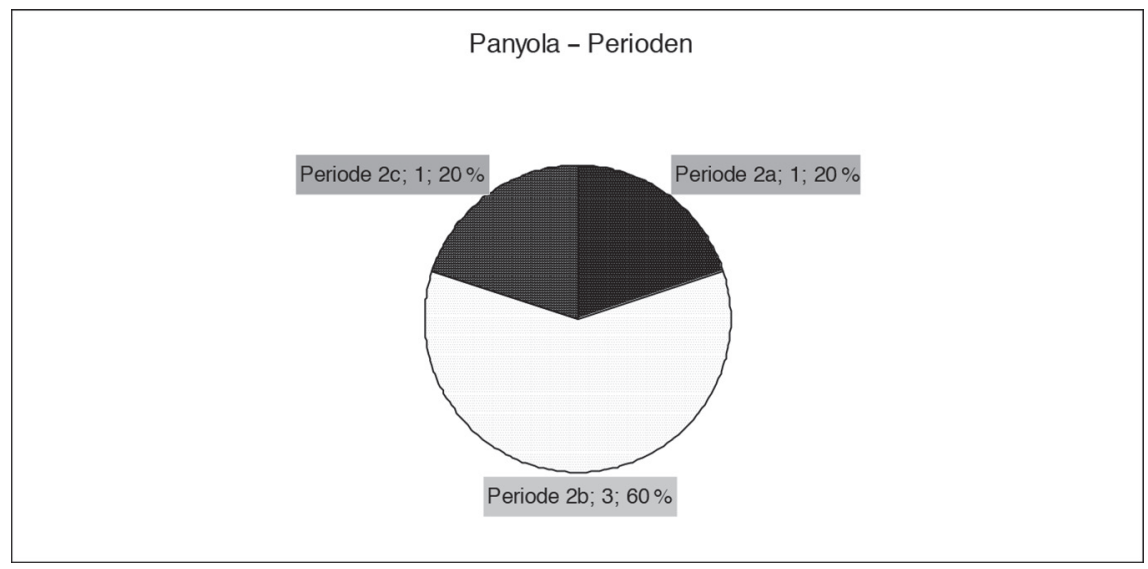

Diagramm 36. Verteilung der Gräber von Panyola nach Belegungsperioden

${ }^{241}$ R. Patay 2003, 11, 2006.
${ }^{242}$ R. Patay 2008, Taf. $1-11$.
${ }^{243}$ ZALAI-GAÁl 2015, Diagramm 18.

${ }^{244}$ R. PATAY 2003, 10-11. 
$(20,0 \%)$. Drei andere Bestattungen (Grab pa202, pa203, pa204) stammen aus der Zeit der Belegungsperiode $2 \mathrm{~b}$ $(60,0 \%)$. Die Benutzung der Gräbergruppe hörte dann in der Belegungsperiode $2 \mathrm{c}$ mit dem Grab pa72 auf (20,0 \%) (Tabelle 2, Diagramm 36).

Auf Grund der Ergebnisse der Analyse und der oben angeführten Daten kann die Belegungsgeschichte des kupferzeitlichen Gräberfeldes von Panyola folgenderweise skizziert werden: Die Gräber pa201, pa203 und pa202 der Belegungsphase 2 datieren in den Formenkreis 1. Die Bestattung pa204 aus derselben Belegungsphase dürfte in den Übergang eingereiht werden. Das Grab pa72 vertritt den Formenkreis 2.

\subsubsection{Bodrogkeresztúr (Kom. Borsod-Abaúj-Zemplén, Bez. Tokaj)}

L. Bella und J. Hillebrand führten hier eine Probegrabung in den Jahren 1920-1922 durch. Damit wurden insgesamt 44 Gräber mit den Knochenresten von 54 Personen entdeckt. P. Patay legte 1958 noch vier weitere Gräber frei. Die bekannte Gräberanzahl ist somit $48 .{ }^{245} \mathrm{~L}$. Bella veröffentlichte die Ergebnisse nur der ersten beiden Ausgrabungen und J. Hillebrand teilte nur den Grabungsplan mit. J. Banner beschrieb die Erscheinungen nur anhand dieses Grabungsplans. Die Grabbeschreibungen sind mit dem Namen von P. Patay verbunden. ${ }^{246}$ Das Gräberfeld hat heute bereits eine kulturgeschichtliche Bedeutung. In die Merkmalanalyse wurden 9 Keramiken aus vier Bestattungen von diesem Fundort einbezogen. Der namengebende Fundort der Bodrogkeresztúr-Kultur hat heute nur mehr eine forschungsgeschichtliche Bedeutung. ${ }^{247}$ Wir können P. Patay zustimmen, dass die Funde von hier keine nutzbaren Daten zur Feststellung der inneren Chronologie dieses Gräberfeldes liefern. Hier konnten acht Gefäßtypen von fünf Gattungen belegt werden. 37,50 \% $(\mathrm{n}=3)$ der Typen vertritt die Gattung der Becher und 25,0 \% $(\mathrm{n}=2)$ die Gattung der Schalen. Typen von Fußgefäßen, Schultergefäßen und Schüsseln kommen je einmal vor.

Zeitbestimmung gemäß Belegungsphasen: Im Fall des namengebenden Fundortes bzw. Gräberfeldes der Bodrogkeresztúr-Kultur wurde die relative chronologische Stellung bei vier Gräbern nach Belegungsphasen bestimmt. Zwei Gräber dürfen in die Belegungsphase 3 und zwei andere in die Belegungsphase 4 datiert werden (Tabelle 7, Diagramm 37).

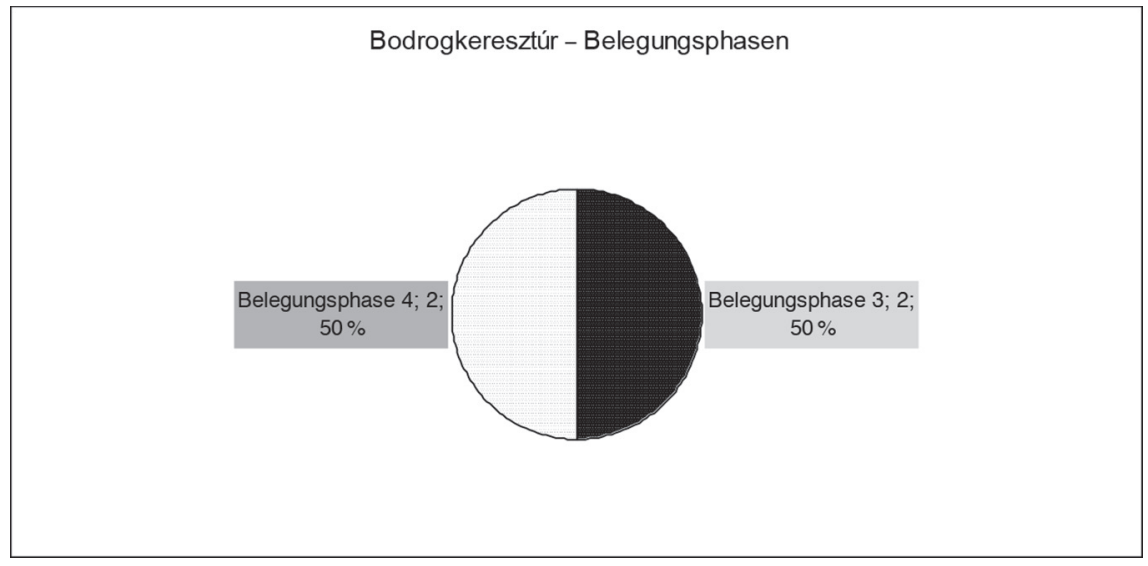

Diagramm 37. Verteilung der Gräber von Bodrogkeresztúr nach Belegungsphasen

Zeitbestimmung gemäß Belegungsperioden: Gestützt auf drei seriierte Befunde ist es annehmbar, dass die Benutzung der Gräberansammlung in der Belegungsperiode 3b mit den Bestattungen bk45 und bk46 begann $(66,67 \%)$ und in der Belegungsperiode 4b mit dem Grab bk48 (33,33\%) endete (Tabelle 2).

Die Gräber bk45 und bk46 der Belegungsphase 3 bzw. die Gräber bk48 und bk47 der Belegungsphase 4 können dem Formenkreis 2 zugeordnet werden.

245 Bella 1923; Hillebrand 1926; Patay 1961, 6-17.

${ }^{246}$ PATAY 1961, 7.
${ }^{247}$ PATAY 1961, 17.

Acta Archaeologica Academiae Scientiarum Hungaricae 67, 2016 


\subsection{Verbreitungsregion 5 - Nördliche Fundorte in Felvidék, Slowakei}

Das Gräberfeld von Abara/Oborín liegt am rechten Ufer des Laborc-Baches, wie das von Nagyráska/Vel'ké Raškovce. Tiba/Tibava kann als das am weitesten nach Norden, dem Uzsoki-Pass der Karpaten nahe liegende unter den untersuchten kupferzeitlichen Gräberfeldern behandelt werden.

\subsubsection{Oborín/Abara (Slowakei, Region Košice)}

Drei Skelettgräber der Tiszapolgár-Kultur wurden hier entdeckt. ${ }^{248}$ Die fünf belegten Keramiken stammen aus zwei Gräbern. I. Bognár-Kutzián datiert sie in die Lucska-Gruppe. ${ }^{249}$ Nach S. Šiška ist da die „ununterbrochene Besiedlung des Ortes angefangen von der Gruppe Tiszapolgár-Csőszhalom-Oborín über die Prototiszapolgár-Phase bis zur Tiszapolgár-Kultur belegt“ ${ }^{250}$ Nach J. Vízdal kann man hier mit zwei „Keramikgattungen“ rechnen: Oborín I vertritt die Grube A und das Grab I/60, während die Funde der Oborín II aus einer Schicht stammen. ${ }^{251}$ J. Vízdal datiert Oborín I an das Ende des slowakischen Jungneolithikums: Zeitlich entspricht die Keramik den Funden des TiszapolgárCsőszhalom-Typus, wahrscheinlich denen der Endphase. Andererseits ist sie den Funden der Etappe Lengyel III in der Südwestslowakei gleichzusetzen. ${ }^{252}$ Der Horizont Oborín II stellt die direkte Fortsetzung der Funde des Typus Oborín I dar. Hierzu handelt es sich um die nach S. Šiška bestimmte Prototiszapolgár-Keramik, ,,deren Stellung zur eigentlichen Tiszapolgár-Kultur auch durch stratigraphische Erkenntnisse in Lúčky belegt ist“ ${ }^{253} \mathrm{~J}$. Vízdal ist der Meinung, dass die Prototiszapolgár-Keramik aus der Ostslowakei dem Horizont Topolčany-Szob entspricht, die eigentliche Tiszapolgár-Keramik hingegen den Funden der Brodzany-Nitra-Gruppe. ${ }^{254}$ Fünf Typen der Grabkeramik nur von zwei Gattungen sind hier belegt. Beachtenswert ist, dass die Fußgefäße sowie die Becherformen fehlen. Der Typ 1d3b11 repräsentiert die Gattung der Schultergefäße, vier andere Gefäßtypen gehören zugleich der Gattung von Schalen zu.

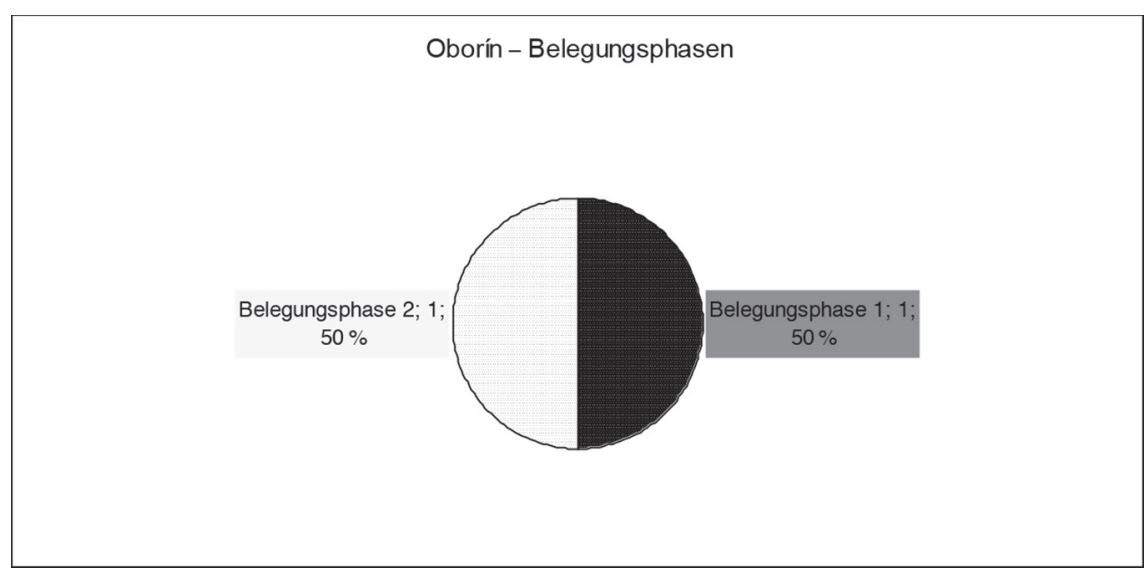

Diagramm 38. Verteilung der Gräber von Oborín nach Belegungsphasen

Zeitbestimmung gemäß Belegungsphasen: Aus dieser Gräberansammlung wurden zwei Gräber nach Belegungsphasen eingeordnet. Eines von ihnen gehört der Belegungsphase 1 und das andere der Belegungsphase 2 an (Tabelle 7, Diagramm 38).

Zeitbestimmung gemäß Belegungsperioden: Das durch Seriation datierte Grab ob1 stammt aus der Belegungsperiode 1c (Tabelle 2).

Die Gräber von Oborín vertreten den Formenkreis 1 und die Grabkeramik weist auch Traditionen des Spätneolithikums auf.

\footnotetext{
${ }^{248}$ VízDAL 1970, 219-234.

${ }^{249}$ BOGNÁR-KUTZIÁN 1972, 175.

${ }^{250}$ VízDAL 1962; ŠIŠKA 1968, 157.

${ }^{251}$ VízDAL 1970, 227-228.
}

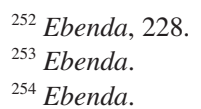




\subsubsection{Tibava/Tiba (Slowakei, Region Košice)}

In diesem Gräberfeld mit 41 Flachgräbern und mit 4 Brandbestattungen wurden nicht weniger als 216 Gefäße entdeckt, die in 30 von 41 Bestattungen hingelegt wurden. ${ }^{255}$ „Nach dem Material lassen sich hier deutlich drei Siedlungshorizonte unterscheiden“ - stellte S. Šiška fest. Es handelt sich dabei um die Periode der Gruppe Tiszapolgár-Csőszhalom-Oborín, die der Tiszapolgár- und die der Bodrogkeresztúr-Kultur. ${ }^{256}$ In dem Gräberfeld setzte S. Šiška zwei Belegungsphasen vor, „die zugleich auch die Aufgliederung der Tiszapolgár-Kultur ermöglichen“. Die ältesten Gräber lagen an der Ost- und teilweise auch an der Südseite (Gräber 16, 17, 19, 20a, 20b, 21, $23,24,25 / 56$ ). Sie respektieren vollauf die an der Westseite festgestellten Siedlungsobjekte. „Dem jüngeren Zeitabschnitt können mit Sicherheit zwei Gräber aus dem südlichen Teil des Gräberfeldes zugewiesen werden (Grab 1/55 und 4/55), ferner alle Gräber aus dem mittleren und nördlichen Teil (Gräber 6/55, 7/55, 10/55, 11/55, 14/55, $15 / 55,17 / 55,18 / 55$ und 1/56, 2/56, 4/56, 8/56, 10/56, 22/56). Hierher zu reihen sind auch die Gräber 5/56, 9/56 und 12/56. “257 Im Fall anderer Bestattungen bestätigt er, dass sie den Übergang zwischen der älteren und jüngeren Belegungsphasen darstellen (Grab 3/55, 8/55, 3/56, 6/56, 7/56, 11/56, 13/56, 14/56, 15/56). ${ }^{258}$ Auch M. Meisenheimer stellte fest, dass die späte Phase im Gräberfeld von Tibava fehlt. ${ }^{259}$ Hier sind 138 Typen von acht Gattungen der Grabkeramik belegt. Die Proportion der Fußgefäßtypen ist nur 6,52 \% $(n=9)$. Typisch ist hier der große Anteil der Schalentypen: $37,68 \%(n=52)$. Die Bechertypen sind in 25,36\% $(n=35)$, die Schultergefäßtypen in $13,77 \%$ $(\mathrm{n}=19)$ und die Schüsseltypen in 10,14 \% $(\mathrm{n}=14)$ belegt. Näpfe und Sonderformen treten in je 2,90 \% $(\mathrm{n}=4-4)$ auf. Auch ein Typ von Butmir-Gefäßen ist hier bekannt.

Zeitbestimmung gemäß Belegungsphasen: 31 Gräber von Tibava konnten nach Belegungsphasen datiert werden. Zwei Bestattungen (6,45\%) stammen aus der Belegungsphase 1. Die Mehrheit, 28 Gräber (90,32 \%), vertritt dagegen die Belegungsphase 2. Nur das Grab ti23.56 konnte in die Belegungsphase 3 zugeordnet werden (Tabelle 7, Diagramm 39).

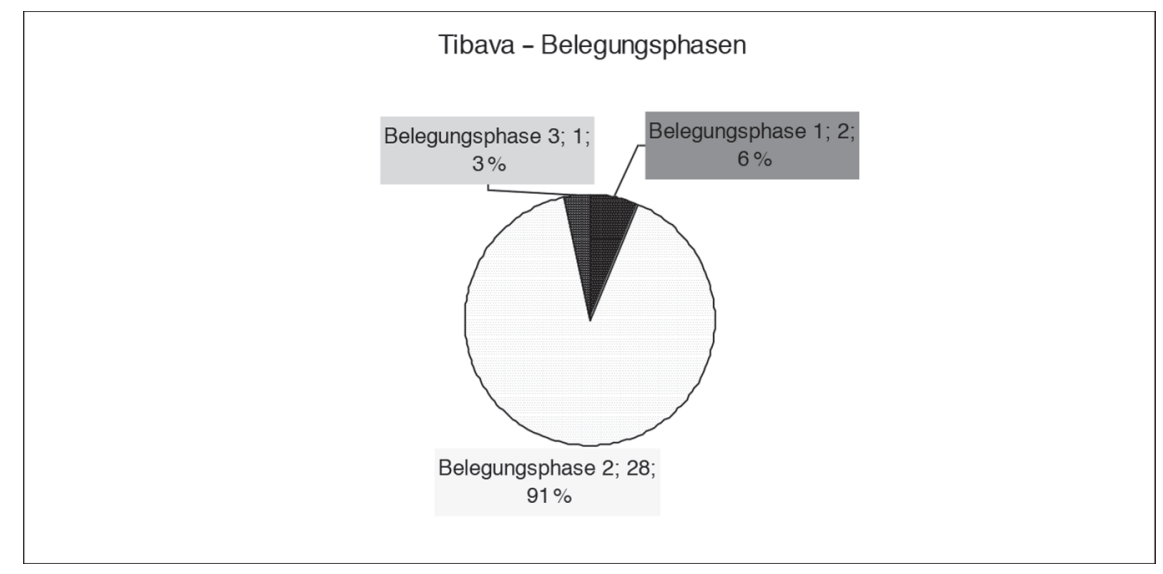

Diagramm 39. Verteilung der Gräber von Tibava nach Belegungsphasen

Zeitbestimmung gemäß Belegungsperioden: Die Verteilung von 25 seriierten Befunden nach Perioden zeigt Folgendes: Die Benutzung des Gräberfeldes begann in der Belegungsperiode 1c mit den Gräbern ti11.56 und ti15.56 (8,0 \%). Die Belegung setzte sich dann in der Belegungsperiode 2a mit 13 Bestattungen fort $(52,0 \%)$ (Grab ti03.55, ti06.56, ti07.55, ti08.55, ti10.55, ti14.55, ti14.56, ti22.56, ti24.56, ti10.56, ti15.55, ti19.56, ti21.56). Auch die Zahl der Befunde der Belegungsperiode 2b ist ziemlich hoch, 8 (32,0 \%) (Grab ti01.55, ti01.56, ti04.55, ti04.56, ti08.56, ti11.55, ti16.56, ti18.55). Die jüngeren Gräber von Tibava (Grab ti3.56, ti17.55) datieren in die Belegungsperiode $2 \mathrm{c}(8,0 \%)$ (Tabelle 2$)$.

${ }^{255}$ ŠIŠKA 1964, 294-356; ŠIŠKA 1968, 63-164; ŠIŠKA 1969, 415-428; ŠIŠKA 1972, 13-21.

${ }^{256}$ ŠIŠKA 1968, 157.

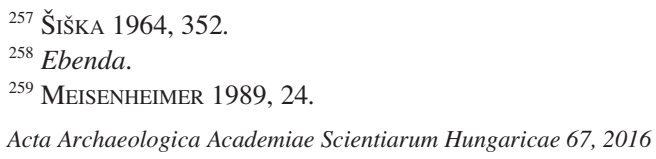


Die Gräber ti11.56 und ti15.56 der Belegungsphase 1 vertreten die älteste Belegungszeit des Gräberfeldes. Auch die anderen Bestattungen können in den Formenkreis 1 datiert werden. Eine Ausnahme stellt das Grab ti23.56 der Belegungsphase 3 dar: Im Fall des Bechers kann man annehmen, dass er eventuell schon den Übergang repräsentieren kann.

\subsubsection{Vel'ké Raškovce/Nagyráska (Slowakei, Region Košice)}

Auf diesem Fundplatz wurden 44 Körperbestattungen in drei Gräbergruppen freigelegt. In 32 Bestattungen fand man hier insgesamt 107 Gefäße. ${ }^{260}$ I. Bognár-Kutzián nahm an, dass die Siedlungsfunde in eine frühere Phase, während jene aus den Brandgräbern in eine spätere Phase zu datieren sind. ${ }^{261}$ Sie vertreten die Lucska-Gruppe nach I. Bognár-Kutzián. ${ }^{262}$ Die 101 untersuchten Gefäße stammen aus 32 Bestattungen. Man konnte dabei 66 Gefäßtypen von 7 Gattungen bestimmen. Fußgefäßtypen sind in $12,31 \%(n=8)$ der Fälle vorhanden, aber mit dem größten Anteil, mit 32,31 \% $(n=21)$, treten hier Schalentypen auf. Die Proportion der Bechervarianten beträgt 20,0 \% $(n=13)$. Schultergefäße, Schüsseln und Sonderformen können in je 9,23\% $(n=6-6)$ nachgewiesen werden. Der Anteil der Napftypen ist 7,69\% $(n=5)$.

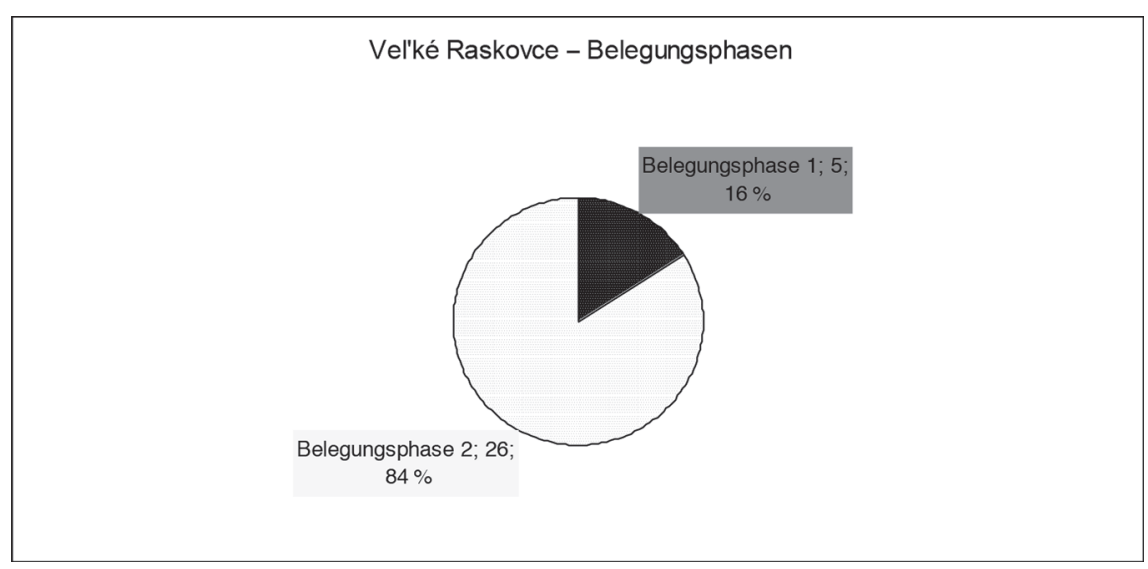

Diagramm 40. Verteilung der Gräber von Vel'ké Raškovce nach Belegungsphasen

Zeitbestimmung gemäß Belegungsphasen: An diesem Gräberfeld konnten wir zwei Belegungsphasen bestimmen. Fünf Gräber (16,13\%) wurden im Zeitraum der Belegungsphase 1 angelegt, 26 andere $(83,87 \%)$ repräsentieren dagegen die Belegungsphase 2 (Tabelle 7, Diagramm 40).

Zeitbestimmung gemäß Belegungsperioden: Auf Grund der Verteilung von 20 seriierten Gräbern gemäß Perioden kann festgestellt werden, dass die Benutzung dieses Bestattungsplatzes zur Zeit der Belegungsperiode $1 \mathrm{~b}$ mit der Bestattung vr16 angefangen haben dürfte (5,0\%). Die Gräber vr4, vr5 und vr22 vertreten die Belegungsperiode 1c (15,0 \%), während die Mehrheit der Befunde, 11 Bestattungen, während der Belegungsperiode 2a angelegt wurde $(55,0 \%$ ) (Grab vr1, vr2, vr6, vr8, vr10, vr15, vr17, vr18, vr28, vr32 und vr42). Die Benutzung dieses Bestattungsplatzes endete dann in der Zeit der Belegungsperiode $2 \mathrm{~b}(25,0 \%)$ mit den Gräbern $\operatorname{vr} 9$, vr11, vr13, vr19 und vr31 (Tabelle 2).

Die Gräber vr16, vr4, vr5, vr22 und vr41 wurden zur Zeit der Belegungsphase 1 angelegt und können damit dem Formenkreis 1 zugeordnet werden. Alle anderen Bestattungen dieses Gräberfeldes vertreten die Belegungsphase 2 und gehören zu diesem Formenkreis. Einige Gefäßtypen im Grab vr4 können von spätneolithischer Herkunft sein.

\footnotetext{
${ }^{260}$ VÍZDAL 1977.

${ }^{261}$ BognÁR-KuTZIÁN 1972, 117.
}

${ }^{262}$ Ebenda, 175. 


\section{VERLAUFPROZESSE IN DER KERAMIK DER KUPFERZEITLICHEN NEKROPOLEN}

\subsection{Die Entwicklung der untersuchten Gräberfelder gemäß Belegungsphasen}

Das Chronologieschema des gesamten Äneolithikums basiert auf der Analyse der Keramik, weil die Keramik einen großen Teil des Fundkontingents ausmacht und damit eine große Variationsbreite der Formen verbunden ist - stellte auch M. Meisenheimer fest. ${ }^{263}$ Wir gingen auch bei der Bearbeitung des grabkeramischen Bestandes der diskutierten Gemeinschaften davon aus, dass die Grundbedingung für eine detaillierte Interpretation regionaler archäologischer Phänomene ist, Funde, Befunde und Gemeinschaften/Gesellschaften auf einer überregionalen Skalenebene miteinander vergleichen zu können.

Das Entwicklungsschema der Benutzung der untersuchten Gräberfelder gemäß Belegungsphasen wird bei 532 Bestattungen bestimmt (Tabelle 7).

Tabelle 7. Entwicklungsschema der kupferzeitlichen Nekropolen gemäß Belegungsphasen

\begin{tabular}{|c|c|c|c|c|c|}
\hline Fundorte & Regionen & Phase 1 & Phase 2 & Phase 3 & Phase 4 \\
\hline Bélmegyer & 2 & 1 & - & - & - \\
\hline Tiszaigar-Csikóstanya & 3 & 1 & - & - & - \\
\hline Okány-Baromfitelep & 2 & 2 & - & - & - \\
\hline Vésztő-Bikeri & 2 & 1 & 1 & - & - \\
\hline Oborín & 5 & 1 & 1 & - & - \\
\hline Deszk B & 1 & 13 & 2 & - & - \\
\hline Hódmezővásárhely-Népkert & 1 & 2 & 3 & - & - \\
\hline Vel'ké Raškovce & 5 & 5 & 26 & - & - \\
\hline Deszk A & 1 & 9 & 3 & - & - \\
\hline Endrőd-Hegedűs-tanya & 2 & 2 & 2 & 1 & - \\
\hline Tápé-Lebö A & 1 & 2 & 5 & 1 & - \\
\hline Körösladány-Bikeri & 2 & 1 & 1 & 1 & - \\
\hline Hódmezővásárhely-Kotacpart & 1 & 2 & 4 & 1 & - \\
\hline Tibava & 5 & 2 & 28 & 1 & - \\
\hline Tiszavalk-Tetes & 3 & 1 & 14 & 8 & - \\
\hline Polgár-Basatanya & 3 & 2 & 77 & 41 & 12 \\
\hline Tiszakeszi & 3 & 1 & 2 & 6 & 4 \\
\hline Tiszabábolna-Szilpuszta & 3 & 1 & 3 & - & 1 \\
\hline Hódmezővásárhely-Szakálhát & 1 & & 1 & - & - \\
\hline Hódmezővásárhely-Laktanya & 1 & & 1 & - & - \\
\hline Polgár-Nagy-Kasziba & 3 & & 1 & - & - \\
\hline Ószentiván VIII & 1 & & 3 & - & - \\
\hline Kisvárda & 4 & & 1 & - & - \\
\hline Köröstarcsa-Kossuth tér & 2 & & 1 & - & - \\
\hline Panyola-Vásárosmező-domb & 4 & & 7 & - & - \\
\hline Polgár-Hajdúnánási út & 3 & & 2 & - & - \\
\hline Hajdúböszörmény-Ficsori-tó-dülő & 3 & & 2 & - & - \\
\hline Újvár & (1) & & 1 & - & - \\
\hline Emöd & 3 & & 1 & - & - \\
\hline Mónosbél & 3 & & 1 & - & - \\
\hline Vásárosnamény & 4 & & 1 & 1 & - \\
\hline Polgár-Bacsókert & 3 & & 3 & 6 & - \\
\hline
\end{tabular}

${ }^{263}$ Meisenheimer 1989, 8. 


\begin{tabular}{|c|c|c|c|c|c|}
\hline Fundorte & Regionen & Phase 1 & Phase 2 & Phase 3 & Phase 4 \\
\hline Magyarhomorog-Kónyadomb & 2 & & 8 & 25 & 13 \\
\hline Tiszavalk-Kenderföldek & 3 & & 3 & 29 & 12 \\
\hline Kiskőrös & & & 1 & 5 & 2 \\
\hline Hajdúszoboszló & 3 & & 1 & 4 & 3 \\
\hline Fényeslitke & 4 & & 7 & 21 & 21 \\
\hline Kunszentmárton-Pusztaistvánháza & 2 & & 1 & 9 & 2 \\
\hline Sárazsadány & 4 & & & 1 & - \\
\hline Hódmezővásárhely-Bodzáspart & 1 & & & 1 & - \\
\hline Mezőkeresztes-Csincse-tanya & 3 & & & 3 & - \\
\hline Mezőkövesd-Patakra járó-dülő & 3 & & & 4 & - \\
\hline Öcsöd-Kendereshalom & 2 & & & 1 & - \\
\hline Jászladány & 3 & & & 12 & 5 \\
\hline Bodrogkeresztúr & 4 & & & 2 & 2 \\
\hline Nagykörü & 3 & & & 1 & 1 \\
\hline Gelej & 3 & & & & 1 \\
\hline
\end{tabular}

In den kupferzeitlichen Nekropolen von Hódmezővásárhely-Szakálhát-Bakay-tanya, Ószentiván VIII, Újvár, Bélmegyer-Monoki-domb, Köröstarcsa-Kossuth tér, Okány-Baromfitelep, Tiszaigar-Csikóstanya, Hajdúböszörmény-Ficsori-tó-dűlő, Polgár-Hajdúnánási út, Polgár-Nagy-Kasziba, Kisvárda, Vásárosnamény und Oborín/Abara sind Gräber nur mit Keramik des Formenkreises 1 vertreten. In Körösladány-Bikeri dürfte eine Bestattung eventuell den Übergang repräsentieren. Die Existenz des Übergangs kann auch im Fall des Gräberfeldes von Tibava/Tiba angenommen werden. Auch die Gräber von Vel'ké Raškovce besitzen Gefäße des Formenkreises 1. Einige Gefäßtypen weisen hier auch typologische Merkmale auf, die von spätneolithischer Herkunft gewesen sein dürften.

Im Fall von sieben Nekropolen mit Formenkreis 1 setzen wir voraus, dass in diesen auch während der Übergangsphase bestattet wurde. In Deszk A findet man Gräber der Belegungsphase 1 sowie der Belegungsphase 2, wo die Keramik typologische Merkmale von spätneolithischen Traditionen aufzeigt. In Deszk B, HódmezővásárhelyNépkert, Hódmezővásárhely-Laktanya und Endrőd-Hegedűs-tanya dürften einige Keramiken dagegen eventuell zum Übergang gestellt werden. In den Gräbern der Belegungsphase 1 und der Belegungsphase 2 von Tápé-Lebő A treten typologische Merkmale von früheren spätneolithischen Traditionen auf. Bei einem Grab der Belegungsphase 3 kann man nicht mit Sicherheit entscheiden, ob die Keramik den Übergang oder den Formenkreis 2 vertritt. In Vésztő-Bikeri trifft man auf Befunde des Formenkreises 1. Man findet Befunde auch in HódmezővásárhelyKotacpart-Vatatanya, deren Keramik spätneolithische Traditionen aufweist. Der Befund von HódmezővásárhelyBodzáspart datiert in die Übergangsperiode und eine Keramik zeigt auch in diesem Fall frühere (spätneolithische) typologische Reminiszenzen.

In einigen Nekropolen treten Gräber mit Keramik sowohl des Formenkreises 1 als auch des Formenkreises 2 auf. Nach P. Patay vertreten diese Typen eine Übergangsphase. Als das früheste von ihnen behandelt er das Gräberfeld von Tiszavalk-Tetes mit Bestattungsritus der Tiszapolgár-Kultur. In diese Zeit datiert er auch die Gräber bt48, bt50, bt57, bt58, bt59, bt63 und bt81 von Polgár-Basatanya, die Bestattungen in der Mitte der Südhälfte der Nekropole von Magyarhomorog-Kónyadomb, eine Gräbergruppe von Tiszakeszi-Fáy-kert und die erwähnten vier Gräber von Pusztaistvánháza. ${ }^{264}$

Übergangsgräber und/oder Gräber des Formenkreises 2 sind in zehn Fundstellen, so in Mezőkövesd-Patakra járó-dülő, Emőd, Tiszakeszi-Fáy-kert, Tiszavalk-Tetes und Magyarhomorog-Kónyadomb, nachgewiesen. Die Keramik von Öcsöd-Kendereshalom vertritt entweder den Übergang oder den Formenkreis 2. Die Mehrheit der Bestattungen von Hajdúszoboszló stammt aus der Zeit des Formenkreises 2. Die Benutzung des Gräberfeldes von Polgár-Bacsókert dürfte zur Zeit des Formenkreises 1 begonnen haben. In Tiszabábolna-Szilpuszta können auch spätneolithische Reminiszenzen der Keramik vorausgesetzt werden. In Panyola beginnt die Benutzung der Nekropole mit Gräbern des Formenkreises 1 und setzt sich über die Übergangphase bis in die Zeit des Formenkreises 2 fort.

${ }^{264}$ PATAY 2008, 38. 
In den Gräberfeldern von Jászladány, Nagykörü-Hidashát, Gelej-Füzeshát, Mezőkeresztes-Csincse-tanya, Mónosbél, Kiskőrös-Seregélyes, Fényeslitke, Bodrogkeresztúr und Sárazsadány treten nur die Befunde des Formenkreises 2 auf. Ebenso wie in Tiszavalk-Kenderföldek, wo typologische Elemente der Hunyadihalom-Kultur nachweisbar sind. Mit Scheibenhenkel verzierte Gefäße wurden auch noch in Gräbern von Polgár-Basatanya, Kunszentmárton-Pusztaistvánháza und Tiszakeszi-Fáy-kert entdeckt.

Bestattungsobjekte mit Typen des Formenkreises 1 und des Übergangs sowie des Formenkreises 2 wurden in Polgár-Basatanya allein registriert, wo auch Bestattungen mit Hunyadihalom-Keramik belegt werden können. Polgár-Basatanya ist ein Beweis dafür, dass eine Nekropole nicht kontinuierlich, sondern abschnittsweise benutzt wurde. ${ }^{265}$

Die Belegung der größeren kupferzeitlichen Nekropolen des östlichen Karpatenbeckens gemäß Belegungsphasen illustriert Diagramm 41.

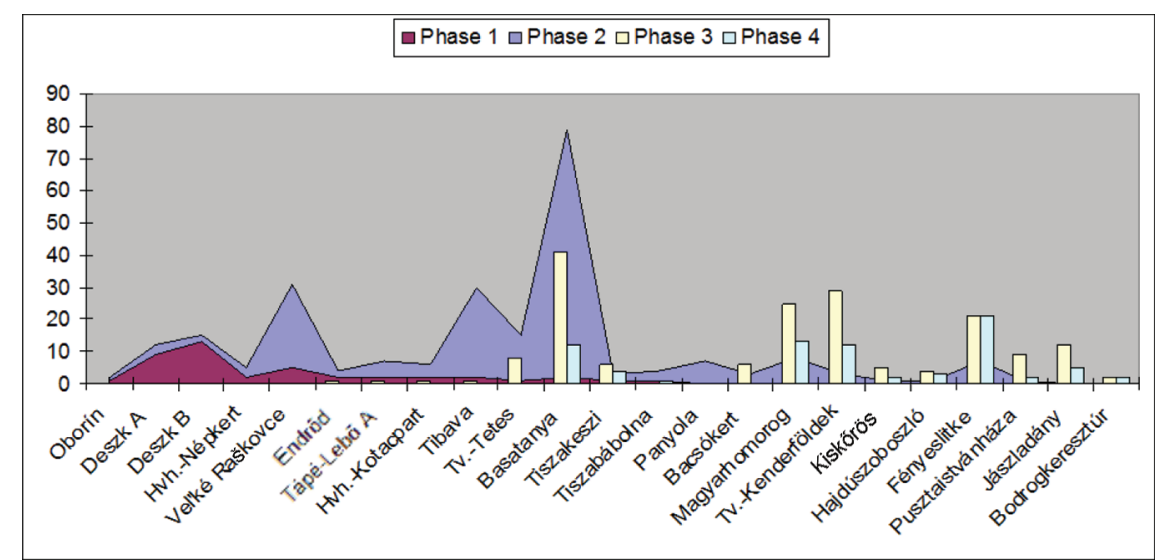

Diagramm 41. Entwicklung der größeren kupferzeitlichen Nekropolen gemäß Belegungsphasen

Auf Grund der aufgezählten Daten und Ergebnisse können wir P. Patay zustimmen, dass die Entwicklung während der Belegungszeit des Polgár-Komplexes kontinuierlich war und sich keine scharfen Grenzlinien zwischen den einzelnen Perioden (Phasen) ziehen lassen. „Ein Gräberfeld konnte auch mehrere Perioden umfassen, und da es nicht in jedem Grab einen typischen zeitbestimmenden Begleitfund gibt, kann nicht von allen kategorisch festgestellt werden, in welche Periode sie gehören. “ ${ }^{266}$ Wie gesehen, frühe Typen verschwunden nicht auf einmal und einige Typen, wenn auch in reduzierter Menge, lebten weiter. „Daher wäre es naiv zu glauben, dass die chronologische Stellung gemäß Phasen oder Perioden bei jedem Grab bestimmt werden kann. “267 Wir finden Beispiele dafür, dass ein Gräberfeld auch mehrere Perioden/Phasen umfassen konnte und es im Fall von mehreren, nicht zeitbestimmenden Gefäßtypen nicht mit Sicherheit festgestellt werden kann, welche Periode/Phase die Gräber mit ihnen vertreten.

Die Verteilung der Gräber gemäß Belegungsphasen in den einzelnen Regionen des Polgár-Komplexes studierend kann Folgendes festgestellt werden (Diagramm 42).

Verbreitungsregion 1: Bei den Befunden des Polgár-Komplexes handelt es sich im unteren Theißgebiet um Gräber des Formenkreises 1 und in einigen Fällen des Übergangs. In Deszk A, Hódmezővásárhely-Bodzáspart, Hódmezővásárhely-Kotacpart und Tápé-Lebő A können spätneolithische Reminiszenzen in der keramischen Typologie nachgewiesen werden. Merkmale der Übergangsphase treten in Hódmezővásárhely-Népkert und Hódmezővásárhely-Laktanya auf. Gestützt auf diese Daten kann man mit Recht annehmen, dass die Benutzung der Gräberfelder in dem diskutierten Bereich, bis in die Zeit der Belegungsphase 3, kontinuierlich gewesen sein dürfte.

Verbreitungsregion 2: Drei Nekropolen weisen Keramik des Formenkreises 1 in dem Theißwinkel und der Körös-Gegend auf (Bélmegyer, Köröstarcsa-Kossuth tér, Okány-Baromfitelep). In der behandelten Verbreitungsregion treten gleichzeitig auch Nekropolen mit Übergangsgräbern und mit denen des Formenkreises 2 auf (ÖcsödKendereshalom, Magyarhomorog-Kónyadomb). In diesen Fällen kann eine ununterbrochene Entwicklung von der

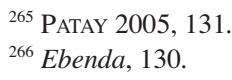

${ }^{267}$ PATAY 2008, 39. 


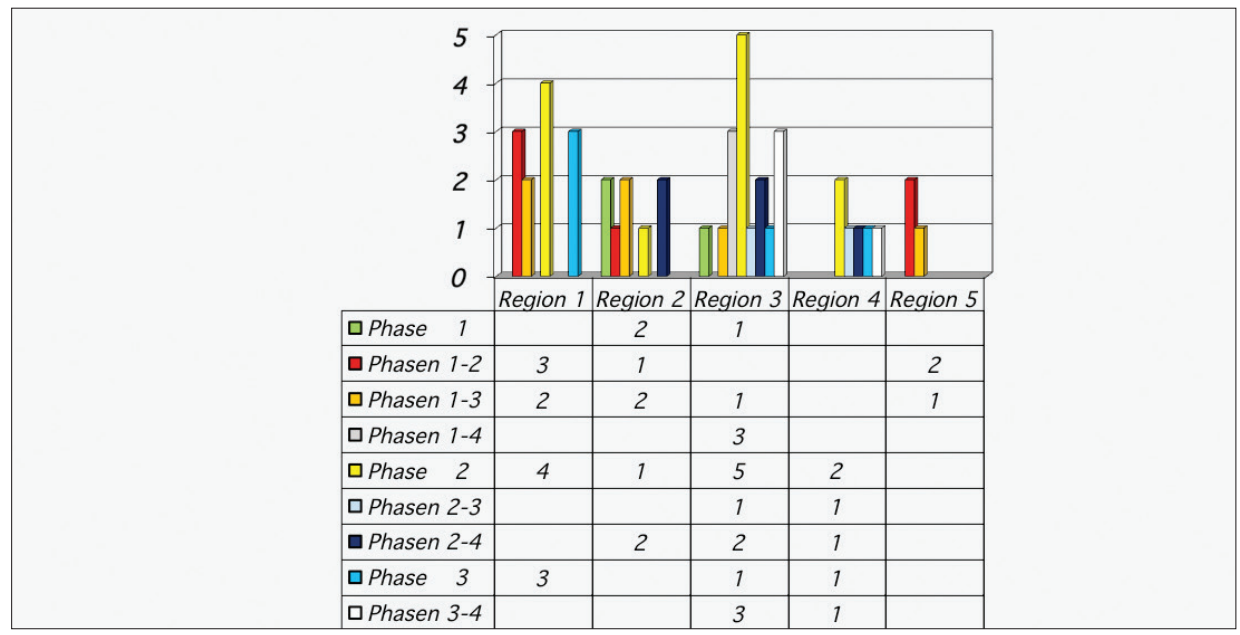

Diagramm 42. Verteilung der kupferzeitlichen Gräber im Verhältnis zu Regionen und Belegungsphasen

Periode $2 \mathrm{a}$ bis in die Periode $2 \mathrm{c}$ beobachtet werden. Im Gräberfeld von Kunszentmárton-Pusztaistvánháza des Formenkreises 2 sind auch frühere typologische Merkmale der Keramik nachweisbar.

Verbreitungsregion 3: Die Entwicklung der Gräberfelder des Polgár-Komplexes zeigt das vielseitigste Bild in der mittleren Theißgegend auf. Hier konnten 19 Gräberfelder oder Gräbergruppen untersucht werden. Die Befunde von Tiszaigar-Csikóstanya und Polgár-Nagy-Kasziba vertreten den Formenkreis 1. Auch die Gräber der Belegungsphase 2 von Hajdúböszörmény-Ficsori-tó-dűlő und Polgár-Hajdúnánási út repräsentieren denselben Formenkreis. Die Mehrheit der Bestattungen dieses Formenkreises erscheint in Polgár-Basatanya. In Polgár-Bacsókert sind Übergangsgräber und Bestattungen des Formenkreises 2 bzw. eventuell auch jene des Formenkreises 1 vorhanden.

Gräber der Übergangsphase sowie des Formenkreises 2 erscheinen in drei Nekropolen (Mezőkövesd-Patakra járó-dűlő, Hajdúszoboszló, Tiszakeszi-Fáy-kert). In Tiszabábolna-Szilpuszta treten Funde der Belegungsphase 1 mit spätneolithischen Reminiszenzen der Keramik auf. Man findet hier auch Übergangsgräber und Befunde des Formenkreises 2. In Tiszavalk-Tetes beginnt die Entwicklung in der Übergangsphase und endet mit dem Formenkreis 2.

In sieben anderen Gräberfeldern (Jászladány, Nagykörü-Hidashát, Gelej, Mezőkeresztes-Csincse-tanya, Mónosbél, Tiszavalk-Kenderföldek, Kiskőrös) wurden Gräber der Belegungsphasen 2 bis 4 bestätigt. All diese können dem Formenkreis 2 zugeordnet werden. Wie gesehen, sind in Polgár-Basatanya Befunde aller Perioden und Belegungsphasen feststellbar.

Man kann mit Recht voraussetzen, dass die Entwicklung der untersuchten kupferzeitlichen Kulturen in diesem Bereich, also im mittleren Theißgebiet, akkumulierte, wo sich die Wirkungen aus allen Richtungen und spätestens im Laufe der Herausbildung und Entwicklung des Formenkreises 2 durchgesetzt haben könnten.

Verbreitungsregion 4: Am Oberlauf der Theiß und in der Bodrog-, Kraszna- und Szamosgegend wurden die chronologischen Verhältnisse von sieben Nekropolen untersucht. Der Befund der Belegungsphase 2 von Kisvárda und die Gräber der Belegungsphasen 2 und 3 von Vásárosnamény wurden mit Gefäßen des Formenkreises 1 ausgestattet, obwohl die Bestattungen der Belegungsphase 3 in anderen Gebieten schon den Formenkreis 2 repräsentieren. In Panyola treten noch Gräber der Belegungsphase 2 auf, die die Typen des Formenkreises 1, des Übergangs und des Formenkreises 2 darstellen. Die Befunde der Belegungsphase 2 von Fényeslitke gehören zum Formenkreis 2, wie diejenige der Belegungsphase 3 und der Belegungsphase 4. Das Grab von Sárazsadány stammt aus der Zeit des Formenkreises 2.

Verbreitungsregion 5: In Felvidék (Slowakei) konnten wir drei Gräberfelder untersuchen. Die Bestattungen von Oborín/Abara und Vel'ké Raškovce/Nagyráska aus der Belegungsphase 1 und der Belegungsphase 2 repräsentieren ausnahmsweise den Formenkreis 1. Da die Gräber von Vel'ké Raškovce - mit einer Ausnahme - die Belegungsphase 2 darstellen, können wir darauf schließen, dass die Entwicklung in Tibava früher begonnen haben dürfte. Die Keramik eines Grabes der letztgenannten Fundstelle weist zugleich typologische Merkmale der Übergangsphase auf. 


\subsection{Zeiträume und keramische Formenkreise in den kupferzeitlichen Nekropolen des östlichen Karpatenbeckens}

Das mittelkupferzeitliche Gräberfeld von Rákóczifalva-Bagi-föld besitzt eine besondere Bedeutung. Die 14C-Daten von hier (4334-4075 cal BC) deuten nämlich darauf hin, dass das Alter dieser Bestattungen teilweise zeitgleich mit dem Bestehen der Tiszapolgár-Kultur gewesen sein dürfte. In Kenntnis dieser Daten und Ergebnisse der jüngsten amerikanisch-ungarischen Untersuchungen halten M. Csányi, P. Raczky und J. Tárnoki den Kontakt in Raum und Zeit bzw. die parallele Entwicklung der beiden archäologischen Kulturen für eine realistische Option. ${ }^{268}$ Die eigenartigen Fundkontexte der frühen Bestattungen und der sog. Übergangsgräber in den Nekropolen von Tiszavalk-Tetes, Magyarhomorog-Kónyadomb, Magyartés usw. dürften also - wie unsere Ergebnisse - nicht auf die zeitliche Abfolge der Kultureinheiten der Tiszapolgár- und der Bodrogkeresztúr-Kultur, sondern auf den räumlichen Kontakt und die parallele Zeit hindeuten. ${ }^{269}$ Auch die Ergebnisse der von P. Raczky und Zs. Siklósi vorgenommenen Bayesischen Analyse zeigen, dass die Keramikstile der Tiszapolgár- und Bodrogkeresztúr-Befunde gleichzeitig in Gebrauch gewesen sein könnten. ${ }^{270}$

M. Szilágyi schreibt zugleich, dass keine solchen zwei, eindeutig bestimmbaren Gruppen auf Grund der Ergebnisse der von ihm durchgeführten Analyse der Siedlungskeramik bestimmt werden können, die als ,Tiszapolgár' oder ,Bodrogkeresztúr' genannt würden: ${ }^{271}$ „Die Radiokarbondaten weisen eindeutig darauf hin, dass die keramischen Stile der Tiszapolgár-Kultur und der Bodrogkeresztúr-Kultur gleichzeitig in Benutzung waren, es handelt sich dabei also nicht um kronologische Marker.“ Die Änderungen der verschiedenen Keramikstile können deswegen nicht auf chronologische, sondern auf andere Gründe zurückgeführt werden - bestätigt M. Szilágyi. ${ }^{272}$

Wir versuchten dieses Problem auf folgende Art, durch die Bestimmung von Zeiträumen in den untersuchten kupferzeitlichen Nekropolen zu lösen.

Die Formenkreise wurden mit Hilfe der Tatsache bestimmt, ob die Gräber mit Keramik der verschiedenen Formenkreise innerhalb der einzelnen Phasen vorherrschen oder nicht. Auf diese Weise wurden insgesamt 517 Gräber untersucht: 35,20 \% $(n=182)$ davon vertreten den Formenkreis 1, 59,57 \% $(n=308)$ den Formenkreis 2. Nur 1,55\% $(\mathrm{n}=8)$ der Bestattungen besitzt Gefäße auch mit Hunyadihalom-Merkmalen und nur 3,68 \% $(\mathrm{n}=19)$ von ihnen können in den Übergang zwischen den Formenkreisen 1 und 2 eingestuft werden (Diagramm 43).

Zeitraum 1: Da konnte etwa 9,28 \% $(n=48)$ der Bestattungen zugeordnet werden. Ihr dominierender Anteil $(91,67 \%, n=44)$ repräsentiert den Formenkreis 1. 6,25 \% $(n=3)$ kann dem Übergang zwischen Formenkreis 1 und Formenkreis 2 zugeordnet werden. 2,08 \% $(n=1)$ der Gräber kann als ein Beweis dienen, dass die Gemeinschaften mit Gräbern des Formenkreises 2 schon während dieses Horizontes erschienen.

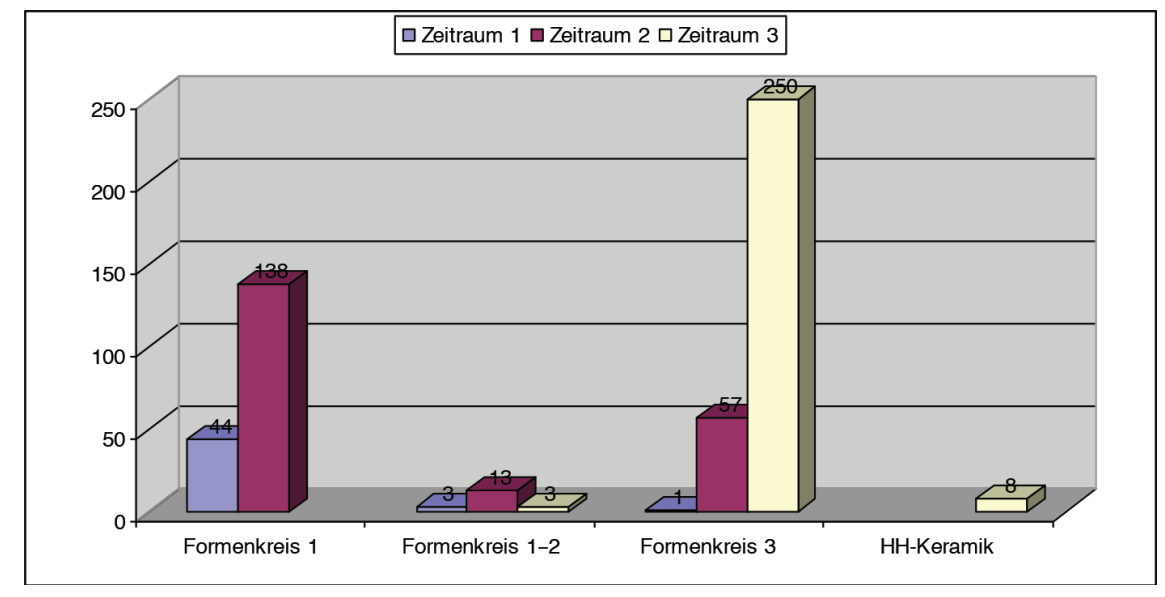

Diagramm 43. Verteilung der Gräber gemäß Belegungshorizonten ( $n=517$ Gräber)

${ }^{268}$ YERKES et al. 2009; CSÁNYI et al. 2009.

${ }^{269}$ CsÁnYi et al. 2009.

270 ,The archaeological examples cited her clearly show that the ceramic styles of the Tiszapolgár and Bodrogkeresztúr assemblages, which until now have been regarded as chronological markers of the Early and Middle Copper Age, could be in use at the same time" (RACZKY-SIKLÓSI 2013, 571).

${ }^{271}$ SZILÁGYi 2015, 326.

${ }^{272}$ Ebenda, 28. 


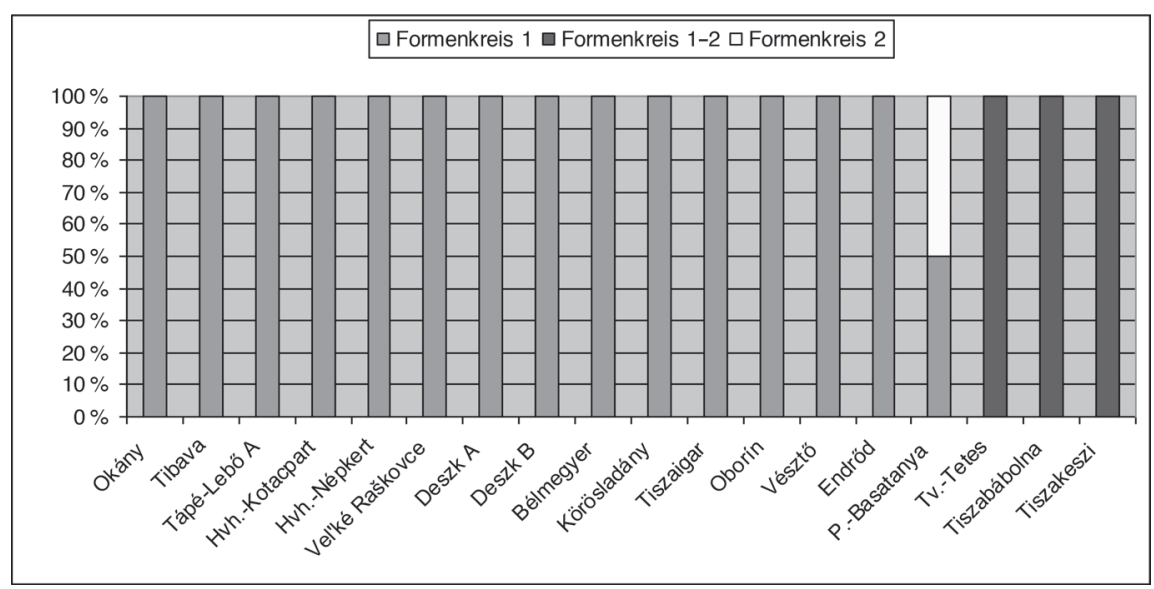

Diagramm 44. Verteilung der Gräber des Zeitraumes 1 gemäß Nekropolen

In den Gräberfeldern Deszk A, Deszk B, Tiszaigar, Tápé-Lebő A, Hódmezővásárhely-Kotacpart, Hódmezővásárhely-Népkert der Verbreitungsregion 1, Endrőd-Hegedűs-tanya, Vésztő-Bikeri und Okány der Verbreitungsregion 2 bzw. Oborín und Tibava der Verbreitungsregion 5 kommen Bestattungen nur des Formenkreises 1 vor. In der Mehrheit dieser Gräberfelder sind aber nur je eine solche Bestattung vorhanden. In Polgár-Basatanya erscheint auch ein Grab des Formenkreises 2. In Tiszavalk-Tetes, Tiszabábolna-Szilpuszta und Tiszakeszi der Verbreitungsregion 3 findet man gleichzeitig je einen Befund, der einen Übergangscharakter darstellen kann (Diagramm 44).

Zeitraum 2: 40,23\% $(n=208)$ der Bestattungen des Polgár-Komplexes kann hier aufgezählt werden. Die Gräber des Formenkreises 1 überwiegen in diesem Zeitraum mit einem Anteil von 66,35\% ( $n=138)$, während diejenige des Formenkreises 2 schon in 27,40 \% $(n=57)$ auftreten. Gräber mit Übergangscharakter können nur in $6,25 \%(n=13)$ der Fälle nachgewiesen werden.

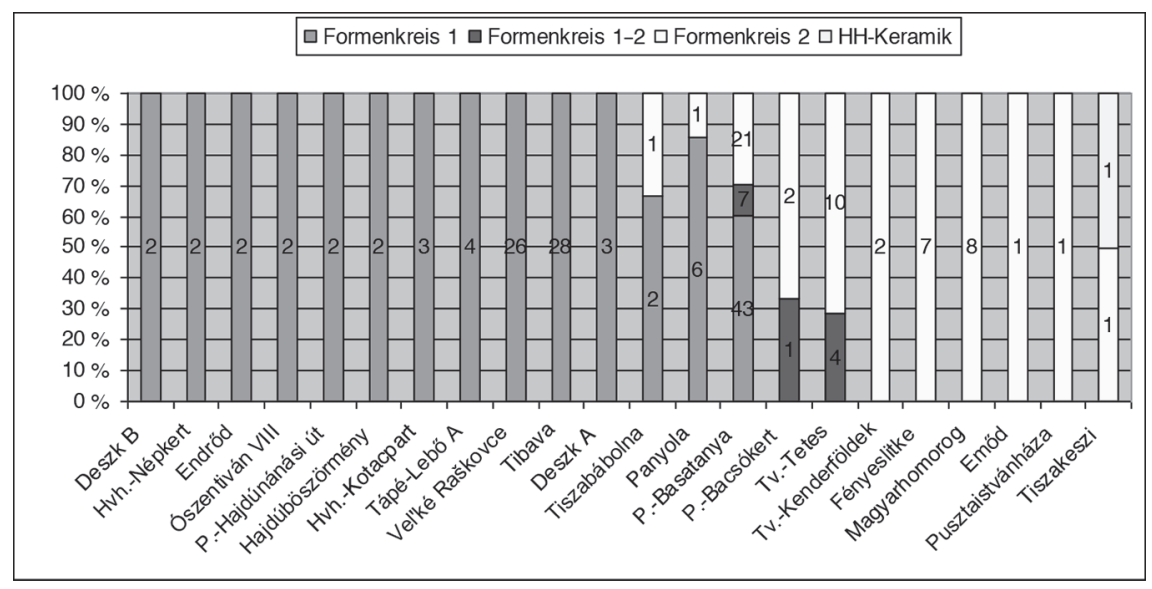

Diagramm 45. Verteilung der Gräber des Zeitraums 2 gemäß Nekropolen

(andere mit je einem TPK-Grab: Újvár, Vésztő-Bikeri, Hódmezővásárhely-Laktanya, Köröstarcsa, Kisvárda, Oborín,

Vásárosnamény, Körösladány-Bikeri, Hódmezővásárhely-Szakálhát, Mónosbél, Polgár-Nagy-Kasziba)

Die Mehrheit der Gräberfelder wurde während dieses Horizontes durch die Gemeinschaften des Formenkreises 1 von Deszk A, Deszk B, Hódmezővásárhely-Népkert, Hódmezővásárhely-Kotacpart, HódmezővásárhelySzakálhát, Hódmezővásárhely-Laktanya, Tápé-Lebő A und Ószentiván VIII der Verbreitungsregion 1, Endrőd-Hegedűs-tanya und Köröstarcsa-Kossuth tér der Verbreitungsregion 2, Polgár-Hajdúnánási út, Polgár-NagyKasziba und Hajdúböszörmény der Verbreitungsregion 3, Kisvárda und Vásárosnamény der Verbreitungsregion 4, Vel'ké Raškovce und Tibava der Verbreitungsregion 5 benutzt. In den Nekropolen von Tiszabábolna und Panyola 
der Verbreitungsregion 3 überwiegen die Bestattungen des Formenkreises 1, zugleich treten aber auch diejenige des Formenkreises 2 auf. In Polgár-Basatanya können Gräber von Übergangscharakter vorausgesetzt werden. In den Gräberfeldern von Polgár-Bacsókert und Tiszavalk-Tetes der Verbreitungsregion 3 sind sowohl Übergangsgräber als auch Bestattungen des Formenkreises 2 nachgewiesen. Die Gräberfelder von Mónosbél, Pusztaistvánháza und Magyarhomorog der Verbreitungsregion 2, Tiszavalk-Kenderföldek, Emőd und Tiszakeszi der Verbreitungsregion 3 bzw. Fényeslitke der Verbreitungsregion 4 wurden während dieses Horizontes ausschließlich von Gräbern der Gemeinschaften des Formenkreises 2 belegt. In Tiszakeszi tritt auch eine Bestattung mit Keramik der HunyadihalomKultur auf (Diagramm 45).

Zeitraum 3: Die Mehrheit, 50,48 \% ( $\mathrm{n}=261)$, der untersuchten kupferzeitlichen Befunde vertritt den finalen Horizont der Entwicklung des diskutierten Zeitraumes. In dieser Zeit findet man keine Tiszapolgár-Bestattungen mehr. Der Anteil der Gräber von Übergangscharakter nimmt nur 1,15\% $(n=3)$ ein. In 95,79\% $(n=250)$ der Gräber des diskutierten Horizontes wurden die Bodrogkeresztúr-Gemeinschaften bestattet und in 3,07\% (n=8) konnten Gräber mit Hunyadihalom-Keramik festgestellt werden.

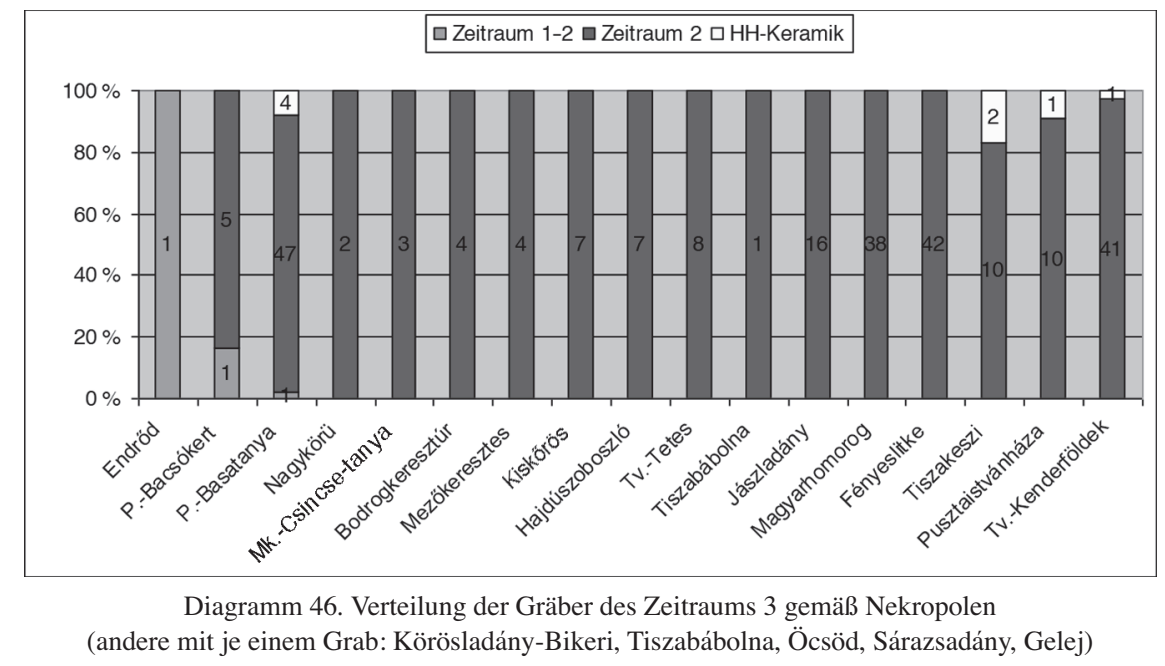

Ein Grab von Endrőd-Hegedűs-tanya der Verbreitungsregion 2 besitzt Übergangcharakter und ein ähnliches Grab ist auch in Polgár-Bacsókert der Verbreitungsregion 3 vorhanden. In den Nekropolen mit Formenkreis 2 von Pusztaistvánháza der Verbreitungsregion 2 bzw. Polgár-Basatanya, Tiszakeszi, Tiszavalk-Kenderföldek der Verbreitungsregion 3 kommen auch einige Bestattungen mit Keramik von Hunyadihalom-Charakter vor. Die anderen Nekropolen von Jászladány, Tiszabábolna-Szilpuszta, Tiszavalk-Tetes, Hajdúszoboszló, Nagykörü und Mezőkeresztes-Csincse-tanya der Verbreitungsregion 3 bzw. Bodrogkeresztúr und Fényeslitke der Verbreitungsregion 4 wurden in diesem Zeitraum nur von den Gemeinschaften des Formenkreises 2 belegt (Diagramm 46).

\section{ERGEBNISSE}

Die in der vorliegenden Arbeit skizzierten Untersuchungen wurden ausschließlich auf die Formanalyse der Grabkeramik gestützt durchgeführt. Die Möglichkeiten für die grabkeramische Analyse sind aber sehr begrenzt. „Da der Zeichencharakter materieller Kultur aber nicht nur die intentionale Ebene umfasst, sondern auch nichtintentionale Botschaften, spielt die Frage der Zeichenverwendung und die Möglichkeit der Identifikation und Unterscheidung intentionaler und nichtintentionaler Zeichen im prähistorischen Kontext eine zentrale Rolle" - stellen M. Furholt und Ph. Stockhammer fest. ${ }^{273}$

\footnotetext{
${ }^{273}$ FURHOLT-STOCKHAMMER 2008, 62.
} 
Ein reales Bild zur Bestimmung der Entwicklung von prähistorischen Kulturen/Gemeinschaften kann man nur durch den Vergleich der Grab- und der Siedlungskeramik gewinnen. Es ist nicht zu entscheiden, ob alle in den Gräbern deponierten Gefäße direkt für die Bestattungszeremonie hergestellt oder auch Haushaltsgefäße ins Grab niedergelegt wurden. Beide Arten der prähistorischen Keramik besitzen nämlich einen voneinander abweichenden typochronologischen Charakter.

Mit den verwendeten Methoden können wir die folgenden Schlussfolgerungen resümieren.

1. In der diskutierten frühkupferzeitlichen Gefäßtypologie können spätneolithische Reminiszenzen entdeckt werden. Die Frühkupferzeit dürfte sich demnach einerseits auf der Grundlage der spätlengyelzeitlichen Entwicklung (Stufe Nyitra-Brodzany) in der Verbreitungsregion 5 des Polgár-Komplexes herausgebildet haben. Es handelt sich dabei um ähnliche, seltener auch übereinstimmende typologische Charakterzüge zwischen den spätneolithischen und frühkupferzeitlichen Gefäßtypen. Ein beachtenswertes Phänomen ist es weiterhin, dass die Bestattungssitten der frühkupferzeitlichen Gemeinschaft in Polgár-Basatanya (Verbreitungsregion 3) viele Gewohnheiten zeigen, die mit denen der westlichen Lengyel-Gemeinschaften zueinander passen. ${ }^{274}$

Die Entwicklung der Frühkupferzeit kann andererseits auch in den Verbreitungsregionen 1 und 2 (untere Theißgegend und Marosgegend) beobachtet werden. In diesem Fall fehlen aber die monographischen Veröffentlichungen der Funde und Befunde der Theiß-Kultur. Die Prototiszapolgár-Grabkeramik als selbstständiger Formenkreis oder selbstständige Entwicklugsperiode konnte nicht bestimmt werden. ${ }^{275}$

2. Die Grabkeramiken der frühkupferzeitlichen und mittelkupferzeitlichen Gemeinschaften besitzen einen signifikant unterschiedlichen Charakter im untersuchten Gebiet. Es gibt Gräberfelder einerseits nur mit der Keramik des Formenkreises 1, andererseits nur mit der des Formenkreises 2. Nekropolen, die Gräber mit Keramik von Übergangscharakter allein aufweisen, sind - wie z. B. im Fall der Nekropolen der Lengyel-Gemeinschaften - nicht vorhanden. In den „Übergangsgräbern“ treten nicht „Übergangsformen“, sondern Gefäße des Formenkreises 1 sowie 2 miteinander vergesellschaftet auf.

3. Man kann mit Recht voraussetzen, dass die Gemeinschaften mit Grabkeramik des Formenkreises 1 und 2 in bestimmten Verbreitungsregionen des Polgár-Komplexes, wenigstens ab Ende des Zeitraumes 1, gleichzeitig nebeneinander gelebt haben dürften. Eine Frage bleibt weiterhin, ob es sich im Fall der Gemeinschaften mit Grabkeramik der beiden Formenkreise um eine oder zwei Volksgruppen handelt, insbesondere, wenn die Gefäßformen und -verzierungen sehr unterschiedlich sind.

4. Die Benutzung der Nekropolen mit Keramik des Formenkreises 2 überlebte den Zeitraum des Formenkreises 1 und endete in der Zeit, als auch Gefäße mit Hunyadihalom-Merkmalen (wie z. B. der Scheibenhenkel) in den Bestattungen einiger Nekropolen des Formenkreises 2 erscheinen. ${ }^{276}$ Festgestellt wurde einerseits, dass die Prämissen der Typen von Hunyadihalom-Charakter ganz am Anfang der Benutzung der Gräberfelder des Formenkreises 2 auftreten. Das Totenritual der Gräber mit Hunyadihalom-Keramik unterscheidet sich andererseits von dem des Formenkreises 2 nicht. Die Tatsache, dass die Gräber mit Hunyadihalom-Charakter untereinander kleine und separierte Gruppierungen in den Nekropolen des Formenkreises 2 bilden, kann man jedoch nicht außer Acht lassen.

\section{LITERATUR}

ANDERS-KULCSÁR 2013

BÁLINT 1941

BANNER 1927

BANNER 1933-1934
= A. Anders-G. Kulcsár (eds): Moments in Time. Papers Presented to Pál Raczky on His 60th Birthday. Budapest 2013.

= A. BÁLINT: Csanád, Arad és Torontál k.e.e. vármegyék régészeti katasztere (Archäologischer Kataster der Komitate Csanád, Arad, Torontál). Csanádvármegyei könyvtár 37. Makó 1941.

= J. BANNER: A magyarországi zsugorított temetkezések (Die in Ungarn gefundenen Hockergräber). Dolg 3 (1927) 1-122.

= J. BANNER: Ásatás a hódmezővásárhelyi Kotacparton (Ausgrabung am Kotacpart bei Hódmezővásárhely). Dolg 9-10 (1933-1934) 54-84.

\footnotetext{
${ }^{274}$ ZALAI-GAÁL 2012; ZALAI-GAÁL 2015

${ }^{275}$ HoRváth 2014, 316. S. Anm. 69.
}

276 „Hunyadihalom is only represented by samples from two sites and cannot be expected to give a good overview over the total range of dates for this phenomenon“ (BRUMMACK-DiACONESCU 2014, 254). 
BANNER 1935

BANNER 1937

BANNER-BÁLINT 1935

BANNER-PÁRDUCZ 1948

BELLA 1923

BENDER 1909

BIEHL-GLESER 2003

BoGNÁR-KuTZIÁN 1958

BogNÁR-KuTZIÁN 1963

BognÁR-KuTZIÁN 1972

BOYADZHIEV 2014

BRUMMACK 2015

BRUMMACK-DIACONESCU 2014

Csalogovits 1931

CsÁNYI et al. 2009

CSÁNYI et al. 2010

DAMMERS 2005

DIACONESCU 2009

DRAŞOVEAN 2014

ECSEDY 1977

ECSEDY 1981

FOLTINY 1941

FURHOLT-STOCKHAMMER 2008

GAZDAPUSZTAI 1964

GLESER 1995

GLESER 2012

GYUCHA 2009
= J. BANNER: Ásatás a hódmezővásárhelyi Kotacparton (Ausgrabung zu Kotacpart bei Hódmezővásárhely). Dolg 11 (1935) 97-125.

= J. BANNER: A hódmezővásárhelyi múzeum ásatásai 1935-ben (Die Ausgrabungen des Museums von Hódmezővásárhely im Jahre 1935). Dolg 13 (1937) 50-77.

= J. BANNER-A. BÁLINT: A szakálháti őskori telep (Die neolithische Ansiedlung von Szakálhát). Dolg 11 (1935) 76-96

= J. BANNER-M. PÁRDUCZ: Újabb adatok Dél-Magyarország újabb-kőkorához (Contributions nouvelles à l'histoire du néolithique en Hongrie). ArchÉrt 1946-1948, 19-31.

= L. BELLA: A bodrogkeresztúri eneolithkori temető (Das äneolithische Gräberfeld von Bodrogkeresztúr). RTÉ 1 (1923) 7-18.

= B. BENDER: Adatok Tiszapolgárról, Szabolcs megye ősrégészetéhez (Data about Tiszapolgár, contributions to the prehistory of Szabolcs county). Tiszapolgári Újság 12, Dezember 1909, 1-2.

= P. BIEHL-R. GLESER: Theorien und Methoden der Stilanalyse. In: M. Heinz-K. H. Eggert-U. Veit (Hrsg.): Zwischen Erklären und Verstehen? Beiträge zu den erkenntnistheoretischen Grundlagen archäologischer Interpretation 2. Münster-New York-München-Berlin 2003, 149-174.

= I. BognÁR-KutziÁN: Über südliche Beziehungen der ungarischen Kupferzeit. ActaArchHung 9 (1958) 155-190

= I. BognÁR-Kutzián: The Copper Age Cemetery of Tiszapolgár-Basatanya. ArchHung 42. Budapest 1963.

= I. BognÁR-Kutzián: The Early Copper Age Tiszapolgár Culture in the Carpathian Basin. ArchHung 48. Budapest 1972.

$=$ Y. BOYADZHIEV: The transition between Neolithic and Chalcolithic on the territory of Bulgaria. In: SCHIER-DRAȘOVEAN 2014, 49-68.

$=\mathrm{S}$. BRUMmACK: New radiocarbon dates from Eastern Slovakia. The cases of Malé Raškovce and Barca Baloty. In: S. Hansen-P. Raczky-A. Anders-A. Reingruber (eds): Chronologies and Technologies. The Fifth and Fourth Millennia BC between the Carpathians and the Aegean Sea. International Workshop Budapest 2012. Bonn 2015, 1-19.

$=\mathrm{S}$. BRUMmaCK-D. Diaconescu: A Bayesian approach to the AMS dates for the Copper Age in the Great Hungarian Plain. PZ 89/2 (2014) 242-260.

$=$ J. CSALOGOviTs: Die neu aufgedeckte neolithische Siedlung und das kupferzeitliche Gräberfeld von Kiskörös. PZ 22 (1931) 102-115.

= M. CSÁNYI-P. RACZKY-J. TÁRNOKI: Előzetes jelentés a rézkori bodrogkeresztúri kultúra Rákóczifalva-Bagi földön feltárt temetőjéröl (Preliminary report on the cemetery of the Bodrogkeresztúr Culture excavated at Rákóczifalva-Bagi föld). Tisicum 18 (2009) 13-34.

= M. CSÁNYI-P. RACZKY-J. TÁRNOKI: Das kupferzeitliche Gräberfeld von Rákóczifalva-Bagi-föld in Ungarn. Das Altertum 55 (2010) 241-270.

= B. Dammers: Die Keramik der Rössener Kultur in Rheinhessen. Manuskript, Inaugurdissertation. Leipzig 2005.

= D. Diaconescu: Cultura Tiszapolgár în România. Bibliotheca Brukenthal 41. Alba Julia 2009.

= F. DRAŞOVEAN: On the Late Neolithic and Early Eneolithic relative and absolute chronology of the Eastern Carpathian Basin. A Bayesian approach. In: SCHIER-DraŞOVEAN 2014, 129-171.

= I. ECSEDY: Die Funde der spätkupferzeitlichen Boleráz-Gruppe von Lánycsók. JPMÉ 22 (1977) $163-184$.

= I. ECSEDY: A kelet-magyarországi rézkor fejlődésének fontosabb tényezői (On the factors of the Copper Age development in Eastern Hungary). JPMÉ 26 (1981) 73-95.

= I. FolTiNY: Koraréz- és bronzkori temető Deszken (Frühkupferzeitliches und bronzezeitliches Gräberfeld in Deszk). FolArch 3-4 (1941) 69-88.

$=$ M. Furholt-Ph. Stockhammer: Wenn stumme Dinge sprechen sollen. Gedanken zu semiotischen Ansätzen in der Archäologie. In: M. Butter-R. Grundmann-Ch. Sanchez (Hrsg.): Zeichen der Zeit. Interdisziplinäre Perspektiven zur Semiotik. Frankfurt/Main-Berlin-Bern-Bruxelles-New YorkOxford-Wien 2008, 59-71.

= Gy. GAZDAPUSZTAI: Hódmezővásárhely Bahnstation Népkert. ArchÉrt 91 (1964) 251.

= R. GLESER: Die Epi-Rössener Gruppen in Südwestdeutschland. Untersuchungen zur Chronologie, stilistischen Entwicklung und kulturellen Einordnung. Saarbrücker Beiträge zur Altertumskunde 61. Bonn 1995.

$=$ R. GLESER: Zeitskalen, stilistische Tendenzen und Regionalität des 5. Jahrtausends in den Altsiedellandschaften zwischen Mosel und Morava. In: R. Gleser-V. Becker (Hrsg.): Mitteleuropa im 5. Jahrtausend vor Christi. Beiträge zur Internationalen Konferenz in Münster 2010. Berlin 2012, 35-103.

= A. GYUCHA: A Körös-vidék kora rézkora [Die Frühkupferzeit der Körösgegend]. Manuskript. Budapest 2009 
HANSEN-MÜLLER 2011

HELlebRANDT-PATAY 1977

HILLEBRAND 1929

HoFMANN 2013

HoFMANN 2014

HoFMANN 2015

HoRVÁth 1988

HORVÁTH 2014

L. A. Horváth 1994

L. A. Horváth 2004

IERCOSAN 2002

JósA 1899

KALICZ 1979-1980

KALICZ 2013

KALICZ-RACZKY 1990

KOREK 1958

KOREK 1964

KovÁCS-VÁCZI 2007

\section{KuTZIÁN 1946}

KuTZIÁN 1955

LAZAROVICI 2014

LICHARDUS 1991a

LICHARDUS 1991b

MÁTHÉ 1974

MEISENHEIMER 1989

MÜLLER 2009
= S. HANSEN-J. MÜLLER: Sozialarchäologische Perspektiven. Gesellschaftlicher Wandel 5000-1500 v. Chr. zwischen Atlantik und Kaukasus. Archäologie in Eurasien 24. Mainz 2011.

= M. HellebrandT-P. PATAY: Újabb rézkori temetők Dél-Borsodban (Neuere Friedhöfe aus der Kupferzeit in Süd-Borsod). HOMÉ 16 (1977) 43-76.

= J. Hillebrand: A pusztaistvánházi korarézkori temető - Das frühkupferzeitliche Gräberfeld von Pusztaistvánháza. ArchHung 4. Budapest 1929.

= K. P. Hofmann: Gräber und Totenrituale: Zu aktuellen Theorien und Forschungsansätzen. In: M. K. H. Eggert-U. Veit (Hrsg.): Theorie in der Archäologie. Zur jüngeren Diskussion in Deutschland. Tübinger archäologische Taschenbücher 10. Münster-New York-München-Berlin 2013, 269-298.

= K. P. HofmanN: Gräberanalyse. In: D. Mölders-S. Wolfram (Hrsg.): Schlüsselbegriffe der prähistorischen Archäologie. Tübinger archäologische Taschenbücher 11. Münster 2014, 115-118.

= K. P. Hofmann: In Geschichten verstrickt... Menschen, Dinge, Identitäten. In: D. Boschung-K.-A. Kreuz-T. Kienlin (Hrsg.): Biography of objects. Aspekte eines kulturhistorischen Konzepts. Morphomata 31. Paderborn 2015, 87-122.

= F. HoRvÁth: Late Neolithic ditches, fortifications and tells in the Hungarian Tisza-Region. In: N. Tasić-J. Petrović (Hrsg.): Gomolava - Chronologie und Stratigraphie der vorgeschichtlichen und antiken Kulturen der Donauniederung und Südosteuropas 1. Symposium Ruma, 1986. Novi Sad 1988, 145-149.

= F. Horváth: Questions relating to the Proto-Tiszapolgár Period in South-Eastern Hungary. Main issues and present state of research. In: SCHIER-DraşoveAn 2014, 297-318.

= L. A. HorvÁth: Beiträge zur Chronologie der mittleren Kupferzeit in der Großen Ungarischen Tiefebene. ActaArchHung 46 (1994) 73-105.

= L. A. HoRvÁth: Bemerkungen zur Chronologie der äneolithischen Gräber in Vajska. Eine Neudatierung. ActaArchHung 55 (2004) 63-79.

= N. IERCoşAn: Cultura Tiszapolgár în vestul României. Satu Mare 2002.

= A. JÓSA: Szabolcsvármegyei múzeum ős- és középkori tárgyainak ismertetése (Description of the prehistoric and mediaeval objects in the Szabolcs County Museum). Nyíregyháza 1899.

= N. KALICZ: Újabb adatok a rézkori Hunyadihalom-csoport történetéhez (Neue Beiträge zur Chronologie der kupferzeitlichen Hunyadihalom-Gruppe). SzMMÉ 1979-1980, 43-62.

= N. KALICZ: Siedlungsstruktur und Bestattungen mit Prestigeobjekten des Fundplatzes Tápé-Lebö (südliches Theißgebiet, Ungarn). In: AndERS-KulCSÁR 2013, 365-384.

= N. KALICZ-P. RACZKY: Das Spätneolithikum im Theißgebiet. Eine Übersicht zum heutigen Forschungsstand aufgrund der neuesten Ausgrabungen. In: P. Raczky-W. Meier-Arendt (Hrsg.): Alltag und Religion. Jungsteinzeit in Ost-Ungarn. Ausstellungskatalog. Frankfurt a. M. 1990, 11-30.

= J. KoREK: Lebő-halmi ásatás 1950-ben (The excavation at Lebőhalom in 1950). ArchÉrt 85 (1958) 132-155.

= J. KOREK: Vásárosnamény. ArchÉrt 91 (1964) 252.

= K. KovÁcs-G. VÁczI: The cemetery of the Early Copper Age Tiszapolgár Culture at Hajdúböszörmény-Ficsori-tó-dülő. In: J. K. Kozłowski-P. Raczky (eds): The Lengyel, Polgár and Related Cultures in the Middle/Late Neolithic in Central Europe. Kraków 2007, 397-409.

= I. KuTZIÁN: A tiszapolgár-basatanyai aeneolithikus temető (Das äneolithische Gräberfeld von Tiszapolgár-Basatanya). ArchÉrt 1946-1948, 42-52.

= I. KutziÁn: Die Ausgrabungen in Tiszapolgár-Basatanya (Gehöft Basa). In: Conférence Archéologique de l'Académie Hongroise des Sciences. Budapest 1955, 69-82.

= C.-M. LAZARovici: The Late Neolithic and Copper Age in Eastern Romania. In: SchIER-DraşovEAN 2014, 69-98.

= J. LichaRdus: Die Kupferzeit als historische Epoche. Versuch einer Deutung. In: J. Lichardus (Hrsg.): Die Kupferzeit als historische Epoche I-II. Symposium Saarbrücken und Otzenhausen 6.-13. 11. 1988. Bonn 1991, 763-800.

= J. LiCHARDUS: Die Bedeutung Südosteuropas für die Herausbildung und Verbreitung der kupferzeitlichen Zivilisation Alt-Europas. In: I. Symposium Illiro-Thrace. Tribus paléobalkaniques entre la Mer Adriatique et la Mer Noire de l'énéolithique jusqu'à l'époque hellénistique. Publications spéciales. Sarajevo-Beograd 1991, 211-224.

= M. Sz. MÁTHÉ: Újabb adatok a rézkor időrendjéhez (On the chronology of the Copper Age. Early Copper Age cemetery in Hajdúszoboszló). DMÉ 1972 (1974) 131-148.

= M. MeISEnHEIMER: Das Totenritual, geprägt durch Jenseitsvorstellungen und Gesellschaftsrealität. Theorie des Totenrituals eines kupferzeitlichen Friedhofs zu Tiszapolgár-Basatanya, Ungarn. BAR IntSer 475. Oxford 1989.

= J. MÜLLER: Materielle Kultur, Territorialität und Bedeutungsinhalte von Identitäten: Die Wirkung verdichteter Kommunikationsräume. In: D. Krausse-O. Nakoinz: Kulturraum und Territorialität. Kolloquium Esslingen. Rahden/Westf. 2009, 95-105. 
PÁRDUCZ 1932

PATAY 1938

PATAY 1944-1945

PATAY 1950

PATAY 1957

PATAY 1958

PATAY 1961

PATAY 1966-1967

PATAY 1969

PATAY 1971

PATAY 1974

PATAY 1976

PATAY 1978 a

PATAY $1978 b$

PATAY 1979

PATAY 1995

PATAY 2004

PATAY 2005

PATAY 2008

R. PATAY 2003

R. PATAY 2004

R. PATAY 2006

R. PATAY 2006-2007

R. PATAY 2008

RACZKY 1988

RACZKY 1991

RACZKY 1995
= M. PÁRDUCZ: A Hódmezővásárhely-kotacparti neolith telep és rézkori temető (Die neolithische Ansiedelung und das kupferzeitliche Gräberfeld von Hódmezővásárhely-Kotacpart). Dolg 8 (1932) 103-111.

= P. PATAY: Korai bronzkori kultúrák Magyarországon - Frühbronzezeitliche Kulturen in Ungarn. DissPann II/13. Budapest 1938.

= P. PATAY: Rézkori temető leletei Jászladányból (Les trouvailles archéologiques du cimitiére de l'âge du Cuivre à Jászladány). ArchÉrt Ser III 5/6 (1944-1945) 1-22.

= P. PATAY: A bodrogkeresztúri kultúra emlékei a Szabolcs megyei múzeumban (Some finds belonging to the Bodrogkeresztúr Culture in the Jósa András Museum in county Szabolcs, Nyíregyháza). ArchÉrt 77 (1950) 110-116.

= P. PATAY: Rézkori temető Tiszakeszin (Gräberfeld aus der Kupferzeit bei Tiszakeszi). HOMÉ 1 (1957) 31-44.

= P. PATAY: Kupferzeitliches Gräberfeld in Polgár, am Bacsókert genannten Hügel. ActaArchHung 9 (1958) 141-154.

= P. PATAY: A bodrogkeresztúri kultúra temetői (Die Gräberfelder der Bodrogkeresztúr-Kultur). RégFüz II/10. Budapest 1961.

= P. PATAY: Gräber von Sippenhäuptlingen aus der Kupferzeit. MFMÉ 1966-1967, 49-55.

= P. PATAY: A fényeslitkei rézkori temető (Das kupferzeitliche Gräberfeld von Fényeslitke). JAMÉ 11 (1968 [1969]) 15-62.

= P. PATAY: Die jüngere Stein- und Kupferzeit im südlichen Teil des Komitates Borsod. AASzeged 14 (1971) 7-15.

= P. PATAY: Die hochkupferzeitliche Bodrogkeresztúr-Kultur. BRGK 55 (1974 [1975]) 1-71.

= P. PATAY: A magyarhomorogi rézkori temető (Das kupferzeitliche Gräberfeld von Magyarhomorog). DMÉ (1975 [1976]) 173-254.

= P. PATAY: A Tiszavalk-tetesi rézkori temető és telep I. (Kupferzeitliches Gräberfeld und Siedlung von Tiszavalk-Tetes. I: Das Gräberfeld). FolArch 29 (1978) 21-58.

= P. PATAY: Das kupferzeitliche Gräberfeld von Tiszavalk-Kenderföldek. FontArchHung. Budapest 1978.

= P. PATAY: A Tiszavalk-tetesi rézkori temető és telep II. (Kupferzeitliches Gräberfeld und Siedlung von Tiszavalk-Tetes. II: Die Siedlung). FolArch 30 (1979) 27-52.

= P. PATAY: Die kupferzeitliche Siedlung Tiszalúc-Sarkad und die Hunyadi-halom-Kultur. In: T. Kovács (Hrsg.): Neuere Daten zur Siedlungsgeschichte und Chronologie der Kupferzeit des Karpatenbeckens. IPH 7. Budapest 1995, 107-115.

= P. PATAY: Gräber der Hunyadi-halom-Kultur. In: B. Hänsel-E. Studeníková (Hrsg.): Zwischen Karpaten und Ägäis. Neolithikum und ältere Bronzezeit. Gedenkschrift für Viera Němejcová-Pavúková. IntArch - Studia honoraria 21. Rahden/Westf. 2004, 169-175.

= P. PATAY: Kupferzeitliche Siedlung von Tiszalúc. IPH 11. Budapest 2005.

= P. PATAY: A bodrogkeresztúri kultúra belső időrendjéről (Über die innere Chronologie der Bodrogkeresztúr-Kultur). ArchÉrt 133 (2008) 21-48.

= R. PATAY: Kora és középső rézkori sírok Panyolán (Früh- und mittelkupferzeitliche Gräber aus Panyola).www.academia.edu/2359958/Patay_Robert_Kora_es_kozepso_rezkori_sirok_Panyolan

= R. PATAY: Középső rézkori temetkezések és telepnyom Mezőkövesd, Patakra járó-dülőből (Mittelkupferzeitliche Gräber und Siedlungen in Mezőkövesd). HOMÉ 43 (2004) 33-58.

$=$ R. PATAY: Kora és középső rézkori sírok Panyolán (Früh- und mittelkupferzeitliche Gräber aus Panyola). JAMÉ 48 (2006) 61-88.

= R. PATAY: Középső rézkori sír Valkó-Tópartról (Middle Copper Age burial from Valkó-Tópart). Ösrégészeti Levelek 8-9 (2006-2007) 99-104.

= R. PATAY: Kora és késő rézkori leletek Hódmezővásárhelyről (Hódmezővásárhely-Laktanya, 47/1. lelőhely) (Früh- und spätkupferzeitliche Funde aus Hódmezővásárhely, HódmezővásárhelyLaktanya, Fundort Nr. 47/1). Ösrégészeti Levelek 10 (2008) 17-32.

= P. RACZKY: A Tisza-vidék kulturális és kronológiai kapcsolatai a Balkánnal és az Égeikummal a neolitikum, rézkor időszakában. Újabb kutatási eredmények és problémák [Die kulturellen und chronologischen Beziehungen der Theißgegend zu dem Balkan und der Ägäis in der Zeit des Neolithikums und der Kupferzeit]. Szolnok 1988.

$=$ P. RACZKY: New data on the southern connections and relative chronology of the "BodrogkeresztúrHunyadi-halom" complex. In: J. Lichardus (Hrsg.): Die Kupferzeit als historische Epoche I-II. Symposium Saarbrücken und Otzenhausen 6.-13. 11. 1988. Bonn 1991, 329-346.

= P. RACZKY: New data on the absolute chronology of the Copper Age in the Carpathian Basin. In: T. Kovács (Hrsg.): Neuere Daten zur siedlungsgeschichte und Chronologie der Kupferzeit des Karpatenbeckens. IPH 7. Budapest 1995, 51-60. 
RACZKY 2011

RACZKY et al. 1998

RACZKY-SIKLÓSI 2013

REIZNER 1899

REIZNER 1904

RÓMER 1870

SCHIER 2008

SCHIER 2013

SCHIER 2014

SCHIER-DRaşovean 2014

ŠIŠKA 1964

ŠIŠKA 1968

ŠIŠKA 1969

ŠIISKKA 1972

STEHLI 1973

STEHLI-ZimMERMANN 1980

STROBEL 1996

SZABÓ 1956

SZILÁGYI 2008

SZILÁGYI 2015

VÍZDAL 1962

VÍZDAL 1970

VíZDAL 1977

VLADÁR-LICHARDUS 1968

YERKES et al. 2009

ZALAI-GAÁL 2002

ZALAI-GAÁL 2007a
= P. RACZKY: Nyomozás egy őskori edény összefüggései után. A régészeti, múzeumi emlékezet rövid és hosszú távú torzulásairól, valamint a régészeti forrásokkal kapcsolatos adatvesztések szakmai környezetéről (Nachforschungen zu den Zusammenhängen eines urzeitlichen Gefäßes - Über kurzund langfristige Entstellungen des archäologischen und musealen Gedächtnisses sowie über Datenverluste bei archäologischen Quellen). MFMÉ-StudArch 12 (2011) 47-58.

= P. RacZKy-A. Anders-E. NAgY-B. KrivecZKy-Zs. Hajdú-T. Szalai: Polgár-Nagy Kasziba. In: Utak a múltba. Az M3-as autópálya régészeti leletmentései. Budapest 1997, 47-50.

$=$ P. RACZKY-Zs. SIKLÓsı: Reconsideration of the Copper Age chronology of the eastern Carpathian Basin. A Bayesian approach. Antiquity 87 (2013) 555-573.

= J. REIZNER: Szeged története 1. [Die Geschichte von Szeged 1]. Szeged 1899.

= J. REIZNER: Lebői, öthalmi és óbébai ásatások (Excavations at Lebő, Öthalom and Óbéba). ArchÉrt ÚF 24 (1904) 76-88.

= F. RóMER: Két Szabolcsmegyei őstemető és egyéb régészeti leletek (Two ancient cemeteries and other archaeological finds in the County of Szabolcs). ArchÉrt 3 (1870) 220-225.

= W. SCHIER: Uivar: A late Neolithic-early Eneolithic fortified tell site in western Romania. In: D. Bailey-A. Whittle-D. Hoffmann (eds): Living Well Together? Settlement and Materiality in the Neolithic of South-East and Central Europe. Oxford 2008, 54-66.

= W. SCHIER: An antiquarian's grave? Early Tiszapolgár burials in the late Vinča tell site of Uivar (Romania). In: ANDERS-KULCSÁR 2013, 569-577.

= W. SCHIER: Der spätneolithisch-kupferzeitliche Tell von Uivar (Rumänien). Prospektionen und Grabungen 1998-2009. In: W. Schier-M. Meyer (Hrsg.): Vom Nil bis an die Elbe. Forschungen aus fünf Jahrzehnten am Institut für Prähistorische Archäologie der Freien Universität Berlin. Rahden/ Westf. 2014, 17-36.

=W. SchIER-F. Draşovean (eds): The Neolithic and Eneolithic in Southeast Europe. New approaches to dating and cultural dynamics in the 6th to 4th millennium BC. Prähistorische Archäologie in Südosteuropa 28. Rahden/Westf. 2014.

= S. ŠIŠKA: Pohrebisko tiszapolgárskej kultúry v Tibave (Gräberfeld der Tiszapolgár-Kultur in Tibava). SIA 12/2 (1964) 294-356.

= S. ŠIŠKA: Tiszapolgárska kultúra na Slovensku (Die Tiszapolgár-Kultur in der Slowakei). SlA 16/1 (1968) 63-164.

= S. ŠIŠKA: Zur Problematik der spätneolithischen Kulturgruppen mit bemalter Keramik in der Ostslowakei. ŠtZ 17 (1969) 415-428.

= S. Šı̌̌KA: Zu Beziehungen des nördlichen Theißgebietes und Südostpolens im Jungneolithikum und älteren Äneolithikum. Musaica 23 (1972) 13-21.

= P. STEHLI: Keramik. In: J.-P. Farrugia-R. Kuper-J. Lüning-P. Stehli: Der bandkeramische Siedlungsplatz Langweiler. 2: Gemeinde Aldenhoven, Kreis Düren. Bonn 1973, 57-100.

= P. Stehli-A. ZimmermanN: Zur Analyse neolithischer Gefäßformen. Archaeo-Physika 7 (1980) $147-177$.

= M. STROBEL: Ein Beitrag zur Gliederung der östlichen Linearbandkeramik. Versuch einer Merkmalanalyse. Sastuma 4/5 (1995/1996 [1997]) 9-98.

= J. SzABÓ: Tiszaigar-Csikóstanya. ArchÉrt 83 (1956) 9.

= M. SZILÁGYI: Változások az Alföldön az i. e. 5. évezred derekán. Átmenet a neolitikumból a rézkorba [Änderungen in der Großen Ungarischen Tiefebene in der Mitte des 5. Jahrtausends]. Első Század 2008/2, 361-427.

= M. SzILÁGYI: Kora rézkori településszerkezet a Közép-Tisza-vidéken [Frühkupferzeitliche Siedlungsstruktur in der mittleren Theißgegend]. Manuskript. Budapest 2015.

= J. VízDAL: Neolitické hroby z Oboríne na Slovensku (Neolithische Gräber aus Oborín in der Slowakei). AR 14 (1962) 605-609.

= J. VízDAL: Neskoroneolitické nálezy z Oborína (Jungneolithische Funde aus Oborín). SlA 18 (1970) 219-234.

= J. VízDAL: Tiszapolgárske pohrebisko vo Vel'kých Raškovciach (Gräberfeld der Tiszapolgár-Kultur in Vel'ké Raškovce). Košice 1977.

= J. VLADÁR-J. LICHARDUS: Erforschung der frühäneolithischen Siedlung in Branč. SIA 16 (1968) 263-352.

$=$ R. W. Yerkes-A. GYUChA-W. PARKInSON: A multiscalar approach to modeling the end of the Neolithic on the Great Hungarian Plain using calibrated radiocarbon dates. Radiocarbon 51/3 (2009) 1071-1109.

= I. ZALAI-GAÁL: Die neolithische Gräbergruppe B1 von Mórágy-Tüzkődomb. I: Die archäologischen Funde und Befunde. Szekszárd-Saarbrücken 2002.

= I. ZALAI-GAÁL: Von Lengyel bis Mórágy. Die spätneolithische Grabkeramik in Südtransdanubien aus den alten Ausgrabungen. I: Analyse. WMMÉ 30 (2007) 1-162. 
ZALAI-GAÁL 2007b

ZALAI-GAÁL 2008

ZALAI-GAÁL 2012

ZALAI-GAÁL 2015

ZALOTAY 1933-1934

ZEEB-LANZ 2003

ZEEB-LANZ 2006

ZOLTAI 1928
= I. ZALAI-GAÁL: Zengővárkony-Svodín-Friebritz. Zu den chronologischen Beziehungen zwischen den territorialen Gruppen der Lengyel-Kultur aufgrund der Gräberfeldanalyse. In: J. K. Kozłowski-P. Raczky (eds): The Lengyel, Polgár and Related Cultures in the Middle/Late Neolithic in Central Europe. Kraków 2007, 147-184.

= I. ZalaI-GAáL: Von Lengyel bis Mórágy. Die spätneolithische Grabkeramik in Südtransdanubien aus den alten Ausgrabungen. II: Katalog. WMMÉ 30 (2008) 7-216.

= I. ZALAI-GAÁL: Frühkupferzeitliche Elemente in den Bestattungssitten der Lengyel-Kultur in Transdanubien. In: R. Gleser-V. Becker (Hrsg.): Mitteleuropa im 5. Jahrtausend vor Christi. Beiträge zur Internationalen Konferenz in Münster 2010. Berlin 2012, 495-508.

= I. ZALAI-GAÁL: Streitfragen der frühkupferzeitlichen Forschungen im östlichen Karpatenbecken. Antaeus. (Im Druck.)

= E. ZALOTAY: A szentes-kistőkei rézkori temető (Der Friedhof in Szentes-Kistőke aus der Kupferzeit). Dolg 9-10 (1933-1934) 85-89.

= A. ZeEB-LANZ: Keramikverzierungsstil als Kommunikationsmittel. Ein Beispiel aus dem frühen Jungneolithikum Südwestdeutschlands. In: U. Veit-T. Kienlin-Ch. Kümmel-S. Schmidt (Hrsg.): Spuren und Botschaften. Interpretationen materieller Kultur. Tübinger archäologische Taschenbücher 4. Münster-New York-München-Berlin 2003, 245-261.

= A. ZEEB-LANZ: Überlegungen zu Sozialaspekten keramischer Gruppen. Beispiele aus dem Neolithikum Südwestdeutschlands. In: S. Burmeister-N. Müller-Scheeßel (Hrsg.): Soziale Gruppen kulturelle Grenzen. Münster 2006, 81-102.

$=$ L. ZoLTAI: Régészeti ásatások 1928-ban. Hajdúszoboszló: rézkori temető és telep. Jelentés Debrecen sz. k. város múzeumának és közművelődési könyvtárának 1928. évi müködéséről (Kupferzeitliches Gräberfeld und Besiedlung in Hajdúszoboszló). Debrecen 1928, 44-50. 